\title{
Effect of acute experimental hand pain on left- right discrimination response latency for hand recognition
}

\author{
Nichole Phillips
}

2014

A thesis submitted in partial requirement for the degree of Master of Osteopathy, Unitec Institute of Technology, 2014 


\section{Declaration}

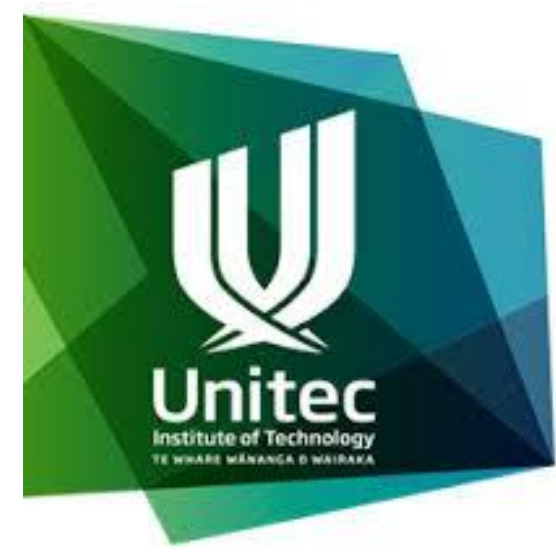

Name of candidate: Nichole Phillips

This Thesis entitled 'Effect of acute experimental hand pain on left-right discrimination response latency for hand recognition' is submitted in partial fulfilment for the requirements for the Unitec degree of Master of Osteopathy.

\section{Candidates Declaration:}

I confirm that:

- This Thesis represents my own work;

- Research for this work has been conducted in accordance with the Health and Disability Ethics Committee Policy and Procedures, and has fulfilled any requirements set for this project by the Health and Disability Ethics Committee (Northern A).

Research Ethics Committee Approval Number: 12/NTA/37

Candidate Signature:

Date:

Student number: 1129330 


\section{Acknowledgements}

Firstly, I am extremely grateful to all of my participants who generously took time out from their busy schedules to put their bodies on the line, and in pain, to make this research project happen. This project would not have been possible without them.

Many thanks must go to my supervisors for their continual encouragement and huge contribution of effort at each stage of this research project. Thank you to Rob, for his enthusiasm and encouragement to do this project. I am especially appreciative of the support provided during the initial hurdles and final stages of writing up. Thank you to Jamie for his vital support and expertise with software development and data analysis, and for bravely taking a double injection to the elbows during our pain trials.

Thank you to Dr Scott McLaren for performing the experimental pain injections with much skill and gusto.

Thank you to Craig for his support during the ethics applications, Lucy for her input into the data analysis, and John for his help with proofreading. Additionally, thank you to my osteopathic colleagues who provided valuable feedback, advice and encouragement during a number of research forum presentations.

I would also like to express my gratitude to the Todd Foundation for their support of a Todd Foundation Award for Excellence. This financial support was a major factor in being able to complete this project.

Lastly, thanks go to my family and friends for their support and encouragement and backing while I struggled to complete this thesis, and to Paul for always being the generous and funny man that he is. 


\section{Preface to thesis}

Generally, pain is a universal sensation. Yet, the experience of pain is an individual and private occurrence, and is difficult to quantify (Auvray, Myin, \& Spence, 2010). Accordingly, there is a large area of research that focusses on developing methods to measure and diagnose pain. One clinical effect that has been explored is that acute experimental pain appears to affect mental motor imagery (Hudson, McCormick, Zalucki, \& Moseley, 2006; Moseley, Sim, Henry, \& Souvlis, 2005). This phenomenon is an interesting observation as it highlights an effect of pain on the cortex that may have potential significant clinical importance as an assessment of pain state (Coslett, Medina, Kliot, \& Burkey, 2010a, 2010b; Schwoebel, Friedman, Duda, \& Coslett, 2001). However, this effect has received relatively little attention detail to date. A more thorough understanding of the magnitude and characteristics of this phenomenon is needed before further steps can be taken in this area.

\section{Organisation of thesis}

This thesis is a 90 credit Master of Osteopathy project. This thesis is arranged into three sections. The first section is a literature review which orients the reader to the relevant background knowledge regarding the neurological basis of pain and chronic pain, and the current knowledge base regarding mental motor imagery. The second section contains manuscript has been prepared in accordance with the Brain Research journal Instructions for Authors [see Appendix 1.15]. The third section contains the appendices and will contain documents that are relevant for this thesis. 


\section{Table of Contents}

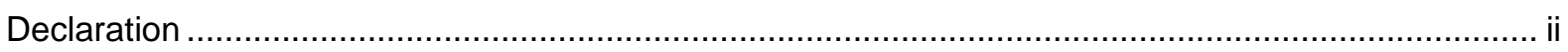

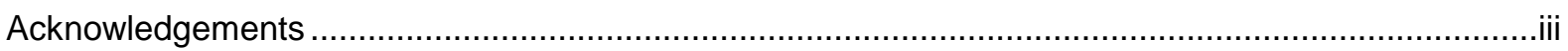

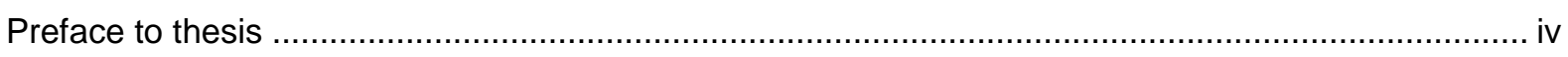

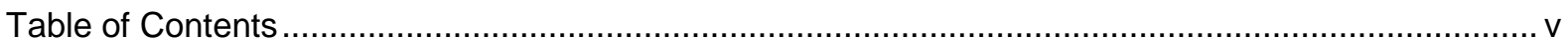

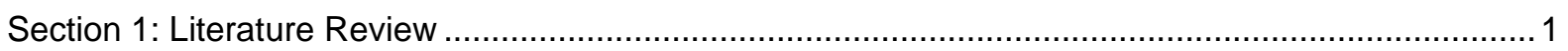

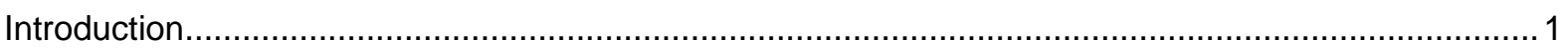

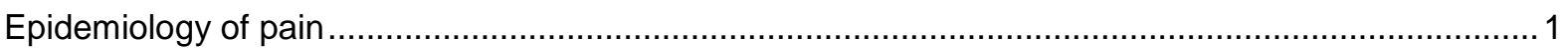

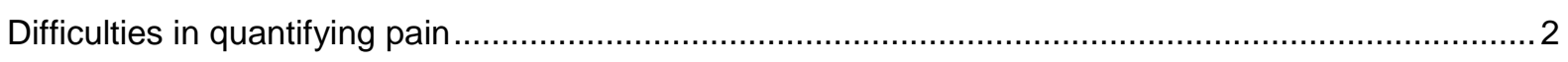

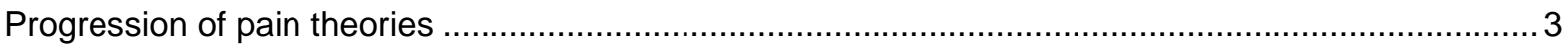

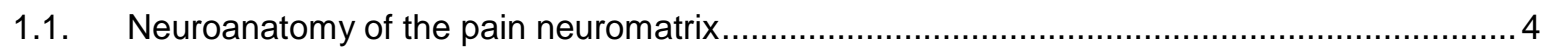

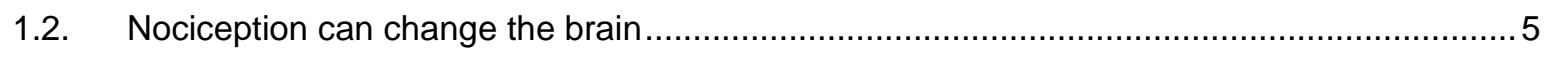

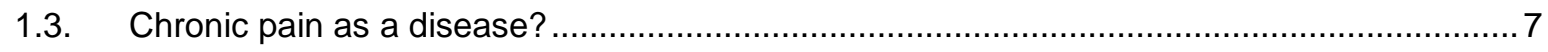

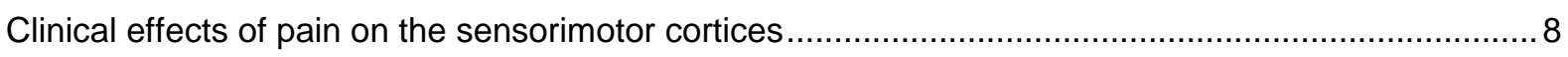

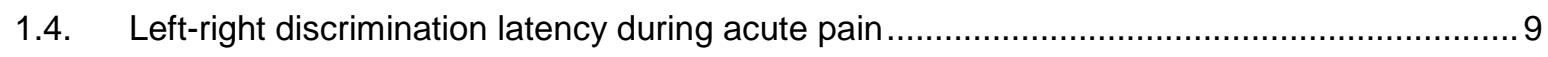

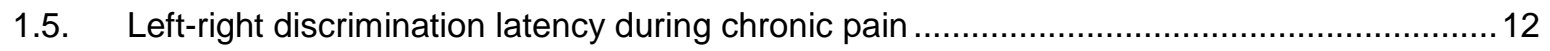

Characteristics of left-right discrimination latency changes ................................................... 13

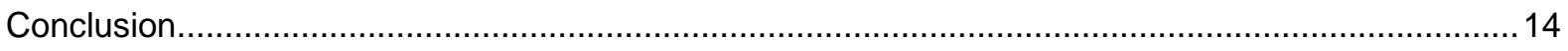

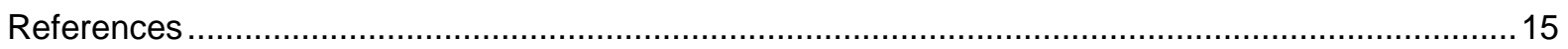

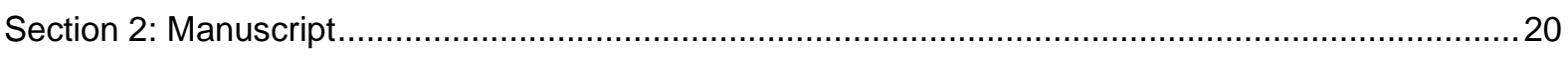

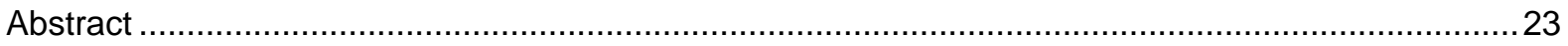

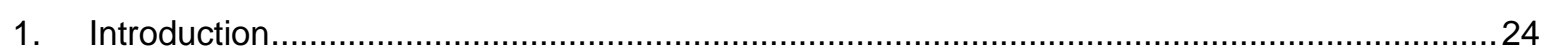

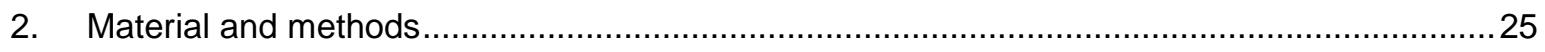

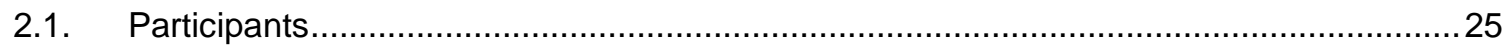

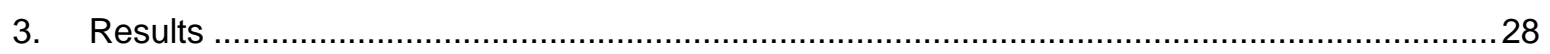

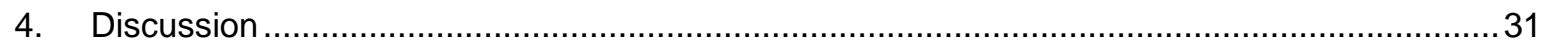

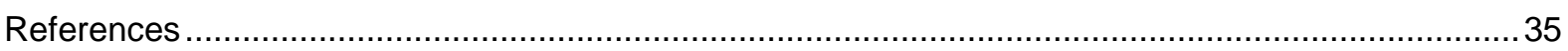

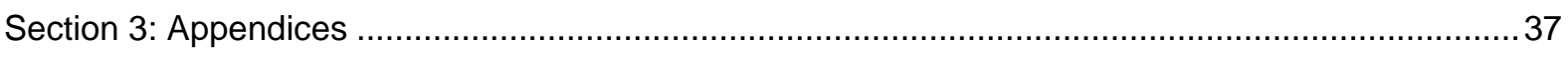

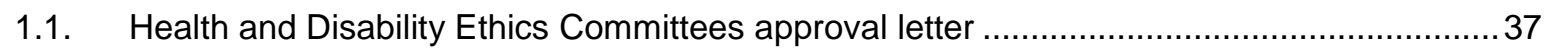


1.2. Health and Disability Ethics Committees renewal letter ................................................ 42

1.3. Health and Disability Ethics Committees amendment approval letter ................................44

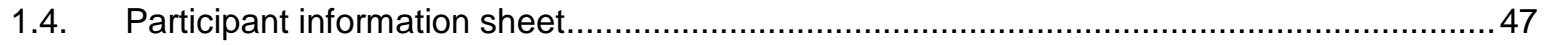

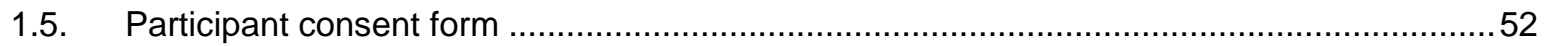

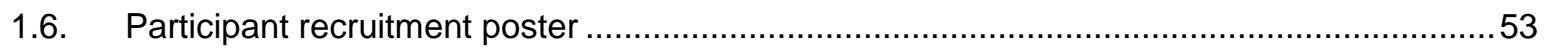

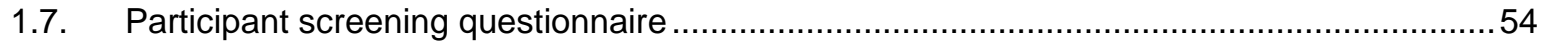

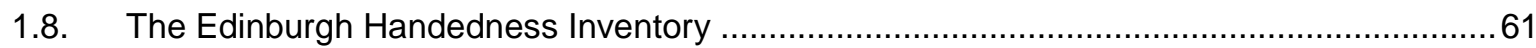

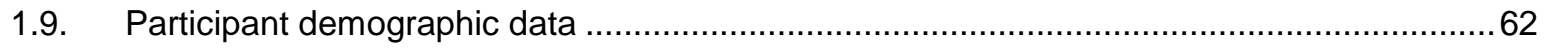

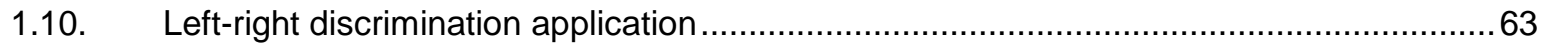

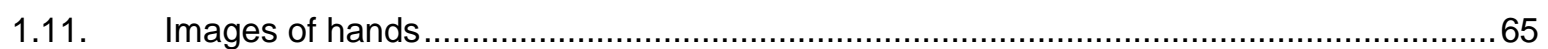

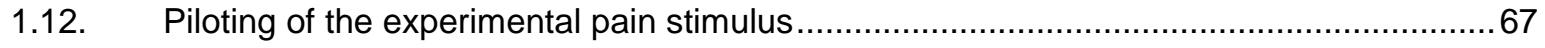

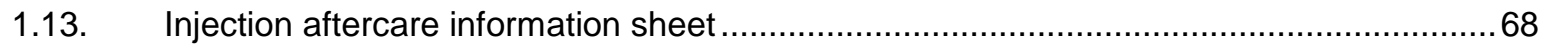

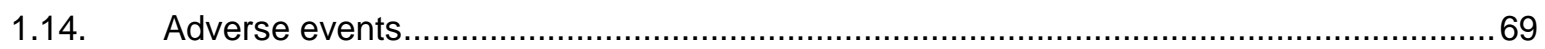

1.15. Brain Research: Instructions for authors .............................................................. 70 


\section{Section 1: Literature Review}

\section{Introduction}

Pain is a protective mechanism that serves to promote survival (lannetti \& Mouraux, 2010) by creating action and protection against damage to body tissue integrity (Moseley, 2003). Pain is a common experience, but it is not understood why some people develop a pain state that becomes persistent and complex to manage. Unfortunately, the process of measuring pain symptoms, identifying at risk people and diagnosing a chronic pain state is problematic (Pergolizzi et al., 2012). Inconsistent temporal based chronic pain definitions (generally between 3-6 months) and limited prognostic tools can delay the diagnosis of a chronic pain state (National Pain Summit Initiative, 2010). Consequently, appropriate clinical interventions for the pain symptoms are delayed. This situation may contribute to the persistence and severity of pain symptoms by allowing the development of central sensitisation, cortical changes associated with chronic pain, and biopsychosocial risk factors which all can begin to create barriers to successful recovery (Moseley, 2003). Therefore, exploratory research into additional diagnostic approaches that may assist to identify people at risk of developing persistent pain is an important area of pain research. In this area, a sizeable amount of literature has explored the effects of pain on cortical processing. One notable aspect is that pain can influence the process of mental motor imagery which subserves left versus right discrimination judgements of body part images, subsequently resulting in findings which have revealed that acute pain and chronic pain have dissimilar effects on the latency of these judgements (Coslett et al., 2010a, 2010b; Moseley et al., 2005; Reinersmann et al., 2010). For this reason, a left-right discrimination task has potential clinical value as a diagnostic support tool to objectively monitor the possibility of pain related interference with this cortical function (Coslett et al., 2010b; Schwoebel et al., 2001). The objective of this literature review is to explore relevant literature regarding the theory and cortical representation of pain generation. Central sensitisation and the associated cortical neuroplastic changes will also be discussed. Studies investigating the effects of pain on mental motor imagery will be evaluated with reference to the current understanding of the neurophysiological mechanisms that underpin the observed effects.

\section{Epidemiology of pain}

Acute pain is universal, normal, temporary response to tissue damage, surgery or other noxious input to the body. Acute pain is a risk factor for the development of chronic pain, and as such, appropriate response, assessment, documentation, and management of symptoms are important factors in prevention of chronic pain development (National Pain Summit Initiative, 2010; Shipton, 2005). Chronic pain is estimated to have a weighted average prevalence of $20 \%$ in adults; one of the most detrimental and costly health problems in developed countries (Andrew, Derry, Taylor, Straube, \& Phillips, 2014; International Association for the Study of Pain, 2003). People who experience severe 
chronic pain have a poorer health-related quality of life (Andrew et al., 2014; Dominick, Blyth, \& Nicholas, 2011) and increased mortality rate (Torrance, Elliott, Lee, \& Smith, 2010). The symptoms of chronic pain can cause a reduction in day to day functional ability (Torrance et al., 2010) which contributes to the high economic cost of chronic pain (National Pain Summit Initiative, 2010; Leadley, Armstrong, Lee, Mien, \& Kleijnen, 2012). Examples of economic burdens created by chronic pain are increased healthcare services usage, lost work days, reduced-effectiveness work days, and lost caregiver potential and opportunities (National Pain Summit Initiative, 2010).

Existing research indicates that patterns of chronic pain in New Zealand appear to be similar to those found internationally (Byrne, 2011; Dominick et al., 2011; Grace \& Zondervan, 2006). The latest epidemiological study analysed data from the 2006/07 New Zealand Health Survey and showed that one in six (16.9\%) people report being in chronic pain (Dominick et al., 2011). Reporting of chronic pain was strongly associated with decreased economic living standards and increased age (Dominick et al., 2011).

\section{Difficulties in quantifying pain}

The subjective nature of pain can create difficulties in the management of symptoms and diagnosis of a persistent pain state. Pain is an interoceptive sense which signifies that an objective perception/reality distinction of symptoms cannot be made (Auvray et al., 2010). Additionally, there is no objectively measurable relationship between a pain experience and tissue state (Moseley \& Flor, 2012). Therefore, there is no absolute method to quantify a pain experience and clinicians and researchers must rely on self-reported measures or make inferences from behavioural or emotional changes (McMahon, Koltzenburg, \& Wall, 2005; Von Korff \& Miglioretti, 2005).

Pain intensity is most often gauged using a scale measurement that provides a numerical measure (examples of scales of response levels include $0-5,0-10,0-100$ or phrases such as 'no pain, mild pain, moderate pain, intense pain, maximum pain') (Ferreira-Valente, Pais-Ribeiro, \& Jensen, 2011). Four common scales are the Visual Analogue Scale, Numerical Rating Scale (NRS), Verbal Rating Scale, and the Faces Pain Scale-Revised (Ferreira-Valente et al., 2011). The NRS appears to have a slightly higher degree of responsiveness and compliance when compared to the other tools (FerreiraValente et al., 2011; Hjermstad et al., 2011). Examples of other tools that explore the quality and affective components of the pain experience are the McGill Pain Questionnaire (Melzack, 2005) and the Pain Quality Assessment Scale (Jensen, Lin, Kupper, Galer, \& Gammaitoni, 2013). These different types of measurement tools attempt to quantify and measure pain symptoms in a consistent and reproducible manner.

The importance of pain measurement tools is emphasised by a body of work that has found that situational and patient variables such as ethnicity, gender (both practitioner and patient), age, presence of organic findings, litigation status, reported pain intensity, and patient distress levels can 
influence an observer's judgement of the patient's pain state (Chibnall \& Tan, 1999; Hirsh, Hollingshead, Matthias, Bair, \& Kroenke, 2014; Wandner et al., 2014; Wandner, Scipio, Hirsh, Torres, \& Robinson, 2012). Also, despite the widespread use of a variety of scales to gauge pain symptoms, Morone and Weiner (2013) identify that the complexity of adequate pain assessment is often beyond the clinical skills of most practitioners. Furthermore, a lack of pain education in healthcare professionals can lead to significant patient morbidity due to over or under treating (Morone \& Weiner, 2013). Therefore, current difficulties in quantification of the pain experience warrant the need for research into more evaluative tools that may circumvent the subjective components of pain assessment.

\section{Progression of pain theories}

Some of the difficulty in measuring and diagnosing pain and chronic pain also stems, in part, from the continuing development of the conceptual models that explain the process of pain production. For centuries, pain theories have described a linear cause and effect relationship between tissue injury, nociceptor stimulation, peripheral nerve pathway activation and pain sensation (Massieh \& Davis, 2013; Melzack, 1996). Accordingly, diagnosis and management of pain and chronic pain emphasised identification of a primary pathological mechanism and source of nociception in the peripheral tissues. This approach to diagnosis and treatment is now considered to have limited and inconsistent success in a number of chronic pain syndromes (Gustin, Wrigley, Siddall, \& Henderson, 2010; Pope, Deer, \& Kramer, 2013; Wand et al., 2011).

A further weakness of the linear model of pain is failure to illuminate the mechanisms of pain phenomena such as referred pain, phantom limb pain, pain resulting from a normally innocuous stimulus, pain in the absence of peripheral injury or nociception and persistent pain symptoms (Massieh \& Davis, 2013). These failings cause patients to be vulnerable to suspicion of symptom fabrication or malingering as judgements that are made by healthcare practitioners are influenced by the degree to which objective medical evidence is able to identify a physical lesion as causing pain (Chibnall \& Tan, 1999). In response to these weaknesses, historic pain theories have been vigorously challenged and have undergone extensive revision in recent years. Revision of pain theories has been an important process because the conceptual models that explain pain form the foundational models that inform management and treatment (Melzack, 1996), the direction of research into new therapies (Massieh \& Davis, 2013; Melzack, 2001), and ultimately, patient outcomes. The two fundamental and most commonly accepted models of pain will be briefly described.

The Gate Control Theory (Melzack \& Wall, 1965) has been described as the most influential concept in the advancement of pain research (Massieh \& Davis, 2013). This theory established the dynamic modulating role of the central nervous system during the formation of pain symptoms and the concept of a significant downward modulation mechanism. However, in a similar manner to linear pain 
theories, the proposed mechanism of the Gate Control Theory was contingent on the existence of nociceptive signals in the periphery. Therefore, the Gate Control Theory does not elucidate the mechanisms of pain phenomena which may lack peripheral nociceptive, or otherwise, signals (Acerra \& Moseley, 2005). Consequently, revision of the Gate Control Theory was prompted by consideration of reports of pain symptoms and phantom limb sensations following deafferentation (amputation, spinal cord transection, surgical removal, or congenital deformity) (Melzack, 1990). It was then proposed that a supraspinal mechanism must also play a significant role in pain generation and the Pain Neuromatrix Theory was developed (Melzack, 1989, 1990, 1992).

Currently, the Pain Neuromatrix Theory (Melzack, 1990) is the most widely recognised and accepted model of pain generation. This theory describes pain as an 'output' of the brain that results from the parallel processing and integration of multiple 'inputs' in various supraspinal neural networks (Melzack, 1999). As a pain generator, the brain responds dynamically to external and internal, conscious and unconscious information, and either in conjunction with or independently of peripheral input (Melzack, 1996). Furthermore, this theory clearly explicates how nociception and pain are independent factors. Additionally, the Pain Neuromatrix Theory provides the conceptual model for how nociception can trigger autonomic or behavioural reflexes in the body (Merskey \& Bogduk, 1994) without generating a conscious experience of pain, and how nociception is neither necessary nor sufficient for pain (lannetti \& Mouraux, 2010; Loeser \& Treede, 2008). Numerous studies support the concept of a pain neuromatrix, including research that shows that pain can be experimentally generated in an artificial limb (Mohan et al., 2012) or manipulated using verbal cognitive modulation (Arntz \& Claassens, 2004). Pain is therefore understood to be the result of many multidimensional physiological, neurological and psychosocial factors. These factors include the sensory-discriminative (intensity, location, quality, and duration), the affective-motivational (unpleasantness and the subsequent flight response), and the cognitive-evaluative (appraisal, cultural values, context, and cognitive state) dimensions of pain (Massieh \& Davies, 2013, p. 10). These factors interact to produce the pain experience, and each can modulate the perception of pain at any given time.

\subsection{Neuroanatomy of the pain neuromatrix}

The definitive anatomy of the pain neuromatrix is yet to be determined. The networks involved are proposed to be predetermined by genetics and continuously updated by sensory input (lonta \& Blanke, 2009; Moseley, 2003). Supraspinal regions that have been shown to consistently respond during processing of nociceptive input specifically are the caudal anterior cingulate cortex, mid-insula, and anterior cerebellum (Ploghaus et al., 1999) and the primary somatosensory cortex, secondary somatosensory cortex and its vicinity in the parietal operculum, insula, anterior cingulate cortex and prefrontal cortex (Treede, Kenshalo, Gracely, \& Jones, 1999). These areas serve to carry out various functions that form the multiple dimensions of a pain experience (Treede et al., 1999), and appear to undertake the parallel processing function as originally proposed (Melzack, 1989, 1990). However, these reported 'pain areas' require careful interpretation as concurrent neurophysiological functions that are non-specific to pain may activate supplementary regions (lannetti \& Mouraux, 2010). This 
problem has been illustrated by Ploghaus et al. (1999) who showed that careful manipulation of pain/anticipation of pain was able to discriminately activate distinct brain regions that had previously been assumed to be solely related to the pain symptoms. Furthermore, evidence of substantial intraand inter-individual variability in neural activation and function during mapping of brain areas in research participants (Kobayashi, Hutchinson, Schlaug, \& Pascual-Leone, 2003) also highlights difficulties in identifying definite brain networks. Therefore, further research is required to establish the definitive neuroanatomy of the pain neuromatrix.

\subsection{Nociception can change the brain}

Nociceptive input can change the function and structure of the neurons that form the pain neuromatrix in the brain. Initially, nociceptive input results in functional changes. One functional change occurs when normal inhibition of neural networks is reduced or lost and results in

which results in reduction or loss of the cortical disinhibition of normally inhibited neural networks (Moseley \& Flor, 2012) and activation of a wider expanse of the pain neuromatrix (Kobayashi et al., 2009). Habituation and conditioning occur when previous or persistent pain symptoms lead to the formation of explicit and implicit pain-related memories and increased sensitivity to previously innocuous stimuli (Flor, 2003). This combination of disinhibition and sensitisation can underpin and perpetuate more long-term cortical reorganisation (Moseley \& Flor, 2012). More sustained functional changes in the supraspinal area occur when the cortical representation zone related to the nociceptive input expands and shifts into immediately adjacent areas, and this change is positively correlated to symptom intensity (Flor, 2003; Gustin et al., 2010; Wrigley et al., 2009). An example of this shift has been shown to occur following deafferentation after an upper extremity amputation. Flor (2003) found that the cortical amputation zone in both the somatosensory and motor cortices was expanded into by the mouth representation zone which caused peripheral input from the mouth area to subsequently be projected onto the absent limb.

The structural properties of cortical neurons have also been shown to change during major nociceptive inputs and central sensitisation. The characteristics of the changes are variable and Gustin et al. (2010) suggest that it is very likely that a multifaceted combination of cell death, cellular proliferation, neuronal sprouting, axonal loss, demyelination, oedema and changes in tissue barriers may occur, even in the same regions. These structural changes are evident in cortical imaging research studies which report evidence that people with chronic pain have areas of altered brain morphology (usually a reduction in size) and function when compared to people who suffer acute pain or no pain (Flor, 2003; Moseley \& Flor, 2012; Vartiainen, Kirveskari, Kallio-Laine, Kalso, \& Forss, 2009). It is theorised that continued central sensitisation may result in more permanent maladaptive neuroplastic change in various cortical regions that form the pain neuromatrix, and these changes begin to generate and perpetuate abnormal pain symptoms (Wand et al., 2011). There is accumulating evidence that the degree of cortical reorganisation is strongly and positively correlated to the severity of the reported phantom limb pain symptoms (Flor, 2003). Also, cortical changes have 
been implicated as contributing to the maintenance of symptoms independently of peripheral factors in some phantom limb pain patients (Birbaumer et al., 1997). Post spinal cord injury neuropathic pain also shows positive correlate between the degree of cortical change and the severity of pain symptoms (Wrigley et al., 2009). In a similar manner, symptom chronicity in chronic low back pain and fibromyalgia also positively correlates with the degree of cortical reorganisation (Flor, 2003).

The cumulative effects of structural and functional changes of the neuromatrix are thought to produce chronic pain symptoms that can appear so significantly discordant to tissue state, activity levels, and expectations of perceptual reports (Moseley \& Flor, 2012). As central sensitisation occurs, the neuromatrix develops "an increased responsiveness of nociceptive neurons in the central nervous system to their normal or subthreshold afferent input" (Loeser \& Treede, 2008, p. 474). The clinical manifestations of temporary central sensitisation usually provide a biological advantage in that they increase sensitivity to subsequent peripheral inputs and minimise the risk of secondary injury, therefore improving the probability of tissue healing (Moseley \& Flor, 2012). However, the prolonged sensitisation of the neuromatrix leads to a heightened response to perceived threats to tissue integrity (Moseley \& Flor, 2012) and an unnecessary protective pain experience occurs.

An important observation regarding central sensitisation is that the relationship between chronic pain and the presence of cortical morphology and functional changes has been observed in a number of different chronic pain states (Moseley \& Flor, 2012; Rodriguez-Raecke, Niemeier, Ihle, Ruether, \& May, 2013). Specifically, changes in the cingulate cortex, the orbitofrontal cortex, the insula and dorsal pons regions have been reported to overlap between different chronic pain syndromes (May, 2008). Examples of chronic pain syndromes that have been associated with cortical changes include carpal tunnel syndrome (Tecchio, Padua, Aprile, \& Rossini, 2002), complex regional pain syndrome (Larbig, Montoya, Braun, \& Birbaumer, 2006), chronic back pain (Wand et al., 2011), fibromyalgia (Flor, 2003), phantom limb pain (Birbaumer et al., 1997; Draganski et al., 2006; Maclver, Lloyd, Kelly, Roberts, \& Nurmikko, 2008), post-herpatic neuralgia (Vartiainen et al., 2009), temporomandibular disorder (Younger, Shen, Goddard, \& Mackey, 2010), some chronic type headaches (Puretić \& Demarin, 2012), post-surgical pain (Shipton, 2011), irritable bowel syndrome and ulcerative colitis (Hong et al., 2014), persistent idiopathic facial pain (Schmidt-Wilcke, Hierlmeier, \& Leinisch, 2010), and persistent neuropathic pain following spinal cord injury (Gustin et al., 2010). Rodriguez-Raecke et al. (2013) highlights an important aspect of these findings; "a striking feature of all of these studies is the fact that the grey matter changes were not randomly distributed, but occur in defined and functionally highly specific brain areas - namely, involvement in supraspinal nociceptive processing" (p. 1). Thus, the presence of cortical changes in the aforementioned chronic pain states provides further evidence for a pain neuromatrix and central sensitisation of these networks during pain. Moreover, the above listed chronic pain states show similar changes in cortical plasticity, thus supporting the concept that central sensitisation and associated cortical neuroplastic change appear to be common features of chronic pain, regardless of considerably dissimilar aetiologies or pathological mechanisms of the nociceptive inputs or painful symptoms. 
There is, however, some evidence that could suggest that cortical changes in chronic pain are secondary to, rather than being the leading cause of, chronic pain symptoms (Rodriguez-Raecke et al., 2013). Rodriguez-Raecke et al. (2013) describe swift partial resolution of structural grey matter alternations in 20 chronic pain patients who became pain free following total hip replacement surgery. The authors conclude that their results strongly suggest that long term nociceptive input and motor impairment are the direct cause of altered processing and structural changes in the cortex, and that these changes appear to be partially reversible with cessation of the nociceptive barrage (RodriguezRaecke et al., 2013). However, these results require careful interpretation and may be limited in their generalisability to other chronic pain states. Unilateral hip osteoarthritis can be considered a chronic pain syndrome that has an easily discernible underlying pathogenesis and aetiology, and very good long term results following surgical intervention (Learmonth, Young, \& Rorabeck, 2007). Thus, surgical removal of the damaged tissues providing nociceptive input will undoubtedly reduce the nociceptive barrage on the central nervous system. Additionally, all the participants in the hip osteoarthritis study experienced pain relief following surgery (Rodriguez-Raecke et al., 2013) and, as a result, are unable to represent the $10 \%$ of patients who experience on-going pain following a total hip replacement (National Pain Summit Initiative, 2010).

Moreover, the psychosocial and contextual consequences of pain are also sufficient to create cortical changes (Rodriguez-Raecke et al., 2013). The consequences of ongoing nociception is not limited to cortical change as mood dysfunction, cognition changes and social disruption can also occur (Siddall \& Cousins, 2004). Therefore, hip osteoarthritis, although painful and debilitating, may have considerably dissimilar emotional load to chronic pain that may be attributed to an unidentifiable peripheral tissue pathology or a significant trauma or injury. Additionally, medically intractable symptoms or unexpected spontaneous onset may also increase the threat value of a painful experience. These contextual factors that may create fear and anxiety can augment the chronic pain experience and contribute to experience and perception of the painful symptoms (Brown, Seymour, El-Deredy, \& Jones, 2008; Siddall \& Cousins, 2004). Indeed, research on brachial plexus blockades in upper extremity phantom limb pain patients showed that anaesthetic blocks of the brachial plexus resulted in symptom relief and cortical reorganisation reduction in only some patients, highlighting that peripheral neural input may only be partially involved in chronic pain symptom production (Birbaumer et al., 1997). Therefore, it may be that ongoing peripheral nociceptive input is an important factor in cortical reorganisation and chronic pain development; however, there is evidence that suggests that this relationship is not clear-cut and that numerous secondary and tertiary factors that contribute to the pain experience are also important (Siddall \& Cousins, 2004).

\subsection{Chronic pain as a disease?}

Until recently, chronic pain has been considered to be a syndrome, a group of syndromes (Tracey \& Bushnell, 2009), or a symptom of an underlying pathology (Siddall \& Cousins, 2004; Wand et al., 2011). At the present time, the cortical changes (both structural and functional) that are observed in 
chronic pain patients strongly suggest that chronic pain may fulfil the definition of a disease; "a disorder of structure or function in a human, animal, or plant, especially one that produces specific symptoms or that affects a specific location and is not simply a direct result of physical injury" (Oxford Dictionaries, 2014; Tracey \& Bushnell, 2009). Thus, the neurological changes that occur during chronic pain may satisfy the requirements for a disease entity irrespective of the primary etiological factors or injury that may have triggered the initial acute pain episode (National Pain Summit Initiative, 2010; Vartiainen et al., 2009). Indeed, May (2008) states that pain loses its functional role when maladaptive neuroplastic changes occur and pain then becomes the disease entity. The potential classification of chronic pain as a disease has led to a change in the focus of chronic pain treatment and management from identification and treatment of a primary underlying tissue pathology, to an integrated interdisciplinary biopsychosocial approach that focuses on the secondary and tertiary factors of pain in an individualised manner (National Pain Summit Initiative, 2010; Pergolizzi et al., 2012). Early intervention and prevention also become priorities when chronic pain is recognised as a disease entity, further supporting the need for appropriate diagnostic approaches (National Pain Summit Initiative, 2010; Siddall \& Cousins, 2004).

The recognition of chronic pain as a disease with specific structural/functional cortical changes also raises the question of whether neuroimaging could be used as a diagnostic tool. There has yet to be sufficient conclusive evidence regarding the structural and functional changes found in the brains of chronic pain patients, and the cause and effect relationship is still unknown (Tracey \& Bushnell, 2009). Significant differences in location and extent of neural structural and functional changes exists, and the frequency of comorbid conditions and secondary effects of pain in chronic pain patients is another factor that needs to be taken into consideration (Tracey \& Bushnell, 2009). Therefore, although the possibility of neuroimaging for chronic pain diagnosis appears promising, only speculation is currently possible and further animal and human studies are required to improve the sensitivity and specificity of imaging techniques (Lee \& Tracey, 2013).

\section{Clinical effects of pain on the sensorimotor cortices}

Central sensitisation has been shown to affect a number of different regions of the neuromatrix (Flor, 2003); however, this literature review will focus on specific manifestations that occur following central sensitisation of the sensorimotor cortices. The effects of central sensitisation on the affected primary sensorimotor cortices do not just occur at the neural level as there are reports of a number of clinical and behavioural effects. Disruption of the spatial representation of the affected body part can lead to changes in processing of tactile stimuli (Moseley, Gallace, \& lannetti, 2012), alterations in the body image of the affected part (Moseley, 2008), and a decline in the ability to perform voluntary movements and motor imagery tasks (Bray \& Moseley, 2011; Coslett et al., 2010a, 2010b; Moseley, 2004; Richter, Röijezon, Björklund, \& Djupsjöbacka, 2010). The disruption to motor imagery can be objectively measured using a left-right discrimination task where participants are asked to identify an object as being either left or right sided or an image of a body part as being an anatomical left or right. 
Research shows that left-right discrimination of body parts is a cortical mental motor imagery task that incorporates visual and sensorimotor processes (Ni Choisdealbha, Brady, \& Maguinness, 2011) resulting in activation of the same primary sensorimotor cortices areas as real movement (Parsons \& Fox, 1998). In contrast to mental motor imagery, mental rotation and left-right discrimination of nonbody part objects invoke different cortical processes and do not involve the same extent of cortical motor processing (Conson, Mazzarella, Donnarumma, \& Trojano, 2012; Ionta, Fourkas, \& Aglioti, 2010). The mental motor imagery that subserves left-right discrimination can be a conscious or subconscious process depending on the degree of explicit instruction. Therefore, an assessment of implicit left-right discrimination ability provides two outcome measures (accuracy, response time) and can provide information on the efficiency of mental motor imagery and degree of sensorimotor integration (Elsig et al., 2014).

The mechanism that subserves left-right discrimination is theorised to consist of the participant choosing an initial rapid pre-conscious selection from the possible two responses (left or right) (Moseley et al., 2005). Imagined movements of the corresponding limb on their cortical representation of their own body ('virtual body') are then used to corroborate the selection and confirm accuracy (Parsons, 1987a, 1987b) before the final decision is made. Incorrect initial pre-conscious selections are corrected by using imagined movements of the opposite hand to re-check the final decision (Moseley et al., 2005). Interestingly, mental motor imagery is subject to the same physiological constraints as actual movement and these restraints are reflected by delays in latency for left-right discrimination of limbs in anatomically difficult positions (Parsons, 1994; Richter et al., 2010; Schwoebel et al., 2001). Another factor that has been shown to modify response time latency of left-right discrimination judgements is pain. Analysis of response time latency during left-right discrimination tasks has shown that there are dissimilar effects of acute and chronic pain on response time latency (Coslett et al., 2010a, 2010b). These findings may indicate that the latency of left-right discrimination judgements may provide an objective indicator of a pain state (Coslett et al., 2010a, 2010b; Schwoebel et al., 2001).

\subsection{Left-right discrimination latency during acute pain}

A small number of studies (with a combined sample size of $n=35$ ) have found that, during acute experimental pain, left-right discrimination response times are delayed when judging images that corresponded to the unaffected limb (Hudson et al., 2006; Moseley et al., 2005). Hudson et al. (2006) report a delay of approximately $600 \mathrm{~ms}(p=0.005)$ for images corresponding to the non-affected hand during actual and expected acute experimental pain stimulus. There was no effect of the experimental conditions on response times for left-right discrimination latency of pictures that corresponded to the affected hand (Hudson et al., 2006). Moseley et al. (2005) found a similar result, with a mean reported delay of $382 \mathrm{~ms}(95 \% \mathrm{Cl}=590$ to $190 \mathrm{~ms}, p<0.01))$ for images of the nonaffected hand. Another example of latency changes also occurs after altering the peripheral input to the cortical body representation by changing the position of the arms (lonta \& Blanke, 2009; Ionta, Perruchoud, Draganski, \& Blanke, 2012). Ionta and Blanke (2009) found that holding the right arm 
behind the back (altered proprioceptive input) was sufficient to increase response time latency to images of the right hand only $(1,302 \mathrm{~ms}, p<0.04)$ when compared to holding the right hand in front of the body $(1,185 \mathrm{~ms})$. Although the different experimental stimuli had different effects (either specific to images corresponding to the affected hand or not), the effects of experimental pain and changes in proprioceptive input are thought to show that the cortical body representation which subserves leftright discrimination is constantly being influenced by peripheral input (Ionta \& Blanke, 2009).

The proposed mechanism of latency changes while completing left-right discrimination during acute experimental pain is that the threat value of the pain creates a bias in information processing towards the affected limb (Hudson et al., 2006; Moseley et al., 2005). Participants are more likely to select the laterality of the affected limb as their initial response, subsequently resulting in a correction and reconfirmation of their selection when the virtual limbs and imaged limb do not match (Hudson et al., 2006). Therefore, response times for the non-affected hands are delayed by this 'doubling up' of mental motor imagery processing. Additionally, it is thought that disinhibition and unmasking of latent neural connections occur in the nociception receptive area (Moseley \& Flor, 2012) resulting in a greater accessibility or sensitisation of the sensorimotor cortex, thus encouraging the selection of the affected limb as the initial response. One notable factor is that acute experimental pain does not affect response times to images corresponding to the affected limb (Hudson et al., 2006; Moseley et al., 2005). It is thought that the lack of any effect on response times towards the affected hand shows that pain and nociception is not sufficient to cause actual disruption or facilitation of sensorimotor integration (Moseley et al., 2005), further supporting the possibility of an attentional bias.

The validity of the hypothesis of an attentional or information processing bias towards the painful limb during left-right discrimination is yet to be confirmed as other forms of peripheral neural input such as proprioception and visual input (Ionta \& Blanke, 2009; Ionta, Fourkas, Fiorio, \& Aglioti, 2007; Ionta et al., 2012) have also been shown to alter response times in a limb and, often contradictory, laterality specific manner. Furthermore, when the effects of experimental elbow pain was compared to experimental hand pain during a hand left-right discrimination task, elbow pain was shown to have no effect on response latency whereas hand pain did (Moseley et al., 2005). This result was unexpected as participants had rated the pain intensity and perceptual characteristics of the elbow pain as similar to that of the hand pain (Moseley et al., 2005). The authors hypothesised a number of possible explanations for their results; however, one criticism of the methodology was that different participant groups were used for the different pain locations, therefore making intra-individual comparisons impossible. Interestingly, expectation of pain has also been shown to produce alterations of left-right discrimination latency in the same way that experimental pain does (Hudson et al., 2006), therefore indicating that that conscious pain symptoms are not necessary, and may only be partly related to, performance during left-right discrimination tests.

Further possible flaws of the attentional or information processing bias during acute pain on left-right discrimination latency may be highlighted by the difference in responses between left and right 
handed people. Research into the effects of lateralisation show that right handed participants are facilitated in recognising images of right hands, whereas left handed participants show no clear facilitation for either laterality ( $\mathrm{Ni}$ Choisdealbha et al., 2011). Despite this facilitation, changes in proprioceptive information from the right upper limb have been shown to reduce response times to images of right hand, an effect that was only observed for right handed people as left handed people showed no alterations in response latency across the experimental conditions (Ionta \& Blanke, 2009). lonta and Blanke (2009) suggest that the mechanisms and factors underlying this effect are more complex than manual dominance and lateralisation alone. A number of possible mechanisms are suggested; a predominantly right handed world may lead to increased visual familiarity with right hands for both groups, greater ambidextrousness in left handed individuals resulting in less lateralisation, and differing interactions between motor, visual and proprioceptive mechanisms in left and right handed people (Ionta \& Blanke, 2009). Because left and right handed people may be employing different underlying cortical mechanism during left-right discrimination, caution must be used when extrapolating experimental data to other populations as the biological factor of these differences has not yet been determined. Additionally, this difference may limit the clinical utility of left-right discrimination latency measurements in different populations.

Another perspective may be that the attentional bias theory is too simplistic to accurately model the effects of acute experimental pain on the cortex. Formation of central sensitisation or an attentional bias has the possibility of opposing effects from both inhibitory and facilitatory neural circuits (Sandkühler, 2007). This is certainly true in the case of pain as there is a degree of uncertainty regarding the definitive functions of spinal and cortical neurons subserving nociception and pain (lannetti \& Mouraux, 2010; Sandkühler, 2007). Consequently, sensitisation includes both algesia and analgesia promoting cortical change. Therefore, it is probable that indiscreet and variable changes are occurring in a number of nociceptive and pain specific brain regions, alongside the hypothesised formation of an isolated attentional bias towards the nociception receptive area.

Furthermore, the attentional bias theory does not include mention of the interhemispheric processes (mainly inhibitory) that occur during primary motor cortex activation (Hanajima et al., 2001). Interhemispheric inhibition and, to a lesser extent, facilitation occur primarily to suppress unwanted mirror movements of the contralateral homologous muscles (Kobayashi et al., 2003). As left-right discrimination activates the same cortical regions as actual movement, it is plausible that interhemipsheric interactions also occur. Consequently, discussion of these interactions is important because, in parallel to lateralisation, differences and asymmetries in the magnitude of interhemispheric interactions are reported between right and left handed people. Studies that have explored the phenomenon of asymmetrical bimanual coupling found that the non-dominant hand was more strongly influenced by dominant hand movements (with a more significant effect in right handed participants) (de Poel, Peper, \& Beek, 2007; Kagerer, Summers, \& Semjen, 2003). Right handed participants also showed stronger transcollosal inhibition of their non-dominant hemisphere following unilateral finger movements (Kobayashi et al., 2003). Interestingly, Kobayashi et al. (2003) also found 
that bilateral primary motor cortex activation occurs in some participants during unilateral nondominant finger movements. Kobayashi et al. (2003) were unable to definitively elucidate the neurophysiological aetiology of this; however, it is interesting to note that this phenomenon indicates that inter-individual differences in the occurrence and magnitude of various interhemispheric interactions also exist. Further hemispheric and motor function asymmetries are described by the 'dynamic dominance' hypothesis (Sainburg, 2002; Schaefer, Haaland, \& Sainburg, 2009), and given that cortical representations of hands in the primary motor cortices are said to be strong and highly effective (Kobayashi et al., 2003), the cortical function differences and resulting interhemispheric interactions may result in dissimilar cortical processes during left-right discrimination judgements between individuals.

As only a small number of studies have investigated the effects of acute experimental pain on response time latency, there exists an opportunity to obtain a more thorough understanding of the magnitude and characteristics of left-right discrimination latency during acute experimental pain. Establishment of the normative latency changes has the potential to offer intriguing clinical opportunities regarding objective assessment and diagnosis of pain state.

\subsection{Left-right discrimination latency during chronic pain}

In contrast to left-right discrimination response time latency during acute pain, chronic pain syndrome patients most frequently show delayed response times to the images of limbs that correspond to the location and laterality of the affected limb (Coslett et al., 2010a, 2010b; Moseley, 2004; Reinersmann et al., 2010; Schwoebel et al., 2001). In a different manner but with possible similar underlying mechanisms, chronic back pain, and history of chronic back pain, also affects mental motor imagery of the trunk by reducing accuracy of left-right discrimination judgements of images of trunks rather than changing response latency (Bowering, Butler, Fulton, \& Moseley, 2014; Bray \& Moseley, 2011). This observed effect is thought to indicate that the development of central sensitisation and neuroplastic change in the sensorimotor cortices disrupts the corresponding part of the virtual body and diminishes the efficiency of neuronal recruitment. The disruption to the virtual body then causes a change in function of the sensorimotor cortex (and therefore mental motor imagery) corresponding to the painful area and altered left-right discrimination response times and accuracy rates (Coslett et al., 2010a, 2010b; Fiorio et al., 2007; Reinersmann et al., 2010; Schwoebel et al., 2001).

In parallel to the relationship that has been observed between chronic pain and the presence of cortical neuroplastic changes (Moseley \& Flor, 2012), the theorised disruption of the virtual body and subsequent altered left-right discrimination latency appears to be a common feature in a number of different chronic limb pain states despite the dissimilar aetiologies or pathological mechanisms (Reinersmann et al., 2010). Delayed left-right discrimination latencies have been shown in complex regional pain syndrome (Moseley, 2004; Reinersmann et al., 2010; Schwoebel et al., 2001), phantom limb pain (Reinersmann et al., 2010), and chronic musculoskeletal or radiculopathy in the arm/shoulder (Coslett et al., 2010b). Reduced accuracy of left-right discrimination judgements have 
been shown for knee osteoarthritis (Stanton et al., 2012) and chronic low back pain (Bowering et al., 2014; Bray \& Moseley, 2011). The consistency of the effects of acute pain and chronic pain on response time latency does show promising implications for the possibility of developing a diagnostic support tool that might be useful for assessing the likelihood of developing a chronic pain state (Schwoebel et al., 2001).

\section{Characteristics of left-right discrimination latency changes}

The current body of research on left-right discrimination latency during acute pain and chronic pain states may indicate that the pattern of latency alterations could be used as a quantitative biomarker to discriminate between pain states (Elsig et al., 2014; Schwoebel et al., 2001). If a left-right discrimination task could detect early and subtle sensorimotor integration changes that are associated with cortical neuroplastic change and central sensitisation, then this tool could be used as a diagnostic aid to improve accuracy and rapidity of a chronic pain diagnosis. This situation would be a positive outcome in regard to the recent push and recommendations for more timely chronic pain diagnoses (National Pain Summit Initiative, 2010). Additionally, there is evidence that the orientation of the imaged body part creates highly reliable effects on the left-right discrimination judgement latency, where the latency of response times can be related to the difficulty in creating the real movement to match the image (Coslett et al., 2010a; Moseley, 2004; Schwoebel et al., 2001). This effect occurs in both left and right handed people (Ionta \& Blanke, 2009). The absence or modification of this effect would identify participants who were not completing the task in the appropriate manner and attempting to distort results (Coslett et al., 2010b). Thus it is possible that a left-right discrimination task could be also used as an objective test for malingering or fictitious pain disorders, as well as discriminating acute and chronic pain states.

In order to establish if the above possibilities are likely, it is important to establish the normative magnitude and characteristics of left-right discrimination responses during acute experimental pain. Normative values of left-right discrimination responses during acute pain would further inform the conclusions that have been reached in previous studies (Hudson et al., 2006; Moseley et al., 2005). Additionally, this data would be valuable in establishing a normative reference group that may be used to compare the left-right discrimination latency results of other individuals in differing pain states. Moreover, the precise cortical mechanisms underpinning left-right discrimination changes during pain remain to be elucidated and future research that utilises a similar methodological approach would be useful to investigate the attentional or information processing bias further.

Assessment of left-right discrimination during acute experimental pain can be the most accessible way to investigate the definitive normative values of response time latency changes. Intramuscular hypertonic saline injection is a widely used experimental pain model which induces reversible, localised pain in the injected area (Capra \& Ro, 2004) in a reliable and safe manner (Graven-Nielsen, 2006). This technique has been used in experimental studies to allow the assessment of left-right 
discrimination latency during acute experimental pain (Hudson et al., 2006; Moseley et al., 2005). It is possible to build upon the results of similar studies who experimentally determined that acute experimental pain significantly delays response time latency to images of the non-affected hand $(\mathrm{P}<$ 0.01) (Hudson et al., 2006; Moseley et al., 2005). It must be noted that experimental pain is inherently different from non-experimental pain in that it is not possible to match the threat value of the possible unknown time course, unknown aetiological factors and unknown possible consequences of clinical pain (Moseley et al., 2005). Additionally, research into experimental pain is vulnerable to self-selection bias due to the nature of the investigation and the experimental conditions (Malone, Nicholl, \& Tracey, 2014). However, experimental pain is an important surrogate model for conducting research on clinical pain (Pryseley et al., 2009) and this is a paradox that is common to all experimental pain research.

\section{Conclusion}

This literature review provides the basis for an investigation into the characteristics and magnitude of left-right discrimination latency changes during acute experimental pain. The effect of acute experimental pain on mental motor imagery has received a limited amount of research attention and a more thorough understanding in this area would be useful as the potential outcomes offer intriguing clinical possibilities. For instance, the results of this investigation may inform the development of a tool that could provide a quantitative biomarker to be used in conjunction with current pain scales and psychosocial assessments to create a cluster of findings that may improve the accuracy of pain state diagnosis. Thus, a diagnosis of chronic pain would not be based on inconsistent definitions of symptoms and chronicity, but possibly on a quantifiable clinical measure of neural change. The potential incorporation of quantitative measures into chronic pain diagnosis is also in line with the progression of modern pain theories and the possible future classification as chronic pain as a disease entity. Research into the neurophysiological basis of pain has created a number of opportunities to improve pain diagnosis and treatment, and hopefully, enable practitioners to start intervention and treatment protocols to try to reduce the negative impact that acute and chronic pain has on sufferers and the burden of chronic pain in healthcare systems. 


\section{References}

Acerra, N. E., \& Moseley, G. L. (2005). Dysynchiria: Watching the mirror image of the unaffected limb elicits pain on the affected side. Neurology, 65(5), 751-753.

Andrew, R., Derry, S., Taylor, R. S., Straube, S., \& Phillips, C. J. (2014). The costs and consequences of adequately managed chronic non-cancer pain and chronic neuropathic pain. Pain Practice, 14(1), 79-94. doi: 10.1111/papr.12050

Arntz, A., \& Claassens, L. (2004). The meaning of pain influences its experienced intensity. Pain, 109(1-2), 20-25.

Auvray, M., Myin, E., \& Spence, C. (2010). The sensory-discriminative and affective-motivational aspects of pain. Neuroscience and Biobehavioral Reviews, 34(2), 214-223. doi: http://dx.doi.org/10.1016/j.neubiorev.2008.07.008

Birbaumer, N., Lutzenberger, W., Montoya, P., Larbig, W., Unertl, K., Töpfner, S., . . Flor, H. (1997). Effects of regional anesthesia on phantom limb pain are mirrored in changes in cortical reorganization. The Journal of Neuroscience, 17(14), 5503-5508.

Bowering, K. J., Butler, D. S., Fulton, I. J., \& Moseley, G. L. (2014). Motor imagery in people with a history of back pain, current back pain, both, or neither. The Clinical Journal of Pain.

Bray, H., \& Moseley, G. L. (2011). Disrupted working body schema of the trunk in people with back pain. British Journal of Sports Medicine, 45(3), 168-173. doi: 10.1136/bjsm.2009.061978

Brown, C. A., Seymour, B., El-Deredy, W., \& Jones, A. K. P. (2008). Confidence in beliefs about pain predicts expectancy effects on pain perception and anticipatory processing in right anterior insula. Pain, 139(2), 324-332. doi: 10.1016/j.pain.2008.04.028

Byrne, K. P. A. (2011). Survey of phantom limb pain, phantom sensation and stump pain in Cambodian and New Zealand amputees. Pain Medicine, 12(5), 794-798.

Capra, N. F., \& Ro, J. Y. (2004). Human and animal experimental models of acute and chronic muscle pain: Intramuscular algesic injection. Pain, 110(1-2), 3-7.

Chibnall, J. T., \& Tan, R. C. (1999). Social and medical influences on attributions and evaluations of chronic pain. Psychology \& Health, 14(4), 719-729. doi: 10.1080/08870449908410760

Conson, M., Mazzarella, E., Donnarumma, C., \& Trojano, L. (2012). Judging hand laterality from my or your point of view: Interactions between motor imagery and visual perspective. Neuroscience Letters, 530(1), 35-40. doi: http://dx.doi.org/10.1016/j.neulet.2012.09.051

Coslett, H. B., Medina, J., Kliot, D., \& Burkey, A. (2010a). Mental motor imagery and chronic pain: The foot laterality task. Journal of The International Neuropsychological Society, 16(4), 603-612.

Coslett, H. B., Medina, J., Kliot, D., \& Burkey, A. (2010b). Mental motor imagery indexes pain: The hand laterality task. European Journal of Pain, 14(10), 1007-1013. doi: 10.1016/j.ejpain.2010.04.001

de Poel, H. J., Peper, C. E., \& Beek, P. J. (2007). Handedness-related asymmetry in coupling strength in bimanual coordination: Furthering theory and evidence. Acta Psychologica, 124(2), 209-237. doi: http://dx.doi.org/10.1016/j.actpsy.2006.03.003

Dominick, C. H., Blyth, F. M., \& Nicholas, M. K. (2011). Patterns of chronic pain in the New Zealand population. The New Zealand Medical Journal, 124(1337), 63-76.

Draganski, B., Moser, T., Lummel, N., Gänssbauer, S., Bogdahn, U., Haas, F., \& May, A. (2006). Decrease of thalamic gray matter following limb amputation. Neuroimage, 31(3), 951-957.

Elsig, S., Luomajoki, H., Sattelmayer, M., Taeymans, J., Tal-Akabi, A., \& Hilfiker, R. (2014). Sensorimotor tests, such as movement control and laterality judgment accuracy, in persons with recurrent neck pain and controls. A case-control study. Manual Therapy.

Ferreira-Valente, M. A., Pais-Ribeiro, J. L., \& Jensen, M. P. (2011). Validity of four pain intensity rating scales. Pain, 152(10), 2399-2404. doi: http://dx.doi.org/10.1016/j.pain.2011.07.005

Fiorio, M., Tinazzi, M., Ionta, S., Fiaschi, A., Moretto, G., Edwards, M. J., . . Aglioti, S. M. (2007). Mental rotation of body parts and non-corporeal objects in patients with idiopathic cervical dystonia. Neuropsychologia, 45(10), 2346-2354.

Flor, H. (2003). Cortical reorganisation and chronic pain: Implications for rehabilitation. Journal of Rehabilitation Medicine Supplement, 35(41), 66-72.

Grace, V., \& Zondervan, K. (2006). Chronic pelvic pain in women in New Zealand: Comparative wellbeing, comorbidity, and impact on work and other activities. Health Care for Women International, 27(7), 585-599.

Graven-Nielsen, T. (2006). Fundamentals of muscle pain, referred pain, and deep tissue hyperalgesia. Scandinavian Journal of Rheumatology, 35, 1-43. doi: $10.1080 / 03009740600865980$ 
Gustin, S. M., Wrigley, P. J., Siddall, P. J., \& Henderson, L. A. (2010). Brain anatomy changes associated with persistent neuropathic pain following spinal cord injury. Cerebral Cortex, 20(6), 1409-1419. doi: 10.1093/cercor/bhp205

Hanajima, R., Ugawa, Y., Machii, K., Mochizuki, H., Terao, Y., Enomoto, H., . . Kanazawa, I. (2001). Interhemispheric facilitation of the hand motor area in humans. The Journal of Physiology, 531(Pt 3), 849-859.

Hirsh, A. T., Hollingshead, N. A., Matthias, M. S., Bair, M. J., \& Kroenke, K. (2014). The influence of patient sex, provider sex, and sexist attitudes on pain treatment decisions. Journal of Pain, 15(5), 551-559. doi: 10.1016/j.jpain.2014.02.003

Hjermstad, M. J., Fayers, P. M., Haugen, D. F., Caraceni, A., Hanks, G. W., Loge, J. H., . . Kaasa, S. (2011). Studies comparing numerical rating scales, verbal rating scales, and visual analogue scales for assessment of pain intensity in adults: A systematic literature review. Journal of Pain and Symptom Management, 41(6), 1073-1093. doi: 10.1016/j.jpainsymman.2010.08.016

Hong, J.-Y., Labus, J. S., Jiang, Z., Ashe-Mcnalley, C., Dinov, I., Gupta, A., . . Mayer, E. A. (2014). Regional neuroplastic brain changes in patients with chronic inflammatory and noninflammatory visceral pain. PLOS ONE, 9(1), 1-8. doi: 10.1371/journal.pone.0084564

Hudson, M. L., McCormick, K., Zalucki, N., \& Moseley, G. L. (2006). Expectation of pain replicates the effect of pain in a hand laterality recognition task: Bias in information processing toward the painful side? European Journal of Pain, 10(3), 219-224.

lannetti, G. D., \& Mouraux, A. (2010). From the neuromatrix to the pain matrix (and back). Experimental Brain Research, 205(1), 1-12. doi: 10.1007/s00221-010-2340-1

International Association for the Study of Pain. (2003). How prevalent is chronic pain? Pain, 11(2).

Ionta, S., \& Blanke, O. (2009). Differential influence of hands posture on mental rotation of hands and feet in left and right handers. Experimental Brain Research, 195(2), 207-217.

Ionta, S., Fourkas, A. D., \& Aglioti, S. M. (2010). Egocentric and object-based transformations in the laterality judgement of human and animal faces and of non-corporeal objects. Behavioural Brain Research, 207(2), 452-457. doi: 10.1016/j.bbr.2009.10.037

lonta, S., Fourkas, A. D., Fiorio, M., \& Aglioti, S. M. (2007). The influence of hands posture on mental rotation of hands and feet. Experimental Brain Research, 183(1), 1-7.

Ionta, S., Perruchoud, D., Draganski, B., \& Blanke, O. (2012). Body context and posture affect mental imagery of hands. PLOS ONE, 7(3), e34382-e34382. doi: 10.1371/journal.pone.0034382

Jensen, M. P., Lin, C.-P., Kupper, A. E., Galer, B. S., \& Gammaitoni, A. R. (2013). Cognitive testing and revision of the pain quality assessment scale. The Clinical Journal of Pain, 29(5), 400410. doi: 10.1097/AJP.0b013e318260857d

Kagerer, F. A., Summers, J. J., \& Semjen, A. (2003). Instabilities during antiphase bimanual movements: Are ipsilateral pathways involved? Experimental Brain Research, 151(4), 489500.

Kobayashi, M., Hutchinson, S., Schlaug, G., \& Pascual-Leone, A. (2003). Ipsilateral motor cortex activation on functional magnetic resonance imaging during unilateral hand movements is related to interhemispheric interactions. Neuroimage, 20(4), 2259-2270.

Kobayashi, Y., Kurata, J., Sekiguchi, M., Kokubun, M., Akaishizawa, T., Chiba, Y., ... Kikuchi, S. (2009). Augmented cerebral activation by lumbar mechanical stimulus in chronic low back pain patients: An FMRI study. Spine, 34(22), 2431-2436. doi: 10.1097/BRS.0b013e3181b1fb76

Larbig, W., Montoya, P., Braun, C., \& Birbaumer, N. (2006). Abnormal reactivity of the primary somatosensory cortex during the experience of pain in complex regional pain syndrome: $\mathrm{A}$ magnetoencephalograhic case study. Neurocase, 12(5), 280-285.

Leadley, R. M., Armstrong, N., Lee, Y. C., Mien, A., \& Kleijnen, I. (2012). Chronic diseases in the European Union: The prevalence and health cost implications of chronic pain. Journal of Pain and Palliative Care Pharmacotherapy, 26(4), 310.

Learmonth, I. D., Young, C., \& Rorabeck, C. (2007). The operation of the century: Total hip replacement. Lancet, 370(9597), 1508-1519.

Lee, M. C., \& Tracey, I. (2013). Imaging pain: A potent means for investigating pain mechanisms in patients. British Journal of Anaesthesia, 111(1), 64-72. doi: 10.1093/bja/aet174

Loeser, J. D., \& Treede, R.-D. (2008). The Kyoto protocol of IASP basic pain terminology. Pain, 137(3), 473-477. doi: http://dx.doi.org/10.1016/j.pain.2008.04.025

Maclver, K., Lloyd, D. M., Kelly, S., Roberts, N., \& Nurmikko, T. (2008). Phantom limb pain, cortical reorganization and the therapeutic effect of mental imagery. Brain: A Journal of Neurology, 131(8), 2181-2191. 
Main, C. J. (1983). The Modified Somatic Perception Questionnaire (MSPQ). Journal of Psychosomatic Research, 27(6), 503-514.

Malone, H., Nicholl, H., \& Tracey, C. (2014). Awareness and minimisation of systematic bias in research. British Journal of Nursing, 23(5), 279-282.

Massieh, M., \& Davis, K. D. (2013). Theories of pain: From specificity to gate control. Journal of Neurophysiology, 109(1), 5-12.

May, A. (2008). Chronic pain may change the structure of the brain. Pain, 137(1), 7-15.

McMahon, S. B., Koltzenburg, M., \& Wall, P. D. (2005). Wall and Melzack's textbook of pain (5th ed.). Edinburgh: Elsevier Churchill Livingstone.

Melzack, R. (1989). Phantom limbs, the self and the brain (the DO Hebb Memorial Lecture). Canadian Psychology, 30(1), 1.

Melzack, R. (1990). Phantom limbs and the concept of a neuromatrix. Trends in Neurosciences, 13(3), 88-92.

Melzack, R. (1992). Phantom limb pain. Patologicheskaia Fiziologiia I Ėksperimental'naia Terapiia(4), $52-54$.

Melzack, R. (1996). Gate control theory: On the evolution of pain concepts. Pain Forum, 5(2), 128138.

Melzack, R. (1999). From the gate to the neuromatrix. Pain, Suppl 6, S121-S126.

Melzack, R. (2001). Pain and the neuromatrix in the brain. Journal of Dental Education, 65(12), 13781382.

Melzack, R. (2005). The McGill Pain Questionnaire: From description to measurement. Anesthesiology, 103(1), 199-202.

Melzack, R., \& Wall, P. D. (1965). Pain mechanisms: A new theory. Science, 150(3699), 971-979.

Merskey, H., \& Bogduk, N. (1994). Classification of chronic pain, IASP Task Force on Taxonomy. Seattle, WA: International Association for the Study of Pain Press. (Also available online at www. iasp-pain. org).

Mohan, R., Jensen, K. B., Petkova, V. I., Dey, A., Barnsley, N., Ingvar, M., ... Ehrsson, H. H. (2012). No pain relief with the rubber hand illusion. PLOS ONE, 7(12), 1-7. doi: 10.1371/journal.pone.0052400

Morone, N. E., \& Weiner, D. K. (2013). Pain as the fifth vital sign: Exposing the vital need for pain education. Clinical Therapeutics, 35(11), 1728-1732. doi: http://dx.doi.org/10.1016/j.clinthera.2013.10.001

Moseley, G. L. (2003). A pain neuromatrix approach to patients with chronic pain. Manual Therapy, $8(3), 130-140$.

Moseley, G. L. (2004). Why do people with complex regional pain syndrome take longer to recognize their affected hand? Neurology, 62(12), 2182-2186.

Moseley, G. L. (2008). I can't find it! Distorted body image and tactile dysfunction in patients with chronic back pain. Pain, 140(1), 239-243. doi: http://dx.doi.org/10.1016/j.pain.2008.08.001

Moseley, G. L., \& Flor, H. (2012). Targeting cortical representations in the treatment of chronic pain: A review. Neurorehabilitation and Neural Repair, 26(6), 646-652. doi: $10.1177 / 1545968311433209$

Moseley, G. L., Gallace, A., \& lannetti, G. D. (2012). Spatially defined modulation of skin temperature and hand ownership of both hands in patients with unilateral complex regional pain syndrome. Brain: A Journal of Neurology, 135(12), 3676-3686.

Moseley, G. L., Sim, D. F., Henry, M. L., \& Souvlis, T. (2005). Experimental hand pain delays recognition of the contralateral hand-evidence that acute and chronic pain have opposite effects on information processing? Brain Research, 25(1), 188-194.

National Pain Summit Initiative. (2010). National pain strategy: Pain management for all Australians. Melbourne: Faculty of Pain Medicine.

Ni Choisdealbha, A., Brady, N., \& Maguinness, C. (2011). Differing roles for the dominant and nondominant hands in the hand laterality task. Experimental Brain Research, 211(1), 73-85.

Oxford Dictionaries. (2014). Disease. Retrieved from http://www.oxforddictionaries.com/definition/english/disease?q=disease

Parsons, L. M. (1987a). Imagined spatial transformation of one's body. Journal of Experimental Psychology, 116(2), 172-191.

Parsons, L. M. (1987b). Imagined spatial transformations of one's hands and feet. Cognitive Psychology, 19(2), 178-241.

Parsons, L. M. (1994). Temporal and kinematic properties of motor behavior reflected in mentally simulated action. Journal of Experimental Psychology, 20(4), 709. 
Parsons, L. M., \& Fox, P. T. (1998). The neural basis of implicit movements used in recognising hand shape. Cognitive Neuropsychology, 15(6-8), 583.

Pergolizzi, J., Ahlbeck, K., Aldington, D., Alon, E., Collett, B., Coluzzi, F., ... Varrassi, G. (2012). The chronic pain conundrum: Should we CHANGE from relying on past history to assessing prognostic factors? Current Medical Research and Opinion, 28(2), 249-256. doi: 10.1185/03007995.2011.651525

Ploghaus, A., Tracey, I., Gati, J. S., Clare, S., Menon, R. S., Matthews, P. M., \& Rawlins, J. N. (1999). Dissociating pain from its anticipation in the human brain. Science, 284(5422), 1979-1981.

Pope, J. E., Deer, T. R., \& Kramer, J. (2013). A systematic review: Current and future directions of dorsal root ganglion therapeutics to treat chronic pain. Pain Medicine, 14(10), 1477-1496. doi: 10.1111/pme.12171

Pryseley, A., Ledent, E. Y., Drewes, A. M., Staahl, C., Olesen, A. E., \& Arendt-Nielsen, L. (2009). Applying concepts of generalizability theory on data from experimental pain studies to investigate reliability. Basic and Clinical Pharmacology and Toxicology, 105(2), 105-112.

Puretić, M. B., \& Demarin, V. (2012). Neuroplasticity mechanisms in the pathophysiology of chronic pain. Acta Clinica Croatica, 51(3), 425-429.

Reinersmann, A., Haarmeyer, G. S., Blankenburg, M., Frettlöh, J., Krumova, E. K., Ocklenburg, S., \& Maier, C. (2010). Left is where the $L$ is right. Significantly delayed reaction time in limb laterality recognition in both CRPS and phantom limb pain patients. Neuroscience Letters, 486(3), 240-245.

Richter, H. O., Röijezon, U., Björklund, M., \& Djupsjöbacka, M. (2010). Long-term adaptation to neck/shoulder pain and perceptual performance in a hand laterality motor imagery test. Perception, 39(1), 119-130.

Rodriguez-Raecke, R., Niemeier, A., Ihle, K., Ruether, W., \& May, A. (2013). Structural brain changes in chronic pain reflect probably neither damage nor atrophy. PLOS ONE, 8(2), 1-8. doi: 10.1371/journal.pone.0054475

Sainburg, R. L. (2002). Evidence for a dynamic-dominance hypothesis of handedness. Experimental Brain Research, 142(2), 241-258.

Sandkühler, J. (2007). Understanding LTP in pain pathways. Molecular Pain, 3, 9-9.

Schaefer, S. Y., Haaland, K. Y., \& Sainburg, R. L. (2009). Hemispheric specialization and functional impact of ipsilesional deficits in movement coordination and accuracy. Neuropsychologia, 47(13), 2953-2966. doi: 10.1016/j.neuropsychologia.2009.06.025

Schmidt-Wilcke, T., Hierlmeier, S., \& Leinisch, E. (2010). Altered regional brain morphology in patients with chronic facial pain. Headache, 50(8), 1278-1285.

Schwoebel, J., Friedman, R., Duda, N., \& Coslett, H. B. (2001). Pain and the body schema: Evidence for peripheral effects on mental representations of movement. Brain: A Journal of Neurology, 124(Pt 10), 2098-2104.

Shipton, E. A. (2005). Predictors of persistent acute postoperative pain: An opportunity for preventative medicine to reduce the burden of chronic pain. The New Zealand Medical Journal, 118(1208), U1261-U1261.

Shipton, E. A. (2011). The transition from acute to chronic post surgical pain. Anaesthesia \& Intensive Care, 39(5), 824-836.

Siddall, P. J., \& Cousins, M. J. (2004). Persistent pain as a disease entity: Implications for clinical management. Anesthesia and Analgesia, 99(2), 510.

Stanton, T. R., Lin, C.-W. C., Smeets, R. J. E. M., Taylor, D., Law, R., \& Lorimer Moseley, G. (2012). Spatially defined disruption of motor imagery performance in people with osteoarthritis. Rheumatology, 51(8), 1455-1464. doi: 10.1093/rheumatology/kes048

Sullivan, M. J., Bishop, S. R., \& Pivik, J. (1995). The pain catastrophizing scale: Development and validation. Psychological assessment, 7(4), 524.

Tecchio, F., Padua, L., Aprile, I., \& Rossini, P. M. (2002). Carpal tunnel syndrome modifies sensory hand cortical somatotopy: A MEG study. Hum Brain Mapp, 17(1), 28-36. doi: 10.1002/hbm.10049

Torrance, N., Elliott, A. M., Lee, A. J., \& Smith, B. H. (2010). Severe chronic pain is associated with increased 10 year mortality. A cohort record linkage study. European Journal of Pain, 14(4), 380-386. doi: 10.1016/j.ejpain.2009.07.006

Tracey, I., \& Bushnell, M. C. (2009). How neuroimaging studies have challenged us to rethink: Is chronic pain a disease? Journal of Pain, 10(11), 1113-1120. doi: 10.1016/j.jpain.2009.09.001

Treede, R. D., Kenshalo, D. R., Gracely, R. H., \& Jones, A. K. (1999). The cortical representation of pain. Pain, 79(2-3), 105-111. 
Vartiainen, N., Kirveskari, E., Kallio-Laine, K., Kalso, E., \& Forss, N. (2009). Cortical reorganization in primary somatosensory cortex in patients with unilateral chronic pain. Journal of Pain, 10(8), 854-859. doi: 10.1016/j.jpain.2009.02.006

Von Korff, M., \& Miglioretti, D. L. (2005). A prognostic approach to defining chronic pain. Pain, 117(3), 304-313. doi: 10.1016/j.pain.2005.06.017

Wand, B. M., Parkitny, L., O'Connell, N. E., Luomajoki, H., McAuley, J. H., Thacker, M., \& Moseley, G. L. (2011). Cortical changes in chronic low back pain: Current state of the art and implications for clinical practice. Manual Therapy, 16(1), 15-20. doi: http://dx.doi.org/10.1016/j.math.2010.06.008

Wandner, L. D., Heft, M. W., Lok, B. C., Hirsh, A. T., George, S. Z., Horgas, A. L., . . Robinson, M. E. (2014). The impact of patients' gender, race, and age on health care professionals' pain management decisions: An online survey using virtual human technology. International Journal of Nursing Studies, 51(5), 726-733. doi: 10.1016/j.jinurstu.2013.09.011

Wandner, L. D., Scipio, C. D., Hirsh, A. T., Torres, C. A., \& Robinson, M. E. (2012). The perception of pain in others: How gender, race, and age influence pain expectations. Journal of Pain, 13(3), 220-227. doi: 10.1016/j.jpain.2011.10.014

Wrigley, P. J., Press, S. R., Gustin, S. M., Macefield, V. G., Gandevia, S. C., Cousins, M. J., . . Siddall, P. J. (2009). Neuropathic pain and primary somatosensory cortex reorganization following spinal cord injury. Pain, 141(1/2), 52-59. doi: 10.1016/j.pain.2008.10.007

Younger, J. W., Shen, Y. F., Goddard, G., \& Mackey, S. C. (2010). Chronic myofascial temporomandibular pain is associated with neural abnormalities in the trigeminal and limbic systems. Pain, 149(2), 222-228. doi: 10.1016/j.pain.2010.01.006 


\section{Section 2: Manuscript}

Note: This manuscript has been prepared in accordance with the Brain Research journal Instructions for Authors [see Appendix 1.15]. Exceptions to these guidelines are length, formatting and arrangement alterations for ease of reading. Mentions of thesis appendices are made in the manuscript using square brackets but are not intended to constitute part of the manuscript. Additionally, the referencing style follows Elsevier's initiative, 'Your Paper, Your Way' (www.elsevier.com/yourpaperyourway), which permits authors to use their own preferred style of referencing. 
Effect of acute experimental hand pain on left-right discrimination response latency for hand recognition: $A$ repeated measures cross-over design 


\section{Effect of acute experimental hand pain on left-right discrimination response latency for hand recognition: A repeated measures cross-over design}

Author: $\quad$ Nichole Phillips BAppSc (HB)

$\begin{array}{ll}\text { Affiliation: } & \text { Department of Osteopathy } \\ & \text { Unitec New Zealand } \\ & \text { Private Bag } 92025 \\ & \text { Auckland } \\ & \text { New Zealand } \\ \text { Contact: } & \text { Email: } \underline{\text { nicholecphillips@hotmail.com }} \\ & \text { Tel: }+6498154321 \\ & \text { Fax: }+6498154573\end{array}$




\section{Abstract}

Background: Acute experimental pain appears to affect left-right discrimination latency. This phenomenon is an interesting observation as it highlights an effect of pain on the cortex that may have potential significant clinical importance as an assessment of pain state. However, this effect has received relatively little attention detail to date (only two studies, $n=35$ ). A more thorough understanding of the magnitude and characteristics of this phenomenon is needed before further steps can be taken in this area.

Objective: This study aims to closely replicate previous studies that have investigated response latency for left-right discrimination judgements during acute experimental pain.

Participants: A sample of 22 ( $n=11$ female, $n=11$ male) right-handed participants took part in this study. All participants were free from pain, analgesia use, pain-related conditions, upper limb trauma/conditions, visual impairment and dyslexia.

Methods: During our repeated measures cross-over study, participants completed a hand left-right discrimination judgement task before, during and after an experimental pain stimulus was delivered to each hand separately. The experimental pain was achieved using an intramuscular injection of hypertonic (5\%) saline into the thenar eminence of the left and right hands. Mean response times for the left-right discrimination task were determined and compared for pain location, pain condition and image laterality. Participants were also asked to report the pain intensity at 20 second intervals during each left-right discrimination task.

Results: There was neither an immediate main effect of the pain stimulus on response times $(p=1)$, nor an effect of pain location on response times $(p=0.202)$. There was, however, an image laterality effect ( $p=0.004)$ which interacted with a right-hand pain location $(p=0.005)$ but not a left-hand pain location $(p=0.515)$. The image laterality and pain location interaction was consistent across all pain conditions.

Conclusion: Our results were not consistent with previous hand left-right discrimination response latency results. Our results do not support the attentional or information processing bias hypothesis that is currently thought to underpin hand left-right discrimination response latency changes during acute experimental pain in the hand. Our findings may, however, suggest that asymmetrical hemispheric function can affect left-right discrimination latency regardless of pain.

MeSH Keywords: Functional laterality; Hand /*physiopathology; Pain/*ºhysiopathology; Pain/chemically induced; Motor Cortex/*physiopathology; Reaction time; Recognition (Psychology)*; Visual Analogue Pain Scale 


\section{Introduction}

Pain is a protective mechanism that serves to promote survival (lannetti \& Mouraux, 2010) by creating action and protection against damage to body tissue integrity (Moseley, 2003). Pain is a common experience, but it is not understood why some people develop pain states that become persistent and complex to manage. This situation is aggravated by a limited understanding of chronic pain and the continuing need for research into the neurophysiology and neuroanatomy of pain (Massieh \& Davis, 2013). A sizeable amount of literature has explored the effects of pain on cortical processing. One notable aspect is that pain can influence the process of 'mental motor imagery' by disrupting sensorimotor integration and the working body schema (Moseley, Sim, Henry, \& Souvlis, 2005). The body schema is a real-time cortical representation of the body consisting of genetically predetermined neural networks, which are continuously updated by sensory input from the periphery (lonta \& Blanke, 2009; Moseley, 2003).

A common function of the body schema is imagining and imitating real-life movements in a process known as 'mental motor imagery'. One form of mental motor imagery is left-right discrimination judgement where people are asked to view images of limbs and decide if the limb is an anatomical left or right. Research shows that left-right discrimination of limbs incorporates visual and sensorimotor processes (Ni Choisdealbha, Brady, \& Maguinness, 2011) resulting in activation of the same primary sensorimotor cortical areas as actual movement execution (Parsons \& Fox, 1998). During left-right discrimination, it has been hypothesised that people make an initial, subconscious selection from the possible two responses (left or right), and then use unconscious imagined movements of the corresponding limb of the cortical representation of their own body to corroborate the selection and confirm accuracy (Parsons, 1987a, 1987b). Response times for left-right discrimination latency can provide a measure of the information processing and sensorimotor integration that underpin mental motor imagery (Hudson, McCormick, Zalucki, \& Moseley, 2006).

A number of studies have revealed that acute and chronic pain can have dissimilar effects on latency of left-right discrimination judgements. In people with chronic pain, response time latencies for image recognition of the affected limb are slower (Coslett, Medina, Kliot, \& Burkey, 2010a, 2010b; Moseley, 2004; Reinersmann et al., 2010; Schwoebel, Friedman, Duda, \& Coslett, 2001). In contrast, people experiencing acute pain show slower response times to images of the unaffected limb (Hudson et al., 2006; Moseley et al., 2005). This difference has generated speculation on the plausibility of left-right discrimination latency as an objective marker for clinical pain states (Elsig et al., 2014; Schwoebel et al., 2001), and subsequently, has raised questions regarding the mechanisms that underpin these changes.

During acute experimental pain, it has been proposed that an immediate attentional or information processing bias is created during left-right discrimination tasks (Hudson et al., 2006; Moseley et al., 2005). That is, due to the threat value of acute pain, participants are more likely to choose the 
laterality corresponding to the painful limb as their initial subconscious response. The subsequent correction and reconfirmation of an incorrect response causes delayed latency for images of the unaffected limb (Hudson et al., 2006). In contrast, central sensitisation in chronic pain is thought to disrupt the cortical representation of the affected body part, thus reducing left-right discrimination ability of corresponding images (Coslett et al., 2010a, 2010b; Fiorio et al., 2007; Reinersmann et al., 2010; Schwoebel et al., 2001). As only a small number of studies have investigated the effects of acute experimental pain on response time latency, there exists an opportunity to obtain a more thorough understanding of the magnitude and characteristics of left-right discrimination latency during acute experimental pain. Additionally, exploration of this phenomenon could provide insight into the plausibility of left-right discrimination latency as a measure that may be a correlate of the neural transition from acute to chronic pain (Coslett et al., 2010b; Schwoebel et al., 2001).

The assessment of left-right discrimination latency during acute experimental pain can be conducted using intramuscular injection of hypertonic saline which induces a standardised, reversible, localised pain (Graven-Nielsen, Arendt-Nielsen, Svensson, \& Jensen, 1997; Hudson et al., 2006; Loram, Horwitz, \& Bentley, 2009; Moseley et al., 2005). The current study aimed to closely follow a previous study which found that acute experimental pain in the hand caused delayed latency for left-right discrimination responses to images of the non-affected hand (Moseley et al., 2005). We hypothesised that acute experimental pain in the thenar eminence would delay mean response time latency images that correspond to the alternate, non-painful, hand.

\section{Material and methods}

\subsection{Participants}

A convenience sample of 23 people responded to recruitment posters and announcements, met the inclusion/exclusion criteria, and were enrolled in the study. All participants gave written informed consent prior to participation. The study was approved by the Health and Disability Ethics Committee (Northern A) (Reference 12/NTA/37). Inclusion criteria were: aged between 18 to 50 years, ability to speak and write English, ability to give informed consent, and New Zealand citizen or resident status. Exclusion criteria were: presence of orthopaedic, neurological, traumatic or cutaneous conditions of the upper limb or neck, pain or analgesia use on the day of testing, dyslexia, significant visual impairment, history of fainting or seizures, diagnosis of clotting disease or latex allergy, and presence of pain related conditions as determined by the Pain Catastrophising Scale (Sullivan, Bishop, \& Pivik, 1995) and the Modified Somatic Perceptions Questionnaire (Main, 1983) [see Appendix 1.7 for patient screening questionnaire and Appendix 1.9 for patient demographic data descriptive statistics]. All participants were naïve to the concept of mental motor imagery and left-right discrimination, and to the experimental pain stimulus. All participants were right-handed (range $=+60$ and +100 ), as verified by the Edinburgh Handedness Inventory Index [see Appendix 1.8 for questionnaire and Appendix 1.9 for descriptive statistics] (Oldfield, 1971). One participant withdrew following the first experimental 
pain stimulus, and full data sets were collected and analysed for $n=22$ ( $n=11$ female, $n=11$ male; mean $\pm \mathrm{SD}$ age $=30.2 \pm 8.66$ years, range $=21-49$ years )

\subsection{Study protocol}

Data collection occurred during two sessions, separated by one week. For each session, participants were randomised to either the left-sided or right-sided pain ('pain location') group. The side to receive the initial injection was randomised and participants were instructed to use the non-pain stimulus side to input their responses during that session. Data was collected using a left-right discrimination software application (further details below) and a single use of this application is defined as a 'task' for the purpose of this study. Participants were familiarised to the left-right discrimination application by completing it three times with each hand. Participants were asked to identify if the images were of left or right hands ('image laterality') by pressing either the left or right keyboard arrows, and to respond as quickly as possible without resorting to guesswork. There were three pain conditions per session (pre-pain, during-pain, and post-pain) and one left-right discrimination task ( $\sim 4$ min duration) was completed per condition. After completing the pre-pain measures, participants received the painful stimulus and immediately proceeded to commence during-pain measures. Participants completed the post-pain measures once the pain perception had resolved to 0 out of 10 following a washout period of $\sim 5$ to 10 minutes. Each session was conducted by a medical doctor who administered the injections, the principal researcher and a research assistant.

\subsection{Measuring equipment}

Based on an established experimental protocol (Hudson et al., 2006; Moseley et al., 2005), a custom designed software application [see Appendix 1.10] was developed to display a pre-determined sequence of images and measure response time latency. Equal numbers of left and right hand images were displayed (anterior and posterior views), that had been rotated clockwise by $0^{\circ}, 90^{\circ}$, $180^{\circ}$ and $270^{\circ}$ [see Appendix 1.11]. Images of feet and cars in similar views and rotated positions were also displayed between images of hands [see Appendix 1.11 for clarification]. The application displayed images at $4 \mathrm{~s}$ intervals in the centre of the computer screen on a blue background (Fig. 1C). Response time latency was recorded with an accuracy of $0.08 \mathrm{~ms}$. Missed images and incorrect responses were recorded as errors, and latency times for these errors were removed from the analysis. The response time for the image immediately following a missed image was excluded from analysis if the response time was less than $500 \mathrm{~ms}$ to prevent late responses from being inaccurately recorded for the following image. At $20 \mathrm{~s}$ intervals (after 5 images), the application automatically displayed a Visual Analogue Scale (VAS) slider arranged as a horizontal axis of approximately $90 \mathrm{~mm}$ (depending on monitor settings) and anchored with the left label 'no pain' and right label 'max pain' (Fig. 1D). Participants indicated their pain intensity level by holding down the keyboard arrow keys to move a pointer along the axis in increments of 1/100. Data collected from the VAS slider will be reported as an arbitrary measure out of 100 for the purposes of this thesis. 
A

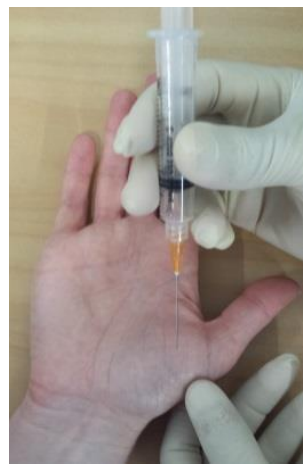

B

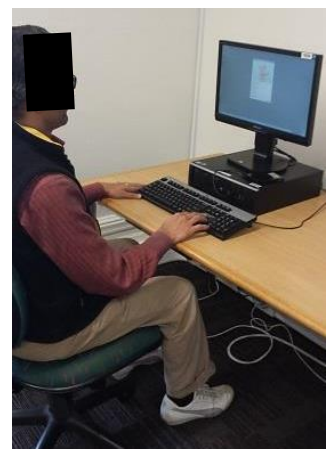

C

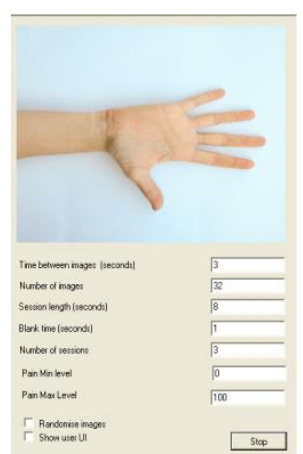

D

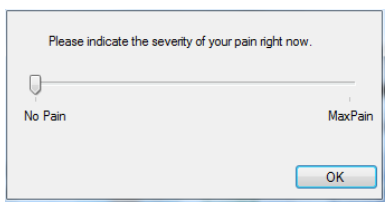

Figure 1 - Image A shows the site of injection of $0.4 \mathrm{ml}$ of hypertonic $5 \%$ saline solution. Injection sites were aspirated to ensure that the needle had not penetrated a vessel prior to injection of the saline solution. Image B shows the position of a participant who is completing the left-right discrimination software application. In this instance, the participant is inputting their responses with their right hand as their left hand will be receiving the acute experimental pain stimulus. The keyboard was moved to the left side during the right-hand pain tasks so a consistent posture was maintained throughout each task. Image $\mathrm{C}$ shows an image presented for judgement in the left-right discrimination application. Image D shows the VAS slider that participants used to input their pain intensity scores.

\subsection{Experimental condition protocol}

Acute experimental pain was achieved using a single $0.4 \mathrm{ml}$ bolus of hypertonic (5\%) saline (Optimus Healthcare, NZ) injected intramuscularly into the thenar eminence with a 25G needle and $1 \mathrm{ml}$ plastic syringe at a depth of approximately $1 \mathrm{~cm}$ (Fig. 1A). Participants had the option of application of topical anaesthetic (ethyl chloride spray) (Arendt-Nielsen, Graven-Nielsen, Svarrer, \& Svensson, 1996), however, no participant chose this option.

\subsection{Participants position}

Participants sat upright at a computer desk with a comfortable viewing distance of approximately 50 $70 \mathrm{~cm}$ from the computer screen (Fig. 1B). They were asked to rest their hands (palm down) on the desk with fingers pointing forward and the fingers of the non-painful limb resting on the left and right arrow keys of the keyboard in front of them. Their feet were positioned flat on the floor with toes pointing forward. Participants were instructed to maintain this position throughout the testing procedures as alterations in proprioceptive input have been shown to affect left-right discrimination latency (Ni Choisdealbha et al., 2011).

\subsection{Adverse events}

One participant (female) experienced an episode of vasovagal syncope following the first experimental pain stimulus and withdrew from the study. Participants were sent a follow-up email after each session and at one week after the final session. A number of temporary and minor reactions were reported [see Appendix 1.14] however no participants required treatment. 


\subsection{Statistical analysis}

Assumptions of normality were explored with the Shapiro-Wilk test, and sphericity was tested using Mauchley's test. Three-way repeated measures ANOVA (Pain location, Image laterality, Pain condition) were conducted to identify main effects and interactions. Bonferroni post-hoc pair-wise comparisons were conducted to further explore significant effects. All statistical analysis was performed using IBM SPSS Statistics (v.22 IBM Corp., NY). Unless otherwise stated, all results are reported as mean \pm standard deviation. Statistical significance was set at $p<0.05$.

\section{Results}

Analysis of the peak pain intensity ratings for the during-pain condition showed that there were no significant differences $(p=0.26)$ between pain intensity ratings when the pain was located in either in the left hand (mean $=50.5 \pm 24.1$ ) or the right hand (mean $=46.9 \pm 19.0$ ). Therefore, the data for both hands have been pooled to show the following mean values for peak pain intensity in each pain condition; pre-pain condition (mean $=0.34 \pm 1.33$ ), during-pain condition (mean $=48.7 \pm 21.56$ ), and post-pain condition (mean $=2.2 \pm 4.92$ ) (Fig. $2 \mathrm{~A}$ ). Mean peak pain intensity ratings recorded in the during-pain conditions were significantly higher $(p<0.001)$ than those recorded in the pre-pain condition and post-pain conditions. There was also a significant difference between the mean pain intensity ratings for the pre-pain conditions and post-pain conditions (mean difference $=1.86,95 \% \mathrm{Cl}$ $=-3.299$ to $-0.421, d=0.515, p=0.012$ ), however, a difference of $1.86 / 100$ was not considered to be of practical importance and not practically different from the pre-pain condition. Indeed, comparing left hand pain during the pre-pain and post-pain conditions was not significantly different (mean difference $=2.44,95 \% \mathrm{Cl}=-5.212$ to $0.332, d=0.643, p=0.098$ ), as was right hand pain during the pre-pain and post-pain conditions (mean difference $=1.28,95 \% \mathrm{Cl}=-3.728$ to $1.168, d=0.370, p=$ 0.573). A within-subject test showed that there was no interaction between the location of the pain stimulus and the pain condition $(p=0.26)$. 
Mean pain intensity rating during each pain condition

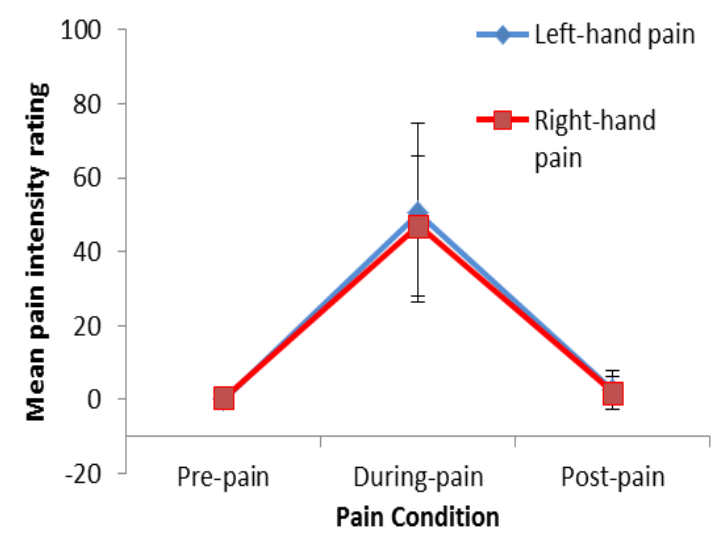

A

\section{Mean response times for all images and pain locations during each pain condition}

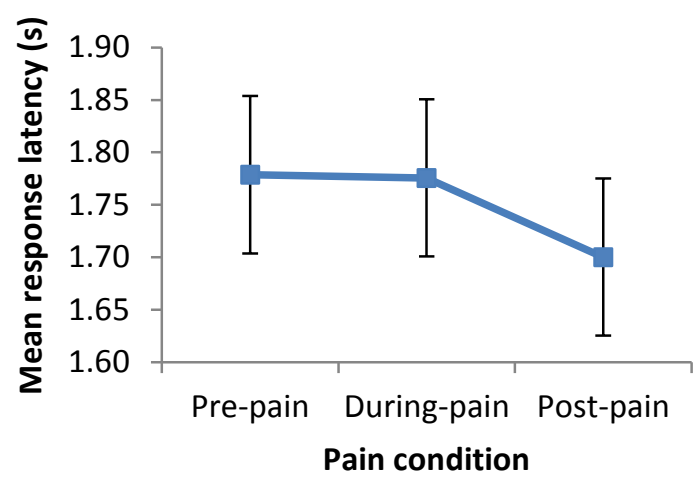

B

Figure 2-Graph A shows the mean peak pain intensity ratings that were recorded during each pain condition for each pain location (left and right thenar eminence). Graph B shows the faster mean response times during the post-pain condition.

A comparison of the mean response latency (for all images and pain locations) during the pre-pain condition (mean $=1.779 \pm 0.347 \mathrm{~s}$ ) and the during-pain condition (mean $=1.776 \pm 0.352 \mathrm{~s}$ ) revealed that there was not a significant difference between the means of these pain conditions (mean difference $=0.003 \mathrm{~s}, 95 \% \mathrm{Cl}=-0.071$ to $0.077 \mathrm{~s}, d=0.009, p=1$ ). A similar comparison of the mean response latency (for all images and pain locations) during the during-pain condition and the post-pain condition (mean $=1.700 \pm 0.352 \mathrm{~s}$ ) revealed that there was a significant difference between the means of these pain conditions. The difference between the means of the during-pain condition and the post-pain condition was $0.076 \mathrm{~s}(95 \% \mathrm{Cl}=0.004$ to $0.147 \mathrm{~s}, d=0.217, p=0.036)$. The difference between the means of the pre-pain condition and the post-pain condition (for all images and pain locations) was significant (mean difference $=0.079 \mathrm{~s}, 95 \% \mathrm{Cl}=0.027$ to $0.131 \mathrm{~s}, d=0.226, p=0.002$ ) (Fig. 2B). There was no significant main effect of pain location when the mean response time latency for all conditions and all images of the left-pain group (mean $=1.718 \pm 0.366 \mathrm{~s}$ ) or the right-pain group (mean $=1.785 \pm 0.361 \mathrm{~s}$ ) were compared (mean difference $=0.067 \mathrm{~s}, 95 \% \mathrm{Cl}=-0.039$ to $0.172 \mathrm{~s}, d=$ $0.184, p=0.202$ ). Pairwise Bonferroni comparison of mean response latency for left and right images across all pain conditions (pre-pain, during-pain, or post-pain) and all pain locations (left and right) revealed significant main effects of image laterality where participants responded faster (mean difference $=0.075 \mathrm{~s}, 95 \% \mathrm{Cl}=0.026$ to $.0123 \mathrm{~s}, d=0.216, p=0.004$ ) to images of right hands (mean $=1.714 \pm 0.356 \mathrm{~s})$ than left hands (mean $=1.789 \pm 0.338 \mathrm{~s}$ ).

When the data was separated according to pain location, the main effects of image laterality were altered and showed an interaction between image laterality and pain location. For all response latency data collected during each left-right discrimination task (pre-pain, during-pain, post-pain) related to a right pain location, comparison of mean response time latency for images of right hands (mean $=1.722 \pm 0.385 \mathrm{~s}$ ) to pictures of left hands (mean $=1.847 \pm 0.375 \mathrm{~s}$ ) revealed a significant mean difference of $0.125 \mathrm{~s}(95 \% \mathrm{Cl}=0.043$ to $0.207 \mathrm{~s}, d=0.329, p=0.005)$ (Fig. 3A). This difference 
was not observed when mean response latency for images of left hands (mean $=1.730 \pm 0.347 \mathrm{~s}$ ) and right hands (mean $=1.706 \pm 0.399 \mathrm{~s}$ ) collected during all conditions (pre-pain, during-pain, post-pain) related to a left pain location were compared (mean difference $=0.025 \mathrm{~s}, 95 \% \mathrm{Cl}=-0.053$ to $0.102 \mathrm{~s}, d$ $=0.0634, p=0.515)($ Fig. 3A). Further consideration of the image laterality and pain laterality data during each of the three pain conditions showed that the image laterality and right handed pain interaction occurred during each pain condition (Fig. 3B and 3C and 3D).

\section{Mean response latency for left and right images during left and right pain (all pain conditions)}

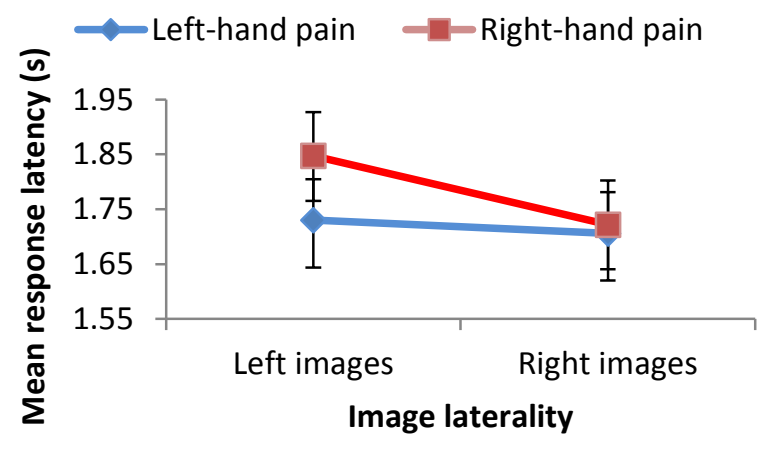

A

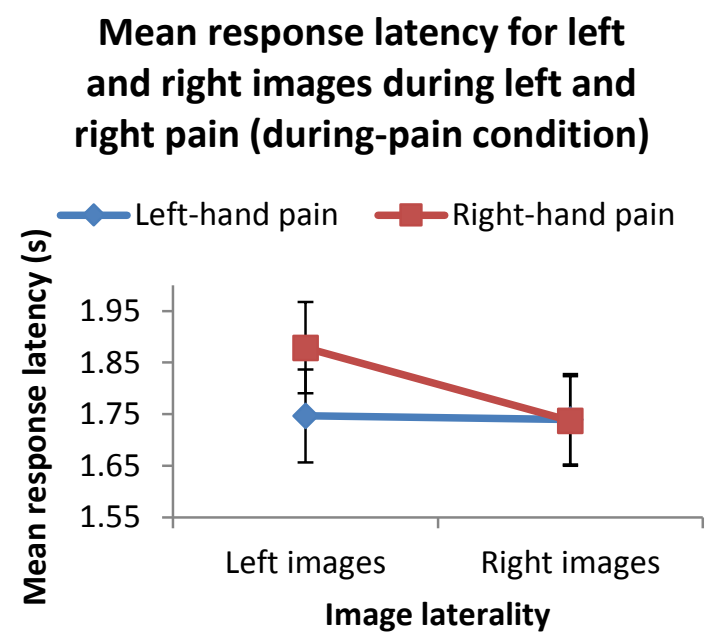

C

\section{Mean response latency for left and right images during left and right pain (pre-pain condition)}

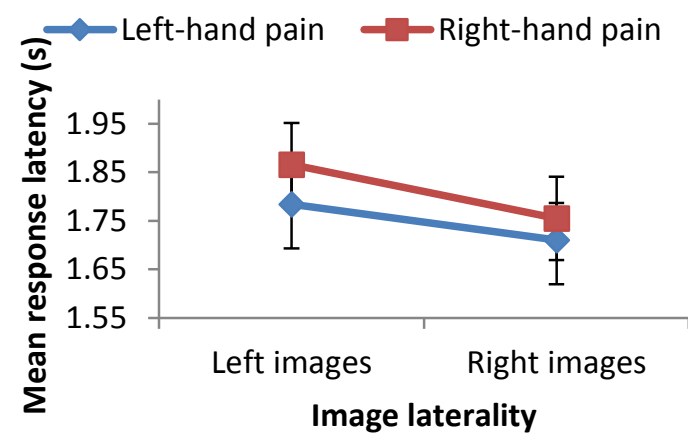

B

\section{Mean response latency for left} and right images during left and right pain (during-pain condition)

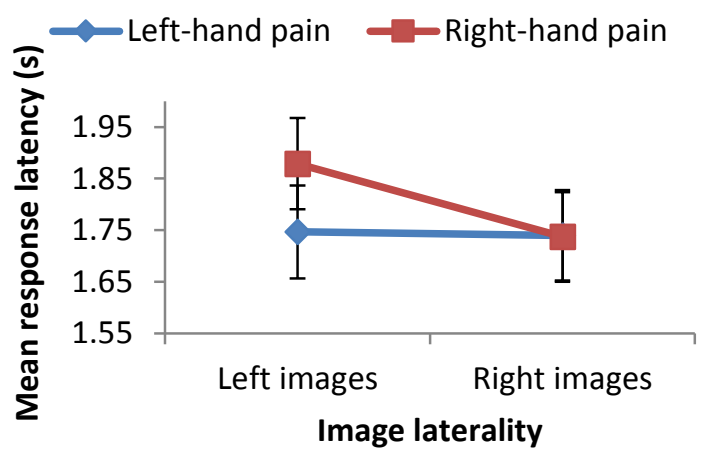

D

Figure 3 - Graph A shows the main effects of image laterality across all pain locations and all pain conditions.

Graph B shows the interaction between image laterality and pain location during the pre-pain condition. During right hand pain, mean response latency for images of right hands (mean $=1.75 \pm 0.39 \mathrm{~s}$ ) was faster than mean response latency for images of left hands $($ mean $=1.87 \pm 0.39 \mathrm{~s})$ (mean difference $=0.111 \mathrm{~s}, 95 \% \mathrm{Cl}=0.004$ to $0.218 \mathrm{~s}, d=0.308, p=0.043$ ).

Graph $\mathrm{C}$ shows the interaction between image laterality and pain location during the during-pain condition. During right hand pain mean response latency for images of right hands (mean $=1.74 \pm 0.40 \mathrm{~s}$ ) was faster than mean response latency for images of left hands $($ mean $=1.88 \pm 0.40 \mathrm{~s}$ ) (mean difference $=0.142 \mathrm{~s}, 95 \% \mathrm{Cl}=0.032$ to $0.253 \mathrm{~s}, d=0.350, p=0.014$ ).

Graph D shows the interaction between image laterality and pain location during the post-pain condition. During right hand pain, mean response latency for images of right hands (mean $=1.68 \pm 0.41 \mathrm{~s}$ ) was faster than mean response latency for images of left hands $($ mean $=1.80 \pm 0.40 \mathrm{~s})$ (mean difference $=0.122 \mathrm{~s}, 95 \% \mathrm{Cl}=0.001$ to $0.243 \mathrm{~s}, d=0.296, p=0.049$ ). 
Comparison of mean response latency for images of the same laterality for each pain location were not significantly different between pre-pain and during-pain conditions (Table 1 and Fig. 3A and 3B). The post-pain condition showed a significant difference in mean response latency during right and left handed pain for left images only (mean difference $=0.137 \mathrm{~s}, 95 \% \mathrm{Cl}=-0.261$ to $-0.014 \mathrm{~s}, d=0.37, p=$ 0.031) (Table 1 and Fig. 3D).

Table 1 - Comparison of mean response latency (s) for all pain conditions, all images and all pain locations using three-way repeated measures ANOVA and Cohen's $d$ effect sizes.

\begin{tabular}{|c|c|c|c|c|c|c|c|c|c|}
\hline \multirow{2}{*}{$\begin{array}{l}\text { Pain condition } \\
\text { Image laterality }\end{array}$} & \multicolumn{3}{|c|}{ Pre-pain } & \multicolumn{3}{|c|}{ During-pain } & \multicolumn{3}{|c|}{ Post-pain } \\
\hline & L & $\mathrm{R}$ & $p^{b}$ & L & $\mathrm{R}$ & $p^{b}$ & $L$ & $\mathrm{R}$ & $p^{b}$ \\
\hline Left hand pain & $1.78(0.36)$ & $1.71(0.42)$ & .143 & $1.75(0.41)$ & $1.74(0.41)$ & .907 & $1.66(0.35)$ & $1.67(0.42)$ & .903 \\
\hline Right hand pain & $1.87(0.39)$ & $1.75(0.39)$ & .043 & $1.88(0.40)$ & $1.74(0.40)$ & .014 & $1.80(0.40)$ & $1.68(0.41)$ & .049 \\
\hline$p^{\mathrm{a}}$ & 0.217 & 0.605 & - & 0.113 & 0.959 & - & 0.031 & 0.90 & - \\
\hline & 0.081 & 0.044 & & 0.132 & 0.004 & & 0.137 & 0.01 & \\
\hline $\begin{array}{l}\text { Mean difference } \\
\qquad(95 \% \mathrm{Cl})\end{array}$ & $\begin{array}{c}(-0.215- \\
0.052)\end{array}$ & $\begin{array}{c}(-0.132- \\
0.22)\end{array}$ & - & $\begin{array}{c}(-0.034- \\
0.30)\end{array}$ & $\begin{array}{c}(-0.153- \\
0.161)\end{array}$ & - & $\begin{array}{l}(-0.261- \\
-0.014)\end{array}$ & $\begin{array}{c}(-0.167- \\
0.148)\end{array}$ & - \\
\hline Effect size $(d)$ & 0.24 & 0.10 & - & 0.32 & 0.00 & - & 0.37 & 0.02 & - \\
\hline
\end{tabular}

Notes: response times are measured in $\mathrm{s}$ and are presented as mean (SD); $\mathrm{L}=$ left; $\mathrm{R}=$ right; $p=\mathrm{p}$-value; $p^{\mathrm{a}}=\mathrm{p}$-values for the mean difference when comparing same image laterality when related to different pain locations; $p^{b}=p$-values for the mean difference when comparing different image laterality when related to the same pain locations.

\section{Discussion}

The current study aimed to replicate previous findings that acute experimental hand pain resulted in delayed response times to images that corresponded to the unaffected hand during a left-right discrimination task. Contrary to expectations, the left-right discrimination latency alterations observed in the current study were somewhat dissimilar in characteristics to those of previous studies (Hudson et al., 2006; Moseley et al., 2005) in that the location of pain did not create any significant image laterality specific changes. Our findings are in contrast to the current 'attentional bias' theory that is proposed to underpin the cortical mechanisms of altered left-right discrimination latency changes during acute pain (Hudson et al., 2006; Moseley et al., 2005).

Not only were pain location-specific effects not observed, the response latency changes that occurred during our study were not immediate or concurrent with the pain experience, nor were they related to the side of pain. Significant decreases in mean response latency overall were only observed during the post-pain discrimination tasks which were conducted following a washout period and cessation of pain symptoms. This unanticipated interval between pain stimulus and latency changes in our study is intriguing. This interval appears to refute the mechanism of an attentional bias or information processing bias, owing to the perception of pain, that has been proposed to explain the left-right discrimination latency changes observed during acute experimental pain (Hudson et al., 2006; 
Moseley et al., 2005). An attentional or information processing bias would be expected to occur with pain symptoms; however, our results show that changes in response latency takes some time to occur, and does not require the simultaneous perception of pain.

It is not clear why the acute experimental pain was not associated with immediate response latency changes. Also, it is not clear why the response latency changes were deferred to the post-pain condition. Our methodology of acute experimental pain was similar to that of previous studies (Hudson et al., 2006; Moseley et al., 2005) and the participants' pain intensity ratings indicate successful generation of pain symptoms (Fig. 2A). Additionally, a washout period that was sufficient to eliminate conscious pain symptoms separated the during-pain and post-pain tasks. A learning effect cannot be ruled out in this instance as repeated post-pain measures were not conducted to determine when mean response latency returned to pre-pain levels, however, the repeated measures design and inclusion of task familiarisation protocols reduces the likelihood of this. Furthermore, a learning effect could be anticipated to occur earlier in the session (i.e., between pre-pain and duringpain conditions) rather than later, as learning effects tend to plateau over time. In retrospect, the washout period was inadequate to return latency measures to pre-pain levels as has been suggested that several pain-related adaptations can persistent following pain cessation, reflecting neuroplastic changes that extend beyond the perception of pain (Le Pera et al., 2001; Schabrun \& Hodges, 2012). However, this persistence of pain-adaptation manifestations does not explain why no effect of the pain was seen in the during-pain condition.

A potential interfering factor could be that, during the pre-pain and during-pain conditions, our participants may have experienced apprehension and fear related to the experimental pain stimulus. If this is true, then these emotions would be expected to decrease following cessation of the experimental pain symptoms and subsequently facilitate the improved left-right discrimination ability that we observed. Expectation of pain has been shown to have a similar effect to pain, in that both create a similar disruption to left-right discrimination latency (Hudson et al., 2006). However, this evidence only indirectly offers some support to our finding as we did not observe an attentional or information bias processing towards the threatened and subsequently painful limb. Rather, an overall impairment in left-right discrimination for all images was observed (Fig. 2B and $2 \mathrm{C}$ ). So it is yet to be determined if the deferred changes in mean latency response times are a likely effect of the experimental pain stimulus with a yet to be determined neurophysiological basis or the result of an interfering factor. Nonetheless, the lack of left-right discrimination latency changes in the during-pain condition is in contrast to other results (Hudson et al., 2006; Moseley et al., 2005), and may indicate that conscious pain symptoms are not necessary, and may only be partly related to, performance during left-right discrimination tests.

The observed main effect of delayed latency changes must also be considered in light of the characteristics of the changes and interactions with other factors. Another main effect was that participants showed a predisposition to faster response times for right-hand images than left-hand 
images across all experimental conditions (pre-pain, during-pain, post-pain). A similar laterality effect has been reported in previous studies (Ionta \& Blanke, 2009; Ionta, Fourkas, Fiorio, \& Aglioti, 2007; Parsons, 1987b), and research into the effects of lateralisation show that right handed participants are facilitated in recognising images of right hands (Ni Choisdealbha et al., 2011). Therefore, this main effect is not surprising as the participants in our study demonstrated a high degree of right-handed lateralisation [see Appendix 1.9]. Conversely, this finding may not represent a normal phenomenon as there are contrasting results which show no significant difference between mean response times for recognition of left and right hands $(p=0.42)$ (Hudson et al., 2006). Therefore, this main effect was explored further.

Additional consideration of the data by pain location (right-hand pain or left-hand pain) revealed that the image laterality effect only reaches significance for response times that are associated with a right-hand pain location (Fig. 3A). Mean response times associated with a left-hand pain location show no significant difference between image laterality. Overall, it appears as though mean response times are consistent for right-hand images between pain locations, and a delay in response times for left-hand images occurs during right-hand pain only. However, separating the data across pain conditions (pre-pain, during-pain, post-pain) shows that the interaction between right-hand pain location and image laterality was a common occurrence during each condition (Fig. 3B and $3 \mathrm{C}$ and 3D.). Therefore, the characteristics of the pre-existing interaction between pain location and image laterality were unchanged across all pain conditions, despite the main effect of faster mean response times that was observed during the post-pain condition.

The observation that the image laterality and pain location interaction is similar across all pain conditions is challenging to interpret. A clear impairment of performance was observed for images of left hands across all right-hand pain conditions, but, in the course of the pre-pain and post-pain tasks, the participants were not experiencing any pain symptoms. Pain appears to not be the cause of this effect. The single factor that changed between left-hand pain and right-hand pain was that participants were inputting their responses with the hand that would not receive the injection on that day. Therefore, during all right-hand pain conditions, participants were using their left hands to input their responses, and this factor appears to have resulted in delayed response latency to images of left hands, regardless of pain.

This observation was not expected as the method for inputting the response was similar to previous studies (Hudson et al., 2006; Moseley et al., 2005). One possible explanation for this effect is that our participants were right handed and the non-dominant left hand exhibited slower reaction times. However, our data showed that there was no significant difference between mean response latency for right-hand images when inputting with either hand, therefore demonstrating no difference in input speeds between the right and left hand (Fig. 3A). Additionally, there is a large amount of contradictory evidence that shows that the dominant right hand is superior to the left hand when considering reaction times (Barthelemy \& Boulinguez, 2001; Mieschke, Elliott, Helsen, Carson, \& 
Coull, 2001; Nisiyama \& Ribeiro-do-Valle, 2014). Another potential explanation for this discrepancy is that use of the left hand to input responses by our right-handed participants may have resulted in a distraction or disruption in sensorimotor integration and left-right discrimination that was specific to images of left hands. Conversely, our explicit instructions not to move the dominant right hand may also be hypothesised to have a similar effect. The mechanism underlying the observed effect is not clear and only speculation is possible at this point.

Although not directly explanatory of our findings, it is interesting to consider the implications of interhemispheric inhibition during motor control. It has been shown that right handed people have a distinct asymmetry in inhibitory circuits that favours a stronger inhibitory control by the left hemisphere over the right hemisphere (de Poel, Peper, \& Beek, 2007; Kagerer, Summers, \& Semjen, 2003; Kobayashi, Hutchinson, Schlaug, \& Pascual-Leone, 2003; Reid \& Serrien, 2012). It is then suggested that this asymmetry can cause difficulty and interference when uncoupling movement patterns for asymmetric bimanual activities because co-activation of the primary motor cortices leads to a more pronounced inhibition of the non-dominant hemisphere (Reid \& Serrien, 2012). Furthermore, complex unimanual tasks also activate both primary motor cortices, again with an asymmetrical magnitude that favours the left hemisphere control over the right hemisphere (Stinear, Fleming, \& Byblow, 2006; van den Berg, Swinnen, \& Wenderoth, 2011). Therefore, the act of inputting responses with the left hand the act of inputting responses with the left hand while concurrently discriminating between left and right hand images (a complex mental motor imagery task) would result in co-activation of the motor cortices and stronger interference and inhibition of the function of the non-dominant hemisphere. This may explain the left-hand image specific impairment seen in our results. Correspondingly, using the same concept, the act of using the right hand to input responses while the left is held motionless may not result in the same degree of bilateral motor cortex co-activation and asymmetrical inhibition, thus potentially suggesting a possible underlying neurophysiological mechanism of our results.

In summary, our hypothesis that acute experimental pain in the thenar eminence would delay mean response time latency to images that correspond to the alternate, non-painful hand was not supported by the findings. The results of our study highlight the individualistic nature of pain and its clinical effects, and as such, the difficulties inherent in its quantification. Our results also raise negative implications regarding the plausibility of the attentional or information processing bias that is currently thought to underpin left-right discrimination changes during acute experimental pain. At present, the specific functional significance of our findings cannot be established and only speculation regarding the mechanism is possible. Future left-right discrimination research may benefit from utilising a verbal recording method (Ionta, Perruchoud, Draganski, \& Blanke, 2012) to record judgement responses. This format may eliminate the potential confounding factors of hand dominance when inputting responses. Additionally, further research on left-right discrimination strategies in left and right handed participants may begin to address some of the points raised by the findings of this study. 


\section{References}

Arendt-Nielsen, L., Graven-Nielsen, T., Svarrer, H., \& Svensson, P. (1996). The influence of low back pain on muscle activity and coordination during gait: A clinical and experimental study. Pain, 64(2), 231-240.

Barthelemy, S., \& Boulinguez, P. (2001). Manual reaction time asymmetries in human subjects: The role of movement planning and attention. Neuroscience Letters, 315(1-2), 41-44.

Coslett, H. B., Medina, J., Kliot, D., \& Burkey, A. (2010a). Mental motor imagery and chronic pain: The foot laterality task. Journal of The International Neuropsychological Society, 16(4), 603-612.

Coslett, H. B., Medina, J., Kliot, D., \& Burkey, A. (2010b). Mental motor imagery indexes pain: The hand laterality task. European Journal of Pain, 14(10), 1007-1013. doi: 10.1016/j.ejpain.2010.04.001

de Poel, H. J., Peper, C. E., \& Beek, P. J. (2007). Handedness-related asymmetry in coupling strength in bimanual coordination: Furthering theory and evidence. Acta Psychologica, 124(2), 209-237. doi: http://dx.doi.org/10.1016/j.actpsy.2006.03.003

Elsig, S., Luomajoki, H., Sattelmayer, M., Taeymans, J., Tal-Akabi, A., \& Hilfiker, R. (2014). Sensorimotor tests, such as movement control and laterality judgment accuracy, in persons with recurrent neck pain and controls. A case-control study. Manual Therapy.

Fiorio, M., Tinazzi, M., Ionta, S., Fiaschi, A., Moretto, G., Edwards, M. J., . . Aglioti, S. M. (2007). Mental rotation of body parts and non-corporeal objects in patients with idiopathic cervical dystonia. Neuropsychologia, 45(10), 2346-2354.

Graven-Nielsen, T., Arendt-Nielsen, L., Svensson, P., \& Jensen, T. S. (1997). Experimental muscle pain: A quantitative study of local and referred pain in humans following injection of hypertonic saline. Journal of Musculoskeletal Pain, 5(1), 49-69.

Hudson, M. L., McCormick, K., Zalucki, N., \& Moseley, G. L. (2006). Expectation of pain replicates the effect of pain in a hand laterality recognition task: Bias in information processing toward the painful side? European Journal of Pain, 10(3), 219-224.

lannetti, G. D., \& Mouraux, A. (2010). From the neuromatrix to the pain matrix (and back). Experimental Brain Research, 205(1), 1-12. doi: 10.1007/s00221-010-2340-1

Ionta, S., \& Blanke, O. (2009). Differential influence of hands posture on mental rotation of hands and feet in left and right handers. Experimental Brain Research, 195(2), 207-217.

Ionta, S., Fourkas, A. D., Fiorio, M., \& Aglioti, S. M. (2007). The influence of hands posture on mental rotation of hands and feet. Experimental Brain Research, 183(1), 1-7.

Ionta, S., Perruchoud, D., Draganski, B., \& Blanke, O. (2012). Body context and posture affect mental imagery of hands. PLOS ONE, 7(3), e34382-e34382. doi: 10.1371/journal.pone.0034382

Kagerer, F. A., Summers, J. J., \& Semjen, A. (2003). Instabilities during antiphase bimanual movements: Are ipsilateral pathways involved? Experimental Brain Research, 151(4), 489500.

Kobayashi, M., Hutchinson, S., Schlaug, G., \& Pascual-Leone, A. (2003). Ipsilateral motor cortex activation on functional magnetic resonance imaging during unilateral hand movements is related to interhemispheric interactions. Neuroimage, 20(4), 2259-2270.

Le Pera, D., Graven-Nielsen, T., Valeriani, M., Oliviero, A., Di Lazzaro, V., Tonali, P. A., \& ArendtNielsen, L. (2001). Inhibition of motor system excitability at cortical and spinal level by tonic muscle pain. Clinical Neurophysiology: Official Journal Of The International Federation Of Clinical Neurophysiology, 112(9), 1633-1641.

Loram, L., Horwitz, E., \& Bentley, A. (2009). Gender and site of injection do not influence intensity of hypertonic saline-induced muscle pain in healthy volunteers. Manual Therapy, 14(5), 526530. doi: 10.1016/j.math.2008.09.002

Main, C. J. (1983). The Modified Somatic Perception Questionnaire (MSPQ). Journal of Psychosomatic Research, 27(6), 503-514.

Massieh, M., \& Davis, K. D. (2013). Theories of pain: From specificity to gate control. Journal of Neurophysiology, 109(1), 5-12.

Mieschke, P. E., Elliott, D., Helsen, W. F., Carson, R. G., \& Coull, J. A. (2001). Manual asymmetries in the preparation and control of goal-directed movements. Brain and Cognition, 45(1), 129-140.

Moseley, G. L. (2003). A pain neuromatrix approach to patients with chronic pain. Manual Therapy, $8(3), 130-140$. 
Moseley, G. L. (2004). Why do people with complex regional pain syndrome take longer to recognize their affected hand? Neurology, 62(12), 2182-2186.

Moseley, G. L., Sim, D. F., Henry, M. L., \& Souvlis, T. (2005). Experimental hand pain delays recognition of the contralateral hand-evidence that acute and chronic pain have opposite effects on information processing? Brain Research, 25(1), 188-194.

Ni Choisdealbha, A., Brady, N., \& Maguinness, C. (2011). Differing roles for the dominant and nondominant hands in the hand laterality task. Experimental Brain Research, 211(1), 73-85.

Nisiyama, M., \& Ribeiro-do-Valle, L. E. (2014). Relative performance of the two hands in simple and choice reaction time tasks. Brazilian Journal of Medical and Biological Research, 47(1), 8089. doi: 10.1590/1414-431X20132932

Oldfield, R. C. (1971). The assessment and analysis of handedness: The Edinburgh inventory. Neuropsychologia, 9(1), 97-113.

Parsons, L. M. (1987a). Imagined spatial transformation of one's body. Journal of Experimental Psychology, 116(2), 172-191.

Parsons, L. M. (1987b). Imagined spatial transformations of one's hands and feet. Cognitive Psychology, 19(2), 178-241.

Parsons, L. M., \& Fox, P. T. (1998). The neural basis of implicit movements used in recognising hand shape. Cognitive Neuropsychology, 15(6-8), 583.

Reid, C. S., \& Serrien, D. J. (2012). Handedness and the excitability of cortical inhibitory circuits. Behavioural Brain Research, 230(1), 144-148. doi: 10.1016/j.bbr.2012.02.008

Reinersmann, A., Haarmeyer, G. S., Blankenburg, M., Frettlöh, J., Krumova, E. K., Ocklenburg, S., \& Maier, C. (2010). Left is where the $L$ is right. Significantly delayed reaction time in limb laterality recognition in both CRPS and phantom limb pain patients. Neuroscience Letters, 486(3), 240-245.

Schabrun, S. M., \& Hodges, P. W. (2012). Muscle pain differentially modulates short interval intracortical inhibition and intracortical facilitation in primary motor cortex. Journal of Pain, 13(2), 187-194.

Schwoebel, J., Friedman, R., Duda, N., \& Coslett, H. B. (2001). Pain and the body schema: Evidence for peripheral effects on mental representations of movement. Brain: A Journal of Neurology, 124(Pt 10), 2098-2104.

Stinear, C. M., Fleming, M. K., \& Byblow, W. D. (2006). Lateralization of unimanual and bimanual motor imagery. Brain Research, 1095(1), 139-147.

Sullivan, M. J., Bishop, S. R., \& Pivik, J. (1995). The pain catastrophizing scale: Development and validation. Psychological assessment, 7(4), 524.

van den Berg, F. E., Swinnen, S. P., \& Wenderoth, N. (2011). Involvement of the primary motor cortex in controlling movements executed with the ipsilateral hand differs between left- and righthanders. Journal of Cognitive Neuroscience, 23(11), 3456-3469. 


\section{Section 3: Appendices}

\subsection{Health and Disability Ethics Committees approval letter}

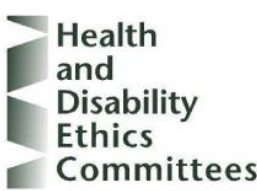

\author{
Health and Disability Ethics Committees \\ Ministry of Health \\ 1 the Terrace \\ PO Box 5013 \\ Wellington
}

08004 ETHICS hdecs@moh.govt.nz

17 September 2012

Ms Nichole Phillips

32 Trinidad Street

Blockhouse Bay

Auckland 0600

Dear Ms Phillips

$\begin{array}{lll}\text { Re: } & \text { Ethics ref: } & 12 / N T A / 37 \\ \text { Study title: } & \text { To what extent does experimentally induced pain affect the mental } \\ & \text { rotation of body parts and non-body objects in healthy participants? }\end{array}$

I am pleased to advise that this application has been approved by the Northern A Health and Disability Ethics Committee. This decision was made through the HDEC-Full Review pathway.

The main issues considered by the HDEC in giving approval were as follows.

- The Committee encourages the collection of ethnicity where possible.

- The Committee is reassured that the sample size may suffice given possible large effect sizes, but encourages data monitoring.

- Please clarify that the health information generated will be stored for 10 years instead of 5 years ( $r .2 .5)$.

- Consider excluding non-New Zealand citizens and residents as they may not be covered by insurance.

- Consistent use of 10 minutes for "the pain to disappear" in all documents

- Consider conducting the study at a nearer location (e.g. Unitec student health).

- The Committee requested the following changes be made to the Participant Information Sheet:

- on letterhead

- include page numbers

- "What will happen?" (page 2) needs amending as this document must include all information to be given to potential participants to assist them in giving informed consent

- outline the inclusion and exclusion criteria

- include details of the Unitec Counselling centre

- include Māori health advisory contact details

- include information on after hours contact details for medical assistance 
- remove all references to the Unitec ethics committee approval; refer to the correct HDEC (Northern A) throughout all documents

- include information that Dr Scott McLaren will also keep patient records of participants seen at his clinic for 10 years.

- The Committee requested the contents of the Consent Form be expanded to include:

- on letterhead

- include page numbers

- a clause that the participant can withdraw from the study at any time

- a way for participants to indicate if they wish to receive a copy of the results

- the option to be accompanied by a whanau or friend to ask questions

- a clause which reads "I understand the compensation provisions for this study"

- a clause which reads "I know who to contact if / experience any side effects from the study

- reword the first sentence of paragraph 5

- explain that if participants withdrew from the study, information already collected may be used and disclosed as necessary to protect the study integrity.

\section{Conditions of HDEC approval}

HDEC approval for this study is subject to the following conditions being met prior to the commencement of the study in New Zealand. It is your responsibility, and that of the study's sponsor, to ensure that these conditions are met. No further review by the Northern A Health and Disability Ethics Committee is required.

Standard conditions:

1. Before the study commences at any locality in New Zealand, all relevant regulatory approvals must be obtained.

2. Before the study commences at any locality in New Zealand, it must be registered in a WHO-approved clinical trials registry (such as the Australia New Zealand Clinical Trials Registry, unww.anzctr.org.au).

3. Before the study commences at a given locality in New Zealand, it must be authorised by that locality in Online Forms. Locality authorisation confirms that the locality is suitable for the safe and effective conduct of the study, and that local research governance issues have been addressed.

\section{After HDEC review}

Please refer to the Standard Operating Procedures for Health and Disability Ethics Committees (available on www.ethics. health. govt.nz) for HDEC requirements relating to amendments and other post-approval processes. 


\section{Participant access to ACC}

The Northern A Health and Disability Ethics Committee is satisfied that your study is not a clinical trial that is to be conducted principally for the benefit of the manufacturer or distributor of the medicine or item being trialled. Participants injured as a result of treatment received as part of your study may therefore be eligible for publicly-funded compensation through the Accident Compensation Corporation (ACC).

Please don't hesitate to contact the HDEC secretariat for further information. We wish you all the best for your study.

Yours sincerely,

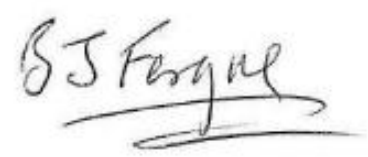

Dr Brian Fergus

Chairperson

Northern A Health and Disability Ethics Committee

Encl: appendix A: documents submitted

appendix B: statement of compliance and list of members 


\section{Appendix A}

\section{Documents submitted}

\begin{tabular}{|c|c|c|}
\hline Document & Version & Date \\
\hline CV for Cl: Short CV for Nichole Phillips & \begin{tabular}{|l|}
1 \\
\end{tabular} & $\begin{array}{l}24 \text { August } \\
2012\end{array}$ \\
\hline $\begin{array}{l}\text { Survey/questionnaire: Pain catastrophising scale (screening potential } \\
\text { participants - see exclusion criteria) }\end{array}$ & 1 & $\begin{array}{l}24 \text { August } \\
2012\end{array}$ \\
\hline $\begin{array}{l}\text { Survey/questionnaire: Modified somatic perceptions questionnnaire as a } \\
\text { screen for somatic hypervigilance(screening potential participants - see } \\
\text { exclusion criteria) }\end{array}$ & 1 & $\begin{array}{l}24 \text { August } \\
2012\end{array}$ \\
\hline $\begin{array}{l}\text { Survey/questionnaire: Short-form McGill pain questionnaire (to investigate } \\
\text { the perceptual characteristics of the experimental pain) }\end{array}$ & 1 & $\begin{array}{l}24 \text { August } \\
2012\end{array}$ \\
\hline PIS/CF: Consent form for participants & 1 & $\begin{array}{l}24 \text { August } \\
2012\end{array}$ \\
\hline Recruitment poster & 1 & $\begin{array}{l}24 \text { August } \\
2012\end{array}$ \\
\hline PIS/CF: Patient information sheet & 1 & $\begin{array}{l}24 \text { August } \\
2012\end{array}$ \\
\hline Covering Letter: Cover letter & 1 & $\begin{array}{l}30 \text { August } \\
2012\end{array}$ \\
\hline Protocol: Research proposal & 1 & $\begin{array}{l}30 \text { August } \\
2012\end{array}$ \\
\hline $\begin{array}{l}\text { Declined letter for previous application in respect of the same (or } \\
\text { substantially similar) study: UREC declined letter }\end{array}$ & 1 & $\begin{array}{l}30 \text { August } \\
2012\end{array}$ \\
\hline $\begin{array}{l}\text { Evidence of scientific review: Unitec Health and Social Sevices proposal } \\
\text { committee acceptance letter }\end{array}$ & 1 & $\begin{array}{l}30 \text { August } \\
2012\end{array}$ \\
\hline Application & & \\
\hline
\end{tabular}




\section{Appendix B}

Statement of compliance and list of members

\section{Statement of compliance}

The Northern A Health and Disability Ethics Committee:

- is constituted in accordance with its Terms of Reference

- operates in accordance with the Standard Operating Procedures for Health and Disability Ethics Committees, and with the principles of international good clinical practice (GCP)

- is approved by the Health Research Council of New Zealand's Ethics Committee for the purposes of section 25(1)(c) of the Health Research Council Act 1990

- is registered (number 00008714) with the US Department of Health and Human Services' Office for Human Research Protection (OHRP).

\section{List of members}

\begin{tabular}{|l|l|l|l|l|l|}
\hline Name & Category & Appointed & $\begin{array}{l}\text { Term } \\
\text { Expires }\end{array}$ & $\begin{array}{l}\text { Present on } \\
11 / 09 / 2012 ?\end{array}$ & $\begin{array}{l}\text { Declaration } \\
\text { of interest? }\end{array}$ \\
\hline $\begin{array}{l}\text { Dr Brian } \\
\text { Fergus }\end{array}$ & $\begin{array}{l}\text { Lay (consumer/community } \\
\text { perspectives) }\end{array}$ & $01 / 07 / 2012$ & $01 / 07 / 2015$ & Yes & No \\
\hline $\begin{array}{l}\text { Ms Susan } \\
\text { Buckland }\end{array}$ & $\begin{array}{l}\text { Lay (consumer/community } \\
\text { perspectives) }\end{array}$ & $01 / 07 / 2012$ & $01 / 07 / 2015$ & Yes & No \\
\hline $\begin{array}{l}\text { Ms } \\
\text { Shamim } \\
\text { Chagani }\end{array}$ & $\begin{array}{l}\text { Non-lay (health/disability } \\
\text { service provision) }\end{array}$ & $01 / 07 / 2012$ & $01 / 07 / 2014$ & Yes & No \\
\hline $\begin{array}{l}\text { Dr } \\
\text { Marewa } \\
\text { Glover }\end{array}$ & $\begin{array}{l}\text { Non-lay (observational } \\
\text { studies) }\end{array}$ & $01 / 07 / 2012$ & $01 / 07 / 2015$ & No & No \\
\hline $\begin{array}{l}\text { Mr Kerry } \\
\text { Hiini }\end{array}$ & $\begin{array}{l}\text { Lay (consumer/community } \\
\text { perspectives) }\end{array}$ & $01 / 07 / 2012$ & $01 / 07 / 2014$ & Yes & No \\
\hline $\begin{array}{l}\text { Prof } \\
\text { Wayne } \\
\text { Miles }\end{array}$ & $\begin{array}{l}\text { Non-lay (intervention } \\
\text { studies), Non-lay } \\
\text { (health/disability service } \\
\text { provision) }\end{array}$ & $01 / 07 / 2012$ & $01 / 07 / 2013$ & No & No \\
\hline $\begin{array}{l}\text { Dr Etuate } \\
\text { Saafi }\end{array}$ & $\begin{array}{l}\text { Non-lay (intervention } \\
\text { studies) }\end{array}$ & $01 / 07 / 2012$ & $01 / 07 / 2014$ & Yes & No \\
\hline $\begin{array}{l}\text { Ms } \\
\text { Michele } \\
\text { Stanton }\end{array}$ & \begin{tabular}{l} 
Lay (the law) \\
\hline
\end{tabular} & $01 / 07 / 2012$ & $01 / 07 / 2014$ & Yes & No \\
\hline
\end{tabular}

\section{http://www.ethics.health.govt.nz}




\title{
1.2. Health and Disability Ethics Committees renewal letter
}

\author{
Health \\ and \\ Disability \\ Ethics \\ Committees
}

\author{
Health and Disability Ethics Committees \\ Ministry of Health \\ C/-MEDSAFE, Level 6, Deloitte House \\ 10 Brandon Street \\ PO Box 5013 \\ Wellington \\ 6011 \\ 08004 ETHICS \\ hdecs@moh.govt.nz
}

18 March 2014

Ms Nichole Phillips

32 Trinidad Street

Blockhouse Bay

Auckland 0600

Dear Ms Phillips

$\begin{array}{lll}\text { Re: } & \text { Ethics ref: } & \text { 12/NTA/37/AM03 } \\ \text { Study title: } & \begin{array}{l}\text { To what extent does experimentally induced pain affect the mental rotation of } \\ \text { body parts and non-body objects in healthy participants? }\end{array}\end{array}$

This letter is to confirm receipt of the annual progress report for this study, submitted on 13 March 2014. This annual progress report will be reviewed via the Expedited Pathway by the Chairperson of the Northern A Health and Disability Ethics Committee.

The 15-day clock for giving a final opinion on this annual progress report starts on 13 March 2014. The Chairperson will be in contact with you within 15 days of this date if the Chair requires further information on any matter relating to this annual progress report, or if the Chair wishes to reconsider its approval for the study.

Please don't hesitate to contact us for further information.

Yours sincerely,

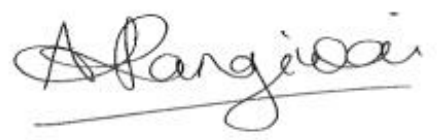

\author{
Awhina Rangiwai \\ Administrator \\ Health and Disability Ethics Committees \\ hdecs@moh.govt.nz
}

Encl: appendix A: documents submitted 
Appendix A

Documents submitted

\begin{tabular}{|l|l|l|}
\hline Document & Version & Date \\
\hline Post Approval Form & & 13 March 2014 \\
\hline
\end{tabular}




\subsection{Health and Disability Ethics Committees amendment approval letter}

\author{
Health \\ and \\ Disability \\ Ethics \\ Committees
}

\author{
Health and Disability Ethics Committees \\ Ministy of Hedth \\ CL-MEDSAFE, Level 6, Deloitte House \\ 10 Brendon Street \\ PO Box 5013 \\ Welington \\ 08004 ETHICS \\ hdecselmoh govenz
}

14 October 2013

Ms Nichole Phillips

32 Trinidad Street

Blockhouse Bay

Auckland 0600

Dear Ms Phillips

Re: Ethics ref:

Study title:
12/NTA/37/AM02

To what extent does experimentally induced pain affect the mental rotation of body parts and non-body objects in healthy participants?

I am pleased to advise that this amendment has been approved by the Northern A Health and Disability Ethics Committee. This decision was made through the HDEC Expedited Review pathway.

Please don't hesitate to contact the HDEC secretariat for further information. We wish you all the best for your study.

Yours sincerely,

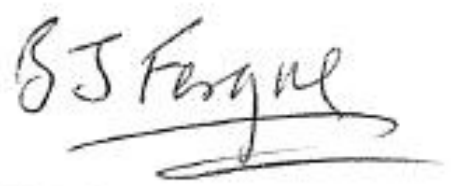

Dr Brian Fergus

Chairperson

Northern A Health and Disability Ethics Committee

Encl: appendix A: documents submitted

appendix B: statement of compliance and list of members 
Appendix A

Documents submitted

\begin{tabular}{|l|l|l|}
\hline Document & Version & Date \\
\hline $\begin{array}{l}\text { Survey/questionnaire: Edinburgh Handedness Inventory } \\
\text { questionnaire sheet to be emailed to participants. }\end{array}$ & 1 & 22 September 2013 \\
\hline Post Approval Form & 02 & 22 September 2013 \\
\hline
\end{tabular}




\section{Appendix B}

\section{Statement of compliance and list of members}

\section{Statement of compliance}

The Northern A Health and Disability Ethics Committee:

- is constituted in accordance with its Terms of Reference

- operates in accordance with the Standard Operating Procedures for Health and Disability Ethics Committees, and with the principles of intemational good clinica practice (GCP)

- is approved by the Health Research Council of New Zealand's Ethics Committee for the purposes of section 25(1)(c) of the Health Research Council Act 1990

- is registered (number 00008714) with the US Department of Health and Human Services' Office for Human Research Protection (OHRP).

\section{List of members}

\begin{tabular}{|l|l|l|l|}
\hline Name & Category & Appointed & Term Expires \\
\hline Dr Brian Fergus & Lay (consumericommunity perspectives) & $01 / 07 / 2012$ & $01 / 07 / 2015$ \\
\hline Dr Karcn Bartholomew & Non-lay (intervention studies) & $01 / 07 / 2013$ & $01 / 07 / 2016$ \\
\hline Ms Susan Buckland & Lay (consumentcommunity perspectives) & $01 / 07 / 2012$ & $01 / 07 / 2015$ \\
\hline Ms Shamim Chagari & Non-lay (healthdisability service provision) & $01 / 07 / 2012$ & $01 / 07 / 2014$ \\
\hline Dr Chrietine Crooks & Non-lay (intervention studies) & $01 / 07 / 2013$ & $01 / 07 / 2015$ \\
\hline Mr Kerry Hiini & Lay (consumericommunity perspectives) & $01 / 07 / 2012$ & $01 / 07 / 2014$ \\
\hline Dr Etuate Sagf & Non-lay (intervention studies) & $01 / 07 / 2012$ & $01 / 07 / 2014$ \\
\hline Ms Michcic Stanton & Lay (the law) & $01 / 07 / 2012$ & $01 / 07 / 2014$ \\
\hline
\end{tabular}

http://www.ethics.health.qovt.nz 


\subsection{Participant information sheet}

Information for participants

\section{What we are doing?}

I am Nichole Phillips, a student in the Master of Osteopathy course at Unitec, NZ. I am undertaking research that investigates the neurological effects of acute experimental pain on how long it takes to recognise whether something is left or right handed (laterality recognition).

Laterality recognition has been shown to be a reliable way of investigating how the brain is influenced in various pain states. Most research has been done with chronic pain patients; therefore this research project will investigate how acute pain influences the brain and changes laterality recognition response times.

The intervention in this research project is the inducement of experimental, acute pain. Injections of hypertonic saline (a sterile salt-based water solution) have been chosen as the most appropriate mode of inducing experimental pain for this research project. Saline injection is widely used and has been shown to be a very safe and effective intervention. It produces a transient, short lasting (average of 7 minutes, and no more than 10 minutes), local area of pain with very minimal risk of adverse events or side effects.

Please note there are no fees or charge to participate in this research.

\section{What we are asking participants to do:}

We require people who are willing to come to two sessions (at least a week apart). During each session you will receive two interventions (total of four across two sessions). These interventions will be hypertonic saline injections, and the possible locations are the muscles at the base of your thumbs and the muscles on the back of your forearm, on both sides. The first session will test one side of your body (for example - your right side) and the second session will test the other side of your body (your left side). You may have a friend or whanau member come with you to the sessions to ask questions if you like.

You will be reimbursed for your travel costs to the clinic for both sessions.

Who can participate in this study?

- Aged $18-50$

- Ability to speak and write English

- Ability to give written, informed consent Who can't participate in this study?

People with:

- Orthopaedic or neurological disorders of the upper limb or neck 
- Significant visual impairment

- Diagnosis of dyslexia

- Pain on the day of testing (chronic or acute)

- Use of pain medications on day of testing

- Trauma to upper limb

- Fracture/dislocation

- Open wounds or skin conditions

- Pain related conditions (determined with an online questionnaire)

- History of fainting or seizures

- Diagnosis of haemophilia or other clotting disease

- Allergy to latex products

- Non-New Zealand citizens or residents

\section{Where is the study being conducted?}

The research will be conducted at the following location:

Unitec Health Centre

Unitec, Mt Albert

Auckland

The process of enrolment:

Once you make contact with me (Nichole Phillips), I will email more information regarding the details of the research. You will then have time to read this information and decide if you would like to find out if you would be suitable for participation.

Screening for suitability for this research project will consist of specific criteria and two online questionnaires. These online questionnaires are designed to screen for people who are at risk of experiencing a negative reaction to the pain intervention, and therefore are not suitable for this research project. The data from these questionnaires will not be kept or used in the final data analysis regardless of whether you chose to participate or not.

Once you have chosen to enroll, a time will be arranged for you to visit with me for a chance to learn more about the study, ask questions, and sign a consent form. A time will then be organised for you to participate in the research (at Unitec Health Centre).

\section{What will you experience during data collection?}

Data collection will take place on two evenings separated by at least one week. I, or one of my research project supervisors, will greet you on arrival for the first session and take you to your allocated computer. There will then be an informative speech where the injection process is explained, the GP will introduce himself and you will be instructed how to use the laterality task software. At this time you will have the opportunity to ask any questions.

The session will start with practice of the laterality recognition task (duration of approximately three minutes). Then you will do the task six times in order to 
establish your normal response pattern. Following this, you will be allocated a location to receive the intervention (either the hand or elbow on the left or right). The laterality task is then repeated again before you feel pain, while you experience pain, and once more once the pain has worn off. This will give data with regard to the effects of the intervention on your responses. The intervention will then be repeated for the other location on the same arm (either hand or elbow). The second session will occur at least one week later, and will be exactly the same as the first except that the other arm will receive the intervention.

\section{The intervention details:}

A total of four injections over two sessions will be given during this research project. A topical anesthetic will be used on your skin prior to injection with hypertonic saline. This will minimise discomfort associated with the needle. The injection is very small $(0.4 \mathrm{ml}$ of $5 \%$ sodium chloride solution) and you may do whatever you like at this point - look away, look at it, talk, listen to music, squeeze a ball with the other hand, etc. Once the injection has finished, we will start the laterality programme on the computer and ask you to sit quietly and follow the instructions on the screen.

The characteristics of the pain caused by the hypertonic saline have been well documented. The peak pain intensity typically occurs 30 seconds after injection and then the intensity quickly decreases until it completely disappears in an average of 7 minutes, no more than 10 minutes. People have described the sensation as similar to muscle pain, using words such as 'aching', 'tight', 'dull', 'deep'. Once the pain has disappeared, there is no lasting feeling or side effects.

As each person interprets and feels pain differently, there is a possibility that a few participants may feel that the pain caused by the hypertonic saline is too much and that they want it to end earlier (a negative reaction, as mentioned previously). During the information stages, all participants will be told that if they feel this happening they can move their arm to stretch and contract the affected muscle, or request to have the muscle massaged by Nichole, Dr McLaren, or one of the research supervisors. This will reduce the duration and intensity of the pain; however we will be unable to collect laterality data from you if this occurs. You will then be able to withdraw from the research project if you wish.

At any point in the experimental stage, you will have the right to withdraw without providing an explanation or at risk of prejudice to services offered by the Department of Osteopathy or Unitec, NZ.

\section{Possible temporary after effects:}

There are no documented side effects of hypertonic saline, however you may experience a slight discomfort or mild bruising at the injection site once the topical anesthetic has worn off. The risk of this will be minimised by using the smallest size needle possible.

Very low risk of infection: 
A registered GP (Scott McLaren, BSc, MB CHB, MRNZCGP) will perform all injections. All safety precautions will be taken with regards to hygiene, sterility and infection control.

The injection needles used are all sterile, single use needles. The hypertonic saline solution is sterile and injectable. All needles are safely disposed of after use, and you will be advised on how to care for the injection sites following the session.

\section{Very low risk of side effects from hypertonic saline injections:}

A review on hypertonic saline injections found that over 6,000 injections were carried out without any significant undesirable events or side effects. Possible results are small bruises and small areas of muscle ache at the injection site. These are temporary and should resolve in less than 24 hours.

Another small risk is slight and reversible muscle damage at the injection site. However, this has been shown to occur following all injections, and is also similar to muscle tissue damage which occurs during sport, exercise or training.

All participants will be able to ask questions at any time, and will be provided with the contact details for the Unitec Counselling Centre if they feel the need to talk about any emotional matters regarding participation in this research project:

Monika Singh

Counselling Centre Administrator

Phone: +6498154321 ext 8160

Mobile: +64 21455764

Email: counselling@unitec.ac.nz

In the case of health matters or side effects following this study, please contact Scott McLaren, Millhouse Integrative Medical Centre, (09) 5374980 or

reception@millhousemedical.co.nz, or Healthline on 0800611116 for after-hours service.

How we handle your personal information:

Your name and information will be kept strictly confidential. All information will be stored on a password protected computer or a locked cabinet. Nichole Phillips and Robert Moran will access this information to complete the analysis. A copy of the study findings can be sent to you at the conclusion of the study if you wish - just let us know when you first attend. All medical records will be kept for a period of 10 years in secure storage at Unitec and at Scott Mclaren's office.

\section{Who are the people involved in this project?}

The main investigator is Nichole Phillips, a student in the Master of Osteopathy course at Unitec, New Zealand. The project supervisors are Robert Moran, a Senior Lecturer and researcher supervisor within the Department of Osteopathy, Unitec NZ, Jamie Mannion, Lecturer and research supervisor within the Department of Osteopathy, and Dr Scott McLaren, registered GP (BSc, MB CHB, MRNZCGP) as an independent medical advisor who will be administering the injections at his clinic. 
Kaupapa Maori consultation was undertaken with Glyn Flutey (registered osteopath); Osteopathic Edge Clinic, Mt Eden, email: Glyn@osteopathicedge.co.nz, phone: 096234296.

\section{Contact us with any questions or comments}

Please contact us if you need any more information about the project. If you have any concerns about this research project please contact either one of us:

Nichole Phillips

Tel: 0210441389

nicholecphillips@gmail.com
Rob Moran

Tel: 098154321 ext 8197 or 0210739984

rmoran@unitec.ac.nz

Thank you for your time in helping us with this research, we are always happy to answer any question you may have about this research.

HDEC (Northern A) REGISTRATION NUMBER: (12/NTA/37)

This study has been approved by the Northern A Health and Disability Ethics Committee from 17 September 2012 to 17 September 2013. If you have any complaints or reservations about the ethical conduct of this research, you may contact the Committee through the HDEC secretariat (ph: 08004438 442,

hdecs@moh.govt.nz). Any issues you raise will be treated in confidence and investigated fully, and you will be informed of the outcome. 


\subsection{Participant consent form}

Northern A Health and Disability Ethics Committee

\section{Consent Form}

\section{Effects of acute experimental pain on laterality recognition response times}

I have seen the Information Sheet about this study. I have read and understand the information sheet given to me. I have had the opportunity to discuss any queries or concerns regarding this project with Nichole Phillips and am satisfied with explanations given.

I understand that that taking part in this project is my choice. I don't have to be part of this if I don't want to and I understand that I may withdraw from this study at any time prior to the time of data analysis. I also understand that withd rawing will not affect my access to any services provided by Clinic 41, the Department of Osteopathy, or Unitec, NZ. However, I understand that following withdrawal, my data may be used and disclosed as necessary to protect the study integrity.

I understand that anything I say and write will be kept completely confidential and that the only persons who will know what I have said or written will be the researcher (Nichole Phillips) and the supervisors. I understand that data collection will involve the provision of medical details. I understand that participation in this research project will involve injections of hypertonic saline $(0.4 \mathrm{ml}, 5 \% \mathrm{NaCl})$ which is designed to cause acute, short lasting pain, and I understand that I have had the characteristic pain profile described to me, and the steps that I can take if I experience excessive symptoms.

I understand that all the information that I give will be stored securely on a computer at Unitec and at Scott Mclaren's office for a period of 10 years and that any information reported will not identify me in any way. I give permission for the data from this study to be retained and combined with other future studies provided that my identity remains anonymous.

I understand that I can withdraw my data from the project up to 2 weeks following data collection. I understand that a friend or whanau member may accompany me to the sessions to ask questions. I understand the compensation provisions for this study.

I understand that I can see the finished res earch document.

I have had time to consider everything and I give my consent to be a part of this project.

I know whom to contact if I have any questions or concerns about this project. I know how to contact if I experience any side effects from this study.

Please indicate if you wish to receive a copy of the results: yes $\bigcirc$ no $\bigcirc$ The principal researcher is:

Nichole Phillips

nicholecphillips@gmail.com

Tel: 0210441389

Participant Name:

Participant Signature:

Date:

\section{Project explained by:}

Signature:

Date:

Thank you for participating in this research

HDEC (Northern A) REGISTRATION NUMBER: (12/NTA/37)

This study has been approved by the Northern A Health and Disability Ethics Committee from 17 September 2012 to 17 September 2013 . If you have any complaints or reservations about the ethical conduct of th is research, you may contact the Committee th rough the HDEC secretariat (ph: 0800 4438442 , hdees $(a$ moh.govt.nz). Any issues you raise will be treated in confidence and investigated fully, and you will be in formed of the outcome. 


\subsection{Participant recruitment poster}

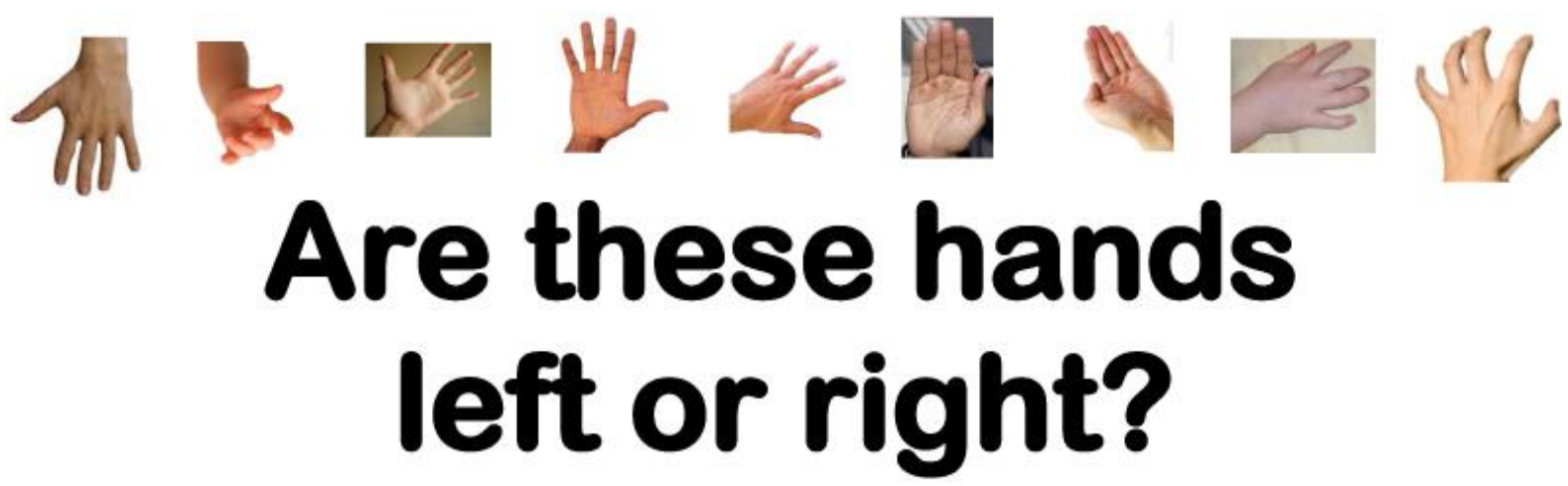

Exciting research at Unitec!

We are conducting a study that looks at how long it takes for people to decide if something is left or right handed.

We are investigating how this changes during acute, experimental pain. This will involve us causing a temporary, short lasting, experimental pain in your hands and elbows over two sessions.

If you fit the criteria below, you may be eligible to participate in this research project:

- between $18-50$ years old

- have no orthopaedic, neurological disorders or chronic pain in your arms, neck or shoulders

- have no visual impairment or diagnosis of dyslexia

- no history of fainting or seizures

- no history of haemophilia or clotting disorder

- no allergy to latex

- are a NZ citizen or resident

\begin{tabular}{|l|l|}
\hline & Please get in touch with Nichole Phillips \\
\hline
\end{tabular}

HDEC (Northern A) REGISTRATION NUMBER: (12/NTA/37)

This study has been approved by the Northern A Health and Disability Ethics Committee from 17 September 2012 to 17 September 2013. If you have any complaints or reservations about the ethical conduct of this research, you may contact the Committee through the HDEC secretariat (ph: 08004438 442, hdecs@moh.govt.nz). Any issues you raise will be treated in confidence and investigated fully, and you will be informed of the outcome. 


\subsection{Participant screening questionnaire}

This questionnaire was used to collect patient demographic data and to inform participant selection by collecting information relevant to the inclusion and exclusion criteria of the study. The Pain Catastrophising Scale (Sullivan, Bishop, \& Pivik, 1995) and the Modified Somatic Perception Questionnaire (Main, 1983) were used to identify potential participants who may have been at risk of experiencing an adverse event as a result of the experimental pain stimulus [see Appendix 1.9 for descriptive statistics].

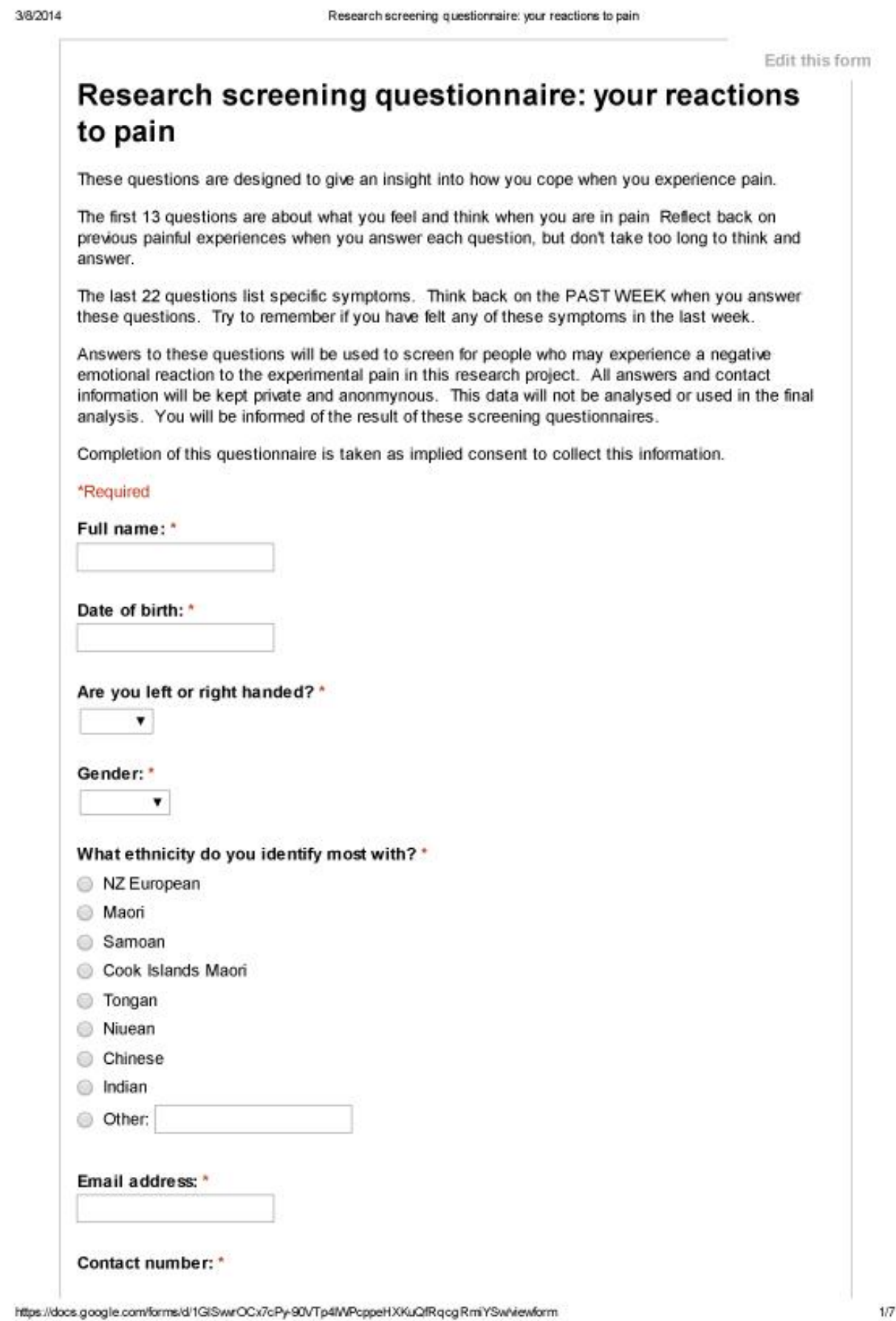


Do you have any pain at this point in time? Please describe it briefly below.

Do you have any of the following?

Check any that apply. Leave blank if not applicable.

Orthopaedic or neurological disorders of the upper limb or neck

Significant and uncorrected visual impairment

History of fainting or seizures

Diagnosis of hemophilia or other blood clotting issue

Diagnosis of dyslexia

Latex allergy

When I am in pain, I worry all the time about whether the pain will end *

0 - not at all

(- 1 - to a slight degree

2 - to a moderate degree

3 - to a great degree

4 - all the time

When I am in pain, I feel that I can't go on *

0 - not at all

1 - to a slight degree

2 - to a moderate degree

3 - to a great degree

4 - all the time

When I am in pain, it's terrible and I think it's never going to get any better *

0 - not at all

1 - to a slight degree

2 - to a moderate degree

3 - to a great degree

Q 4 - all the time

When I am in pain, it's awful and I feel that it overwhelms me

0 - not at all

1 - to a slight degree

2 - to a moderate degree

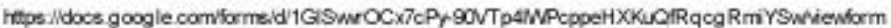



3 - to a great degree

4 - all the time

When I am in pain, I feel I can't stand it anymore *

0 - not at all

1 - to a slight degree

2 - to a moderate degree

3 - to a great degree

(1) 4 - all the time

When I am in pain, I become afraid that the pain will get worse *

0 - not at all

- 1 - to a slight degree

2 - to a moderate degree

3 - to a great degree

4 - all the time

When I am in pain, I keep thinking of other painful events *

0 - not at all

1 - to a slight degree

2 - to a moderate degree

3 - to a great degree

4 - all the time

When I am in pain, I anxiously want the pain to go away *

0 - not at all

1 - to a slight degree

2 - to a moderate degree

3 - to a great degree

4 - all the time

When I am in pain, I can't seem to keep it out of my mind *

0 - not at all

(1) - to a slight degree

2 - to a moderate degree

3 - to a great degree

4 - all the time

When I am in pain, I keep thinking about how much it hurts *

0 - not at all

1 - to a slight degree

2 - to a moderate degree

3 - to a great degree

4 - all the time 
When I am in pain, I keep thinking about how badly I want the pain to stop *

0 - not at all

1 - to a slight degree

2 - to a moderate degree

3 - to a great degree

4 - all the time

When I am in pain, there's nothing I can do to reduce the intensity of the pain *

0 - not at all

1 - to a slight degree

2 - to a moderate degree

3 - to a great degree

4 - all the time

When I am in pain, I wonder whether something serious may happen *

0 - not at all

1 - to a slight degree

2 - to a moderate degree

3 - to a great degree

4 - all the time

Heart rate increase *

Please describe how you have felt during the PAST WEEK by checking the appropriate box

0 - not at all

1 - a little, slightly

2 - a great deal, quite a bit

3 - extremely, could not have been worse

Feeling hot all over *

Please describe how you have felt during the PAST WEEK by checking the appropriate box

0 - not at all

1 - a little, slightly

2 - a great deal, quite a bit

3- extremely, could not have been worse

\section{Sweating all over *}

Please describe how you have felt during the PAST WEEK by checking the appropriate box

0 - not at all

1 - a little, slightly

2 - a great deal, quite a bit

3 - extremely, could not have been worse

\section{Sweating in a particular part of the body *}

Please describe how you have felt during the PAST WEEK by checking the appropriate box 0 - not at all 
1 - a little, slightly

2 - a great deal, quite a bit

3 - extremely, could not have been worse

Pulse in neck*

Please describe how you have felt during the PAST WEEK by checking the appropriate box

0 - not at all

1 - a little, slightly

2 - a great deal, quite a bit

3 - extremely, could not have been worse

\section{Pounding in head *}

Please describe how you have felt during the PAST WEEK by checking the appropriate box

0 - not at all

1 - a little, slightly

2 - a great deal, quite a bit

3 - extremely, could not have been worse

\section{Dizziness *}

Please describe how you have felt during the PAST WEEK by checking the appropriate box

0 - not at all

1 - a little, slightly

2 - a great deal, quite a bit

3 - extremely, could not have been worse

\section{Blurring of vision *}

Please describe how you have felt during the PAST WEEK by checking the appropriate box

0 - not at all

- 1 - a little, slightly

2 - a great deal, quite a bit

3 - extremely, could not have been worse

\section{Feeling faint *}

Please describe how you have felt during the PAST WEEK by checking the appropriate box

0 - not at all

1 - a little, slightly

2 - a great deal, quite a bit

3 - extremely, could not have been worse

\section{Everything appearing unreal *}

Please describe how you have felt duning the PAST WEEK by checking the appropriate box

0 - not at all

1 - a little, slightly

2 - a great deal, quite a bit

3 - extremely, could not have been worse 


\section{Nausea}

Please describe how you have felt duning the PAST WEEK by checking the appropriate box

0 - not at all

1 - a Iittle, slightly

2 - a great deal, quite a bit

3 - extremely, could not have been worse

\section{Butterflies in stomach *}

Please describe how y ou have felt during the PAST WEEK by checking the appropriate box

0 - not at all

1 - a little, slightly

2 - a great deal, quite a bit

3 - extremely, could not have been worse

\section{Pain or ache in stomach *}

Please describe how you have felt during the PAST WEEK by checking the appropriate box

0 - not at all

1 - a little, slightly

2 - a great deal, quite a bit

3 - extremely, could not have been worse

\section{Stomach churning *}

Please describe how you have felt during the PAST WEEK by checking the appropriate box

0 - not at all

1 - a little, slightly

2 - a great deal, quite a bit

(1) - extremely, could not have been worse

\section{Desire to pass water *}

Please describe how you have felt during the PAST WEEK by checking the appropriate box

0 - not at all

(1) 1 - a little, slightly

2 - a great deal, quite a bit

3 - extremely, could not have been worse

\section{Mouth becoming dry *}

Please describe how you have felt during the PAST WEEK by checking the appropriate box

0 - not at all

(1) 1 - a little, slightly

2 - a great deal, quite a bit

- 3 - extremely, could not have been worse

\section{Difficultly swallowing *}

Please describe how you have felt during the PAST WEEK by checking the appropriate box

0 - not at all

1 - a little, slightly 
2 - a great deal, quite a bit

3 - extremely, could not have been worse

Muscles in neck aching *

Please describe how you have felt duning the PAST WEEK by checking the appropriate box

0 - not at all

1 - a little, slightly

2 - a great deal, quite a bit

3 - extremely, could not have been worse

\section{Legs feeling weak *}

Please describe how you have felt during the PAST WEEK by checking the appropriate box

0 - not at all

1 - a little, slightly

2 - a great deal, quite a bit

3 - extremely, could not have been worse

\section{Muscles twitching or jumping *}

Please describe how you have felt during the PAST WEEK by checking the appropriate box

0 - not at all

1 - a little, slightly

2 - a great deal, quite a bit

3 - extremely, could not have been worse

\section{Tense feeling across forehead *}

Please describe how you have felt during the PAST WEEK by checking the appropriate box

0 - not at all

1 - a little, slightly

2 - a great deal, quite a bit

3 - extremely, could not have been worse

Tense feeling in jaw muscles *

Please describe how you have felt during the PAST WEEK by checking the appropriate box

0 - not at all

1 - a little, slightly

2 - a great deal, quite a bit

3 - extremely, could not have been worse

\section{Submit}

Never submit passwords through Google Forms 


\subsection{The Edinburgh Handedness Inventory}

The Edinburgh Handedness Inventory was administered to assess the degree of handedness of participants. The descriptive statistics resulting from analysis of data from this questionnaire are located in Appendix 1.9.

\section{EDINBURGH HANDEDNESS INVENTORY}

Please indicate your answer to the following questions by highlighting your answer. Here is an example:

\begin{tabular}{|c|c|c|c|c|c|c|}
\hline & EXAMPLE ONLY: & $\begin{array}{c}\text { Always } \\
\text { left }\end{array}$ & $\begin{array}{c}\text { Mostly } \\
\text { left }\end{array}$ & Both* & $\begin{array}{c}\text { Mostly } \\
\text { right }\end{array}$ & $\begin{array}{c}\text { Always } \\
\text { right }\end{array}$ \\
\hline 1 & Writing & 2 & 1 & 1 & 1 & 2 \\
\hline
\end{tabular}

Which hand do you use to do the following tasks?

\begin{tabular}{|c|l|c|c|c|c|c|}
\cline { 2 - 6 } \multicolumn{2}{l|}{} & $\begin{array}{c}\text { Always } \\
\text { left }\end{array}$ & $\begin{array}{c}\text { Mostly } \\
\text { left }\end{array}$ & Both* & $\begin{array}{c}\text { Mostly } \\
\text { right }\end{array}$ & $\begin{array}{c}\text { Always } \\
\text { right }\end{array}$ \\
\hline 1 & Writing & 2 & 1 & 1 & 1 & 2 \\
\hline 3 & Drawing & 2 & 1 & 1 & 1 & 2 \\
\hline 4 & Using scissors & 2 & 1 & 1 & 1 & 2 \\
\hline 5 & Using a toothbrush & 2 & 1 & 1 & 1 & 2 \\
\hline 6 & Using a knife (without a fork) & 2 & 1 & 1 & 1 & 2 \\
\hline 7 & Using a spoon & 2 & 1 & 1 & 1 & 2 \\
\hline 8 & Using a broom (the upper hand) & 2 & 1 & 1 & 1 & 2 \\
\hline 9 & $\begin{array}{l}\text { Striking a match (the hand with the } \\
\text { match) }\end{array}$ & 2 & 1 & 1 & 1 & 2 \\
\hline 10 & $\begin{array}{l}\text { Opening a box (the hand with the lid) } \\
\text { Total each column (please leave blank) }\end{array}$ & 2 & 1 & 1 & 1 & 2 \\
\hline
\end{tabular}

* Both would infer that you would use each hand to an equal degree to do the task, or that $50 \%$ of the time you would use your right hand and $50 \%$ of the time you would use your left hand to do the task.

Please leave blank

\begin{tabular}{|l|l|}
\hline Total all (left + right) & \\
\hline Difference (right - left) & \\
\hline Difference / Total all $* 100$ & \\
\hline
\end{tabular}




\subsection{Participant demographic data}

Summary of demographic data

\begin{tabular}{|c|c|c|}
\hline \multicolumn{3}{|l|}{ Gender } \\
\hline & Male & 11 \\
\hline & Female & 11 \\
\hline & $n$ & 22 \\
\hline \multicolumn{3}{|l|}{ Ethnicity } \\
\hline & NZ European & 17 \\
\hline & NZ Maori & 1 \\
\hline & Other European & 3 \\
\hline & Other Asian & 1 \\
\hline & $n$ & 22 \\
\hline \multicolumn{3}{|l|}{ Age } \\
\hline & Mean & 30.2 \\
\hline & SD & 8.66 \\
\hline & Std Error Mean & 1.85 \\
\hline & Median & 28 \\
\hline & Min-Max & $21-49$ \\
\hline & $n$ & 22 \\
\hline \multicolumn{3}{|c|}{ Pain Catastrophising Scale results } \\
\hline & Mean & 5.9 \\
\hline & SD & 4.19 \\
\hline & Std Error Mean & 0.94 \\
\hline & Median & 5 \\
\hline & Min-Max & $0-14$ \\
\hline & $n$ & 20 \\
\hline \multicolumn{3}{|c|}{ Modified Somatic Perceptions Questionnaire results } \\
\hline & Mean & 16.79 \\
\hline & SD & 10.37 \\
\hline & Std Error Mean & 2.32 \\
\hline & Median & 15.38 \\
\hline & $n$ & 20 \\
\hline \multicolumn{3}{|c|}{ Edinburgh Handedness Inventory results } \\
\hline & Mean & 0.924 \\
\hline & SD & 0.102 \\
\hline & Std Error Mean & 0.0218 \\
\hline & Median & 0.975 \\
\hline & $n$ & 22 \\
\hline $\begin{array}{l}n \text { represen } \\
=\text { standarc }\end{array}$ & $\begin{array}{l}\text { er of patients contril } \\
\text { n. }\end{array}$ & statistics \\
\hline
\end{tabular}




\subsection{Left-right discrimination application}

An in-house left-right discrimination software application was designed by the researcher and supervisors, and produced by an external software designer. Initial pilot testing of the application revealed problems with accuracy of latency measurement (was corrected to $0.06 \mathrm{~ms}$ accuracy) and difficulties obtaining the VAS readings (was corrected with a sliding scale). The application is designed to be adaptable to different types of left-right discrimination tasks by allowing any number or type of images and changes to the scheduling (see Screenshot 3 below for details).

Pilot measurements of left-right discrimination latency showed a learning effect which did not plateau after approximately 8 repetitions of the task (approximately 1 hour of use). Thus, habituation to reduce this effect was problematic during data collection due to time constraints so a randomised crossover design was used to determine order of pain locations.

These screenshot images are intended to show the function of the left-right discrimination application.

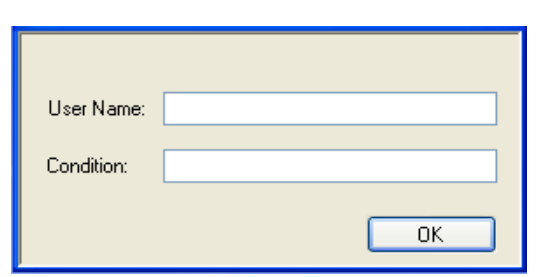

Screenshot 1: This initial textbox allows participants to input their user name and the condition; the location of the experimental pain stimulus (left or right) and the pain condition (pre-, during- or postpain). These details are used to identify the response time data sets that are collected once the task has finished.

Screen shot 2: This image shows the starting point of the image presentation. This image appears between each hand image for one second during the 'blank time' section.

\section{left or right}

Time between images (seconds)

Number of images

Session length (seconds)

Blank time (seconds)

Number of sessions

Pain Min level

Pain Max Level

Randomise images

Show user UI
30

48

30

1

0

100
Participants indicated their responses to the images that followed by pressing the arrow keys on the keyboard. 


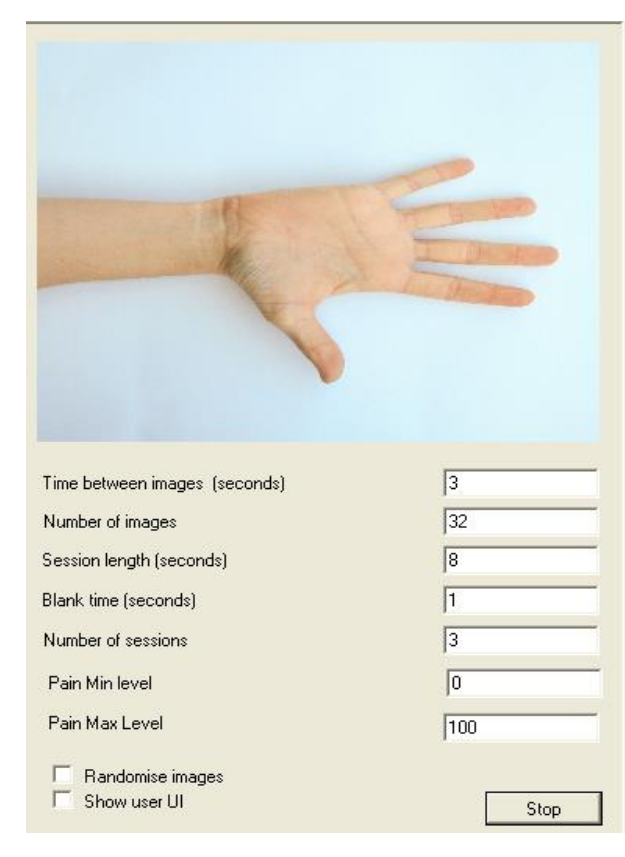

Screenshot 3: This screenshot shows an example of an image presented for left-right discrimination judgement. The scheduling is able to be changed. For example, 'time between images' represents the duration of time the image is presented for judgement before loading the next image. The 'number of images' is how many images will be presented for judgement; this can be set to show each image once or multiple times. The 'session length' represents the duration of time between automatic requests for a VAS rating. "Blank time' represents a pause between images. The 'number of sessions' represents the number of times a VAS rating will be requested. The pain levels represent the minimum and maximum values that will be presented on the VAS image. The sequence of images may also be set by using a sequential naming pattern or randomised by checking the randomise images box.
Please indicate the severity of your pain right now. ○ No Pain MaxPain
Screenshot 4: The VAS sliding scale allowed users to indicate their pain intensity by using the arrow keys to move the marker. An automatic VAS request was timed to occur every 20 seconds to monitor the temporal profile of the experimental pain stimulus. 


\subsection{Images of hands}

These hand images were presented for judgement during the left-right discrimination task. The images were developed from photos of a single hand (anterior and posterior view) which had any distinctive or distinguishing marks removed using Photoshop. The images were then mirrored to create identical left and right versions. Each version was then rotated by $90^{\circ}, 180^{\circ}$ and $270^{\circ}$ to create a bank of 16 images.

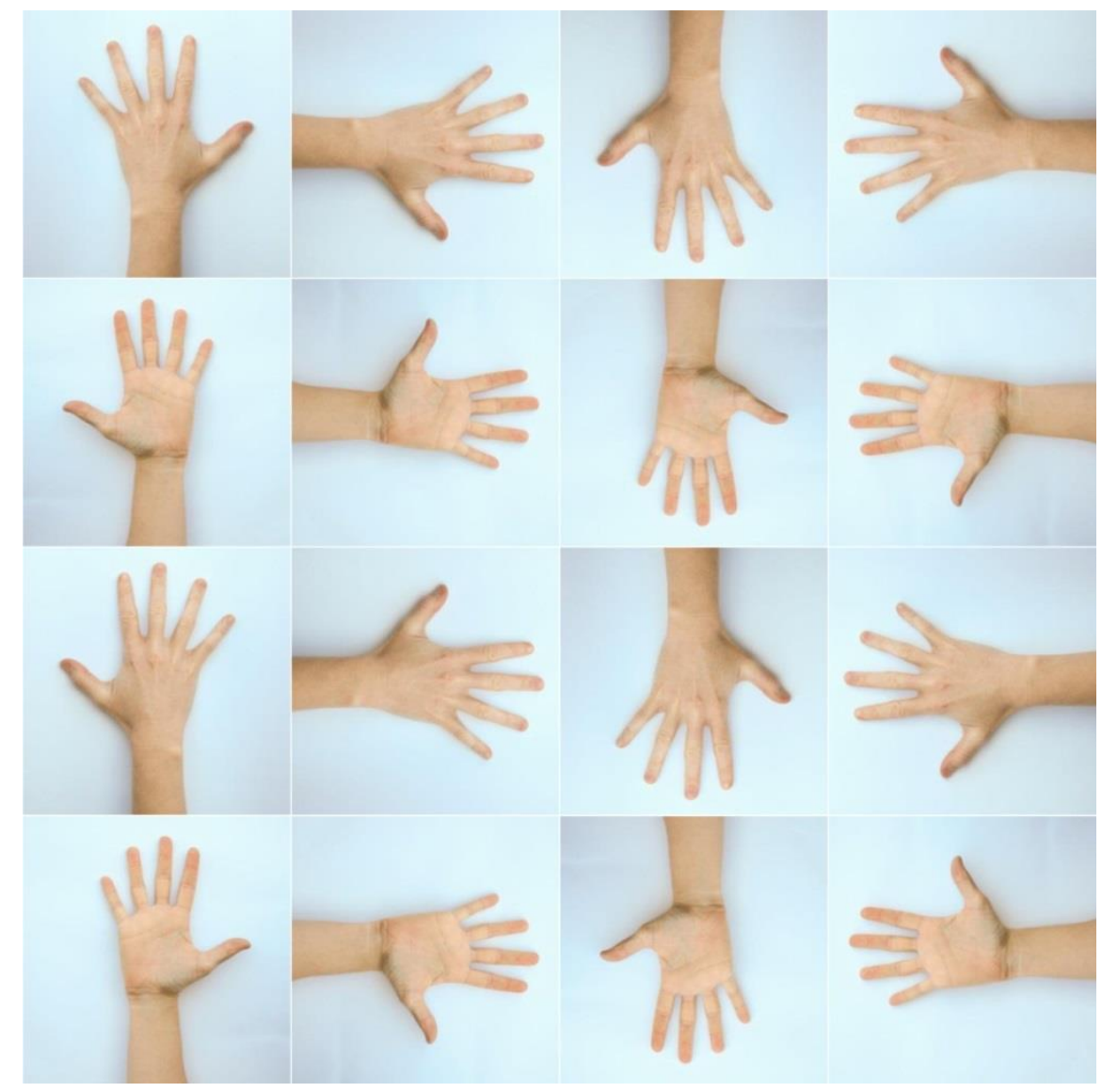

Pilot measurements of left-right discrimination latency of the left-right discrimination application showed that increased anatomical difficulty of the hand position resulted in increased response times during the task. This observation is in line with results from other studies (lonta \& Blanke, 2009; lonta et al., 2012; Moseley et al., 2005). Additionally, the intensity of the experimental pain created by hypertonic saline has been shown to peak at 30 seconds following injection and continue for $\sim 7$ minutes (Moseley et al., 2005). Therefore, the order of images presented during the left-right discrimination task was prearranged to consist of the simplest images in the first 30 seconds followed by the remainder of the images in decreasing order from most difficult as the experimental pain was expected to decrease. This arrangement was intended to provide an order of images that would be somewhat standardised at approximately similar levels of experimental pain intensity to facilitate more accurate response time comparison. 
The original proposal for this research project included objectives regarding investigation into response latency data for left-right discrimination of images of a foot/ankle (a limb that is distant to the experimental pain stimulus) and of a car with the left or right door open (a non-corporeal object).

According to previous studies, the cortical processes that underpin left-right discrimination latency of images of body parts and non-body objects is different, therefore, the effects of pain on response latency for these different images are dissimilar (Fiorio et al., 2007). The images of feet and cars were displayed between images of hands during the left-right discrimination task and the total number of images judged during each task was 48 . However, due to the size requirements for the purpose of this thesis, the response latency data for non-hand images was removed and not analysed or reported. 


\subsection{Piloting of the experimental pain stimulus}

Pilot testing of the experimental pain stimulus was conducted by the researcher and supervisors to ensure generation of adequate pain intensity and duration (data not formally collected or analysed). Initial trials of $0.4 \mathrm{ml} 5 \%$ hypertonic saline resulted in adequate pain intensity, however, the duration of pain symptoms only lasted for $\sim 3$ minutes which is shorter than has been reported previously (Moseley et al., 2005). This duration was insufficient to allow each image to be judged multiple times during the left-right discrimination task as planned. Further trials of $0.4 \mathrm{ml} 7.5 \%$ and $0.4 \mathrm{ml} 10 \%$ injections revealed that the higher concentrations of hypertonic saline increased the pain duration somewhat ( 2 minutes longer) without increasing the pain intensity. Unfortunately, the higher concentrations of hypertonic saline created a minor tenderness at the injection site which lasted approximately 24 hours. This side effect meant that it was not appropriate to use the higher concentrations of hypertonic saline. Therefore, the $0.4 \mathrm{ml} 5 \%$ hypertonic saline injections were used during the experimental procedure and the duration of the left-right discrimination task was shortened to match the length of the pain symptoms.

The following link shows the principal researcher receiving a $0.4 \mathrm{ml} 5 \%$ hypertonic saline injection to the right thenar eminence; http://youtu.be/cW6icafUCTE 


\subsection{Injection aftercare information sheet}

This injection aftercare information sheet was provided to all participants following each data collection session.

\section{Caring for your injection site}

Side effects that may occur following the injections include a small amount of bleeding, a small amount of bruising, and a small amount of tenderness.

- Avoid rubbing or scratching the area for 2 hours following the injection

- Keep the site covered with a sterile plaster, and change daily

- Rest the muscle if tenderness on movement occurs (this will resolve in less than 24 hours)

Please get in touch if you have any queries or worries about your injection sites after this session.

Nichole Phillips

nicholecphillips@hotmail.com

0210441389 


\subsection{Adverse events}

One participant (female) experienced an episode of vasovagal syncope follow the first experimental pain stimulus and withdrew from the study. She did not experience any lasting side effects.

Participants who completed each data collection session were sent a follow-up email after each session and at one week following the final session. A number of minor reactions were reported. Participants who reported side effects were spoken to and examined by the principal researcher and a supervisor. The General Practitioner who performed the injections was briefed regarding these reports and determined that all were minor side effects consistent with a needle puncture wound:

- A report of spontaneous mild aching in the right thenar eminence (injected in first session) which was localised to the muscle belly and aggravated by palpation and resisted muscle tests. This occurred five days after the second session and lasted a few hours.

- Slight bruising at the injection site in two participants which lasted approximately two days.

- A transient sharp pain in the left thenar eminence on active thumb abduction that occurred intermittently for one week following the second session.

No participants required treatment during or following the research project. There were no reports of long term or serious adverse events following the experimental pain stimulus. 


\title{
1.15. Brain Research: Instructions for authors
}

\section{GUIDE FOR AUTHORS}

\author{
INTRODUCTION
}

Brain Research publishes papers reporting interdisciplinary investigations of nervous system structure and function that are of general interest to the international community of neuroscientists. As is evident from the journals name, its scope is broad, ranging from cellular and molecular studies through systems neuroscience, cognition and disease. Invited reviews are also published; suggestions for and inquiries about potential reviews are welcomed.

Note: With the appearance of the final issue of the 2011 subscription, Vol. 67/1-2 (24 June 2011), Brain Research Reviews has ceased publication as a distinct journal separate from Brain Research. Review articles accepted for Brain Research are now published in that journal.

In the journals Table of Contents, published papers will be shown under one of the Section titles listed (in bold type) below. Authors will be given the opportunity to choose the most appropriate section upon manuscript submission.

\section{SECTIONS}

\section{Cell Biology, Signaling and Synaptic Transmission}

Senior Editors: Leonard K. Kaczmarek (New Haven, CT, USA), Diane Lipscombe (Providence, RI, USA) Studies investigating the cellular, molecular and genetic bases of structure, function and signaling (both intracellular and intercellular) in nervous systems.

\section{Cognition and Computation}

Senior Editors: Francesco P. Battaglia (Amsterdam, Netherlands), Erich Schröger (Leipzig, Germany), Christina L. Williams (Durham, NC, USA)

Studies of the neural mechanisms of cognition and behavior in humans and animal models including basic behaviors and higher mental functions; as well as studies dealing with realistic simulation, analysis and prediction of the structure and functions of nervous systems and individual neuronal and glial elements within nervous systems.

\section{Development, Degeneration and Regeneration, and Aging}

Senior Editors: Fen-Biao Gao (Worcester, MA, USA), Michael E. Selzer (Philadelphia, PA, USA), Flora M. Vaccarino (New Haven, CT, USA)

Studies concerning neuronal and glial development and the formation of the nervous system, molecular and cellular aspects of degeneration and regeneration, and changes associated with the aging brain.

\section{Neurobiology of Disease}

Senior Editors: Lorraine Iacovitti (Philadelphia, PA, USA), Jae-Young Koh (Seoul, Korea), Brian A. MacVicar (Vancouver, Canada), Peter H. Reinhart (Boston, MA, USA), J. Paul Taylor (Memphis, TN, USA)

Studies whose primary focus is on clinically diseased nervous systems or disease models, including molecular, cellular, systems and behavioral approaches and analysis of therapeutic interventions.

\section{Reviews}

Senior Editor: Irwin B. Levitan (Philadelphia, PA, USA)

Invited reviews on all aspects of nervous system structure and function. The editors welcome suggestions for specific review topics. .

\section{Systems Neuroscience and Behavior}

Senior Editors: Gary Aston-Jones (Charleston, SC, USA), Leslie C. Griffith (Waltham, MA, USA), David J. Perkel (Seattle, WA, USA)

Studies concerning structure and organization of neural circuits, sensory and motor systems, internal regulatory systems and the control of behaviors.

\section{TYPES OF PAPERS}


1.Research Reports reporting results of original fundamental research in any branch of the brain sciences. Papers describing new methods or significant developments of recognised methods which provide significant insight into the structure or function of the nervous system, the pathophysiology of a disease, or its treatment may also be submitted. Articles should be written in sufficient detail to allow others to verify/replicate the described methods.

2. Reviews: Reviews are by invitation only. Inquiries and suggestions for reviews should be directed to the Brain Research Editorial Office (bres@elsevier.com).

Brain Research will also regularly publish thematic special issues highlighting important new developments in neuroscience research.

\section{The Neuroscience Peer Review Consortium}

Brain Research is a member of the Neuroscience Peer Review Consortium (NPRC). The NPRC has been formed to reduce the time expended and, in particular, the duplication of effort by, and associated burden on reviewers involved in the peer review of original neuroscience research papers. It is an alliance of neuroscience journals that have agreed to accept manuscript reviews from other Consortium journals. By reducing the number of times that a manuscript is reviewed, the Consortium will reduce the load on reviewers and Editors, and speed the publication of research results.

If a manuscript has been rejected by another journal in the Consortium, authors can submit the manuscript to Brain Research and indicate that the referees' reports from the first journal be made available to the Editors of Brain Research.

It is the authors' decision as to whether or not to indicate that a set of referee's reports should be forwarded from the first journal to Brain Research. If an author does not wish for this to happen, the manuscript can be submitted to Brain Research without reference to the previous submission. No information will be exchanged between journals except at the request of authors. However, if the original referees' reports suggested that the paper is of high quality, but not suitable for the first journal, then it will often be to an author's advantage to indicate that referees' reports should be made available.

Authors should revise the original submission in accordance with the first journal's set of referee reports, reformat the paper to Brain Research's specification and submit the paper to Brain Research with a covering letter describing the changes that have been made, and informing the Editors that the authors will ask for the referee's reports to be forwarded from the first Consortium journal. The authors then must contact the first journal, and ask that reviews be forwarded, indicating they have submitted to Brain Research, and providing the new manuscript ID number.

The Editors of Brain Research will use forwarded referees' reports at their discretion. The Editors may use the reports directly to make a decision, or they may request further reviews if they feel such are necessary.

Visit http://nprc.incf.org for a list of Consortium journals, as well as further information on the scheme. Contact Details for submission

Submission of manuscripts to Brain Research is entirely online at http://ees.elsevier.com/bres. Queries about the submission or editorial processes may be directed to the Brain Research Editorial Office, Elsevier, 525 B Street, Suite 1800, San Diego, CA 92101-4495, USA; Fax: (1)-619-699.6850, Email: bres@elsevier.com

\section{BEFORE YOU BEGIN}

\section{Ethics in publishing}

For information on Ethics in publishing and Ethical guidelines for journal publication see http://www.elsevier.com/publishingethics and http://www.elsevier.com/journal-authors/ethics.

Policy and ethics

The work described in your article must have been carried out in accordance with The Code of Ethics of the World Medical Association (Declaration of Helsinki) for experiments involving humans http://www.wma.net/en/30publications/10policies/b3/index.html; EC Directive 86/609/EEC 
for animal experiments http://ec.europa.eu/environment/chemicals/lab_animals/legislation_en.htm; Uniform Requirements for manuscripts submitted to Biomedical journals http://www.icmje.org. This must be stated at an appropriate point in the article.

For other policy issues, authors are referred to the policy guidelines of the Society for Neuroscience (see their website http://www.jneurosci.org/misc/itoa.shtml).

\section{Conflict of interest}

All authors are requested to disclose any actual or potential conflict of interest including any financial, personal or other relationships with other people or organizations within three years of beginning the submitted work that could inappropriately influence, or be perceived to influence, their work. See also http://www.elsevier.com/conflictsofinterest. Further information and an example of a Conflict of Interest form can be found at: http://help.elsevier.com/app/answers/detail/a_id/286/p/7923.

\section{Submission declaration}

Submission of an article implies that the work described has not been published previously (except in the form of an abstract or as part of a published lecture or academic thesis or as an electronic preprint, see http://www.elsevier.com/postingpolicy), that it is not under consideration for publication elsewhere, that its publication is approved by all authors and tacitly or explicitly by the responsible authorities where the work was carried out, and that, if accepted, it will not be published elsewhere including electronically in the same form, in English or in any other language, without the written consent of the copyright-holder.

\section{Contributors}

Each author is required to declare his or her individual contribution to the article: all authors must have materially participated in the research and/or article preparation, so roles for all authors should be described. The statement that all authors have approved the final article should be true and included in the disclosure.

Addition, deletion, or rearrangement of author names in the authorship of accepted manuscripts Before the accepted manuscript is published in an online issue Requests to add or remove an author, or to rearrange the author names, must be sent to the Journal Manager from the corresponding author of the accepted manuscript and must include:The reason the name should be added or removed or the author names rearranged. Written confirmation (email, fax, letter) from all authors that they agree with the addition, removal or rearrangement. In the case of addition or removal of authors, this includes confirmation from the author being added or removed.

Requests that are not sent by the corresponding author will be forwarded by the Journal Manager to the corresponding author, who must follow the procedure as described above. Note that: Journal Managers will inform the Journal Editors of any such requests. Publication of the accepted manuscript in an online issue is suspended until authorship has been agreed.

After the accepted manuscript is published in an online issue

Any requests to add, delete, or rearrange author names in an article published in an online issue will follow the same policies as noted above and result in a corrigendum.

\section{Changes to authorship}

This policy concerns the addition, deletion, or rearrangement of author names in the authorship of accepted manuscripts:

Before the accepted manuscript is published in an online issue: Requests to add or remove an author, or to rearrange the author names, must be sent to the Journal Manager from the corresponding author of the accepted manuscript and must include: (a) the reason the name should be added or removed, or the author names rearranged and (b) written confirmation (e-mail, fax, letter) from all authors that they agree with the addition, removal or rearrangement. In the case of addition or removal of authors, this includes confirmation from the author being added or removed. Requests that are not sent by the corresponding author will be forwarded by the Journal Manager to the corresponding author, who must follow the procedure as described above. Note that: (1) Journal Managers will inform the Journal Editors of any such requests and (2) publication of the accepted manuscript in an online issue is suspended until authorship has been agreed.

After the accepted manuscript is published in an online issue: Any requests to add, delete, or rearrange author names in an article published in an online issue will follow the same policies as noted above and result in a corrigendum. 


\section{Copyright}

This journal offers authors a choice in publishing their research: Open Access and Subscription.

For Subscription articles

Upon acceptance of an article, authors will be asked to complete a 'Journal Publishing Agreement' (for more information on this and copyright, see http://www.elsevier.com/copyright). An e-mail will be sent to the corresponding author confirming receipt of the manuscript together with a 'Journal Publishing Agreement' form or a link to the online version of this agreement.

Subscribers may reproduce tables of contents or prepare lists of articles including abstracts for internal circulation within their institutions. Permission of the Publisher is required for resale or distribution outside the institution and for all other derivative works, including compilations and translations (please consult http://www.elsevier.com/permissions). If excerpts from other copyrighted works are included, the author(s) must obtain written permission from the copyright owners and credit the source(s) in the article. Elsevier has preprinted forms for use by authors in these cases: please consult http://www.elsevier.com/permissions.

\section{For Open Access articles}

Upon acceptance of an article, authors will be asked to complete an 'Exclusive License Agreement' (for more information see http://www.elsevier.com/OAauthoragreement). Permitted reuse of open access articles is determined by the author's choice of user license (see http://www.elsevier.com/openaccesslicenses).

\section{Retained author rights}

As an author you (or your employer or institution) retain certain rights. For more information on author rights for:

Subscription articles

please

see

http://www.elsevier.com/journal-authors/author-rights-and-responsibilities.

Open access articles please see http://www.elsevier.com/OAauthoragreement.

\section{Role of the funding source}

You are requested to identify who provided financial support for the conduct of the research and/or preparation of the article and to briefly describe the role of the sponsor(s), if any, in study design; in the collection, analysis and interpretation of data; in the writing of the report; and in the decision to submit the article for publication. If the funding source(s) had no such involvement then this should be stated. Please see http://www.elsevier.com/funding.

\section{Funding body agreements and policies}

Elsevier has established agreements and developed policies to allow authors whose articles appear in journals published by Elsevier, to comply with potential manuscript archiving requirements as specified as conditions of their grant awards. To learn more about existing agreements and policies please visit http://www.elsevier.com/fundingbodies.

\section{Open access}

This journal offers authors a choice in publishing their research:

\section{Open Access}

- Articles are freely available to both subscribers and the wider public with permitted reuse

- An Open Access publication fee is payable by authors or their research funder

\section{Subscription}

- Articles are made available to subscribers as well as developing countries and patient groups through our access programs (http://www.elsevier.com/access)

- No Open Access publication fee

All articles published Open Access will be immediately and permanently free for everyone to read and download. Permitted reuse is defined by your choice of one of the following Creative Commons user licenses:

Creative Commons Attribution (CC BY): lets others distribute and copy the article, to create extracts, abstracts, and other revised versions, adaptations or derivative works of or from an article (such as a translation), to include in a collective work (such as an anthology), to text or data mine 
the article, even for commercial purposes, as long as they credit the author(s), do not represent the author as endorsing their adaptation of the article, and do not modify the article in such a way as to damage the author's honor or reputation.

Creative Commons Attribution-NonCommercial-ShareAlike (CC BY-NC-SA): for noncommercial purposes, lets others distribute and copy the article, to create extracts, abstracts and other revised versions, adaptations or derivative works of or from an article (such as a translation), to include in a collective work (such as an anthology), to text and data mine the article, as long as they credit the author(s), do not represent the author as endorsing their adaptation of the article, do not modify the article in such a way as to damage the author's honor or reputation, and license their new adaptations or creations under identical terms (CC BY-NC-SA).

Creative Commons Attribution-NonCommercial-NoDerivs (CC BY-NC-ND): for noncommercial purposes, lets others distribute and copy the article, and to include in a collective work (such as an anthology), as long as they credit the author(s) and provided they do not alter or modify the article.

To provide Open Access, this journal has a publication fee which needs to be met by the authors or their research funders for each article published Open Access.

Your publication choice will have no effect on the peer review process or acceptance of submitted articles.

The publication fee for Open Access in this journal is $\mathbf{\$ 1 , 8 0 0}$, excluding taxes. Learn more about Elsevier's pricing policy: http://www.elsevier.com/openaccesspricing.

\section{Language (usage and editing services)}

Please write your text in good English (American or British usage is accepted, but not a mixture of these). Authors who feel their English language manuscript may require editing to eliminate possible grammatical or spelling errors and to conform to correct scientific English may wish to use the English Language Editing service available from Elsevier's WebShop (http://webshop.elsevier.com/languageediting/) or visit our customer support site (http://support.elsevier.com) for more information.

\section{Submission}

Submission to this journal proceeds totally online and you will be guided stepwise through the creation and uploading of your files. The system automatically converts source files to a single PDF file of the article, which is used in the peer-review process. Please note that even though manuscript source files are converted to PDF files at submission for the review process, these source files are needed for further processing after acceptance. All correspondence, including notification of the Editor's decision and requests for revision, takes place by e-mail removing the need for a paper trail.

Submit your article

Please submit your article via http://ees.elsevier.com/bres

\section{Section, Senior Editor and Reviewers}

Authors will be asked during manuscript submission to select a section of the journal, and a senior editor from that section whom they consider most appropriate to edit their manuscript. While every effort will be made to honor authors' selections, the assignment to a handling editor will be made by the Editor-in-Chief. Please submit, with the manuscript, the names, addresses and email addresses of 3 potential reviewers. Note that the handling editor retains the sole right to decide whether or not the suggested reviewers are used.

\section{Referees}

Please submit, with the manuscript, the names, addresses and e-mail addresses of three potential referees. Note that the editor retains the sole right to decide whether or not the suggested reviewers are used.

\section{Additional information}

Cover illustrations: Authors are encouraged to submit visually and scientifically interesting figure(s) representative of their data, though not necessarily as they appear in the manuscript, for potential cover illustrations (see specific instructions for submission of cover art under PREPARATION / Color Artwork below). The use of illustrations for journal covers is at the discretion of the Editors; only those related to articles accepted for publication will be considered. At the end of each year, all published 
covers will automatically be considered in a competition for the year's best cover illustration, and will be judged on their aesthetic value and scientific interest. The author(s) of the winning image will receive US\$ 500 from Elsevier.

\section{PREPARATION}

\section{Use of word processing software}

It is important that the file be saved in the native format of the word processor used. The text should be in single-column format. Keep the layout of the text as simple as possible. Most formatting codes will be removed and replaced on processing the article. In particular, do not use the word processor's options to justify text or to hyphenate words. However, do use bold face, italics, subscripts, superscripts etc. When preparing tables, if you are using a table grid, use only one grid for each individual table and not a grid for each row. If no grid is used, use tabs, not spaces, to align columns. The electronic text should be prepared in a way very similar to that of conventional manuscripts (see also the Guide to Publishing with Elsevier: http://www.elsevier.com/guidepublication). Note that source files of figures, tables and text graphics will be required whether or not you embed your figures in the text. See also the section on Electronic artwork.

To avoid unnecessary errors you are strongly advised to use the 'spell-check' and 'grammar-check' functions of your word processor.

\section{Article structure}

\section{Subdivision}

Divide your article into clearly defined and numbered sections (e.g. Abstract, 1. Introduction, 2. Results, 3. Discussion, 4. Experimental Procedure, Acknowledgements, References). Subsections should be numbered 1.1 (then $1.1 .1,1.1 .2, \ldots), 1.2$, etc. (the abstract is not included in section numbering). Use this numbering also for internal cross-referencing: do not just refer to " the text" . Any subsection may be given a brief heading. Each heading should appear on its own separate line.

\section{Introduction}

State the objectives of the work and provide relevant background information. Published studies should be described concisely, and be cited appropriately.

Results

The results should be described clearly and in logical order without extended discussion of their significance. Results should usually be presented descriptively and be supplemented by photographs or diagrams.

\section{Discussion}

The results of the research should be discussed in the context of other relevant published work; Extensive citations and discussion of published literature should be avoided. The main conclusions of the study may be presented in a short Conclusions section, which may stand alone or form a subsection of a Discussion section.

\section{Experimental Procedure}

This section should contain all the details necessary to reproduce the experiments. Avoid re-describing methods already published; only relevant modifications should be included in the text.

\section{Essential title page information}

- Title. Concise and informative. Titles are often used in information-retrieval systems. Avoid abbreviations and formulae where possible.

- Author names and affiliations. Where the family name may be ambiguous (e.g., a double name), please indicate this clearly. Present the authors' affiliation addresses (where the actual work was done) below the names. Indicate all affiliations with a lower-case superscript letter immediately after the author's name and in front of the appropriate address. Provide the full postal address of each affiliation, including the country name and, if available, the e-mail address of each author.

- Corresponding author. Clearly indicate who will handle correspondence at all stages of refereeing and publication, also post-publication. Ensure that phone numbers (with country and area code) are provided in addition to the e-mail address and the complete postal address. Contact details must be kept up to date by the corresponding author.

- Present/permanent address. If an author has moved since the work described in the article was done, or was visiting at the time, a 'Present address' (or 'Permanent address') may be indicated as a footnote to that author's name. The address at which the author actually did the work must be retained as the main, affiliation address. Superscript Arabic numerals are used for such footnotes. 


\begin{abstract}
The abstract should state briefly (in no more than 250 words) the purpose of the research, the principal results and major conclusions. An abstract is often presented separately from the article, so it must be able to stand alone. For this reason, References should be avoided, but if essential, then cite the author(s) and year(s). Also, non-standard or uncommon abbreviations should be avoided, but if essential they must be defined at their first mention in the abstract itself.
\end{abstract}

\title{
Graphical abstract
}

A Graphical abstract is optional and should summarize the contents of the article in a concise, pictorial form designed to capture the attention of a wide readership online. Authors must provide images that clearly represent the work described in the article. Graphical abstracts should be submitted as a separate file in the online submission system. Image size: Please provide an image with a minimum of $531 \times 1328$ pixels $(h \times w)$ or proportionally more. The image should be readable at a size of $5 \times$ $13 \mathrm{~cm}$ using a regular screen resolution of $96 \mathrm{dpi}$. Preferred file types: TIFF, EPS, PDF or MS Office files. See http://www.elsevier.com/graphicalabstracts for examples.

Authors can make use of Elsevier's Illustration and Enhancement service to ensure the best presentation of their images also in accordance with all technical requirements: Illustration Service.

\section{Highlights}

Highlights are mandatory for this journal. They consist of a short collection of bullet points that convey the core findings of the article and should be submitted in a separate file in the online submission system. Please use 'Highlights' in the file name and include 3 to 5 bullet points (maximum 85 characters, including spaces, per bullet point). See http://www.elsevier.com/highlights for examples.

\section{Keywords}

Immediately after the abstract, provide a maximum of 6 keywords, using American spelling and avoiding general and plural terms and multiple concepts (avoid, for example, "and", "of"). Be sparing with abbreviations: only abbreviations firmly established in the field may be eligible. These keywords will be used for indexing purposes.

\section{Abbreviations}

Define abbreviations that are not standard in this field in a footnote to be placed on the first page of the article. Such abbreviations that are unavoidable in the abstract must be defined at their first mention there, as well as in the footnote. Ensure consistency of abbreviations throughout the article.

\section{Acknowledgements}

Collate acknowledgements in a separate section at the end of the article before the references and do not, therefore, include them on the title page, as a footnote to the title or otherwise. List here those individuals who provided help during the research (e.g., providing language help, writing assistance or proof reading the article, etc.).

\section{Units}

Follow internationally accepted rules and conventions: use the international system of units (SI). If other units are mentioned, please give their equivalent in SI.

\section{Database linking}

Elsevier encourages authors to connect articles with external databases, giving their readers oneclick access to relevant databases that help to build a better understanding of the described research. Please refer to relevant database identifiers using the following format in your article: Database: $x x x x$ (e.g., TAIR: AT1G01020; CCDC: 734053; PDB: 1XFN). See http://www.elsevier.com/databaselinking for more information and a full list of supported databases.

\section{Minimal Data Standards}

Resources reported in neuroscience articles often lack sufficient detail to enable reproducibility or reuse. To facilitate resource identification in the neuroscience literature, we recommend to include relevant accession numbers and identifiers in your article, which will be converted into links to corresponding data repositories and embedded enrichments once the article is published and appears on SciencDirect. Please consider inclusion of GenBank accession numbers, antibody identifiers, species specific nomenclatures, and software identifiers in the method section of your article. The complete set of recommendations with detailed instructions is available at: http://www.elsevier.com/about/content-innovation/minimal-data-standards 


\section{Electronic artwork}

\section{General points}

- Make sure you use uniform lettering and sizing of your original artwork.

- Embed the used fonts if the application provides that option.

- Aim to use the following fonts in your illustrations: Arial, Courier, Times New Roman, Symbol, or use fonts that look similar.

- Number the illustrations according to their sequence in the text.

- Use a logical naming convention for your artwork files.

- Provide captions to illustrations separately.

- Size the illustrations close to the desired dimensions of the printed version.

- Submit each illustration as a separate file.

A detailed guide on electronic artwork is available on our website:

http://www.elsevier.com/artworkinstructions

You are urged to visit this site; some excerpts from the detailed information are given here. Formats

If your electronic artwork is created in a Microsoft Office application (Word, PowerPoint, Excel) then please supply 'as is' in the native document format.

Regardless of the application used other than Microsoft Office, when your electronic artwork is finalized, please 'Save as' or convert the images to one of the following formats (note the resolution requirements for line drawings, halftones, and line/halftone combinations given below):

EPS (or PDF): Vector drawings, embed all used fonts.

TIFF (or JPEG): Color or grayscale photographs (halftones), keep to a minimum of $300 \mathrm{dpi}$.

TIFF (or JPEG): Bitmapped (pure black \& white pixels) line drawings, keep to a minimum of $1000 \mathrm{dpi}$. TIFF (or JPEG): Combinations bitmapped line/half-tone (color or grayscale), keep to a minimum of 500 dpi.

\section{Please do not:}

- Supply files that are optimized for screen use (e.g., GIF, BMP, PICT, WPG); these typically have a low number of pixels and limited set of colors;

- Supply files that are too low in resolution;

- Submit graphics that are disproportionately large for the content.

Cover art: Illustrations to be considered for the cover should be related to the authors' submitted article and be representative of their data, but need not necessarily be as they appear in the manuscript. Cover art should be formatted to occupy an area of $18 \times 21 \mathrm{~cm}$ and should be submitted in digital format (TIFF, Photoshop, JPEG or Powerpoint) with a resolution of at least $300 \mathrm{dpi}$. Please also include a descriptive text with your cover art submission. The files should be uploaded to a specified FTP site - please contact the Editorial Office at bres@elsevier.com for instructions. For authors who wish to postal mail a CD with the cover art, please send it to:

Brain Research Editorial Office, Elsevier, 525 B Street, Suite 1800, San Diego, CA 92101-4495, USA. Please ensure that the manuscript reference number is included on all materials.

\section{Color artwork}

Please make sure that artwork files are in an acceptable format (TIFF (or JPEG), EPS (or PDF) or MS Office files) and with the correct resolution. If, together with your accepted article, you submit usable color figures then Elsevier will ensure, at no additional charge, that these figures will appear in color on the Web (e.g., ScienceDirect and other sites) in addition to color reproduction in print. For further information on the preparation of electronic artwork, please see http://www.elsevier.com/artworkinstructions.

\section{Figure captions}

Ensure that each illustration has a caption. Supply captions separately, not attached to the figure. A caption should comprise a brief title (not on the figure itself) and a description of the illustration. Keep text in the illustrations themselves to a minimum but explain all symbols and abbreviations used.

\section{Tables}

Number tables consecutively in accordance with their appearance in the text. Place footnotes to tables below the table body and indicate them with superscript lowercase letters. Avoid vertical rules. Be sparing in the use of tables and ensure that the data presented in tables do not duplicate results described elsewhere in the article. 


\section{Citation in text}

Please ensure that every reference cited in the text is also present in the reference list (and vice versa). Any references cited in the abstract must be given in full. Unpublished results and personal communications are not recommended in the reference list, but may be mentioned in the text. If these references are included in the reference list they should follow the standard reference style of the journal and should include a substitution of the publication date with either 'Unpublished results' or 'Personal communication'. Citation of a reference as 'in press' implies that the item has been accepted for publication.

\section{Reference links}

Increased discoverability of research and high quality peer review are ensured by online links to the sources cited. In order to allow us to create links to abstracting and indexing services, such as Scopus, CrossRef and PubMed, please ensure that data provided in the references are correct. Please note that incorrect surnames, journal/book titles, publication year and pagination may prevent link creation. When copying references, please be careful as they may already contain errors. Use of the DOI is encouraged.

\section{Web references}

As a minimum, the full URL should be given and the date when the reference was last accessed. Any further information, if known (DOI, author names, dates, reference to a source publication, etc.), should also be given. Web references can be listed separately (e.g., after the reference list) under a different heading if desired, or can be included in the reference list.

References in a special issue

Please ensure that the words 'this issue' are added to any references in the list (and any citations in the text) to other articles in the same Special Issue.

\section{Reference formatting}

There are no strict requirements on reference formatting at submission. References can be in any style or format as long as the style is consistent. Where applicable, author(s) name(s), journal title/book title, chapter title/article title, year of publication, volume number/book chapter and the pagination must be present. Use of DOI is highly encouraged. The reference style used by the journal will be applied to the accepted article by Elsevier at the proof stage. Note that missing data will be highlighted at proof stage for the author to correct. If you do wish to format the references yourself they should be arranged according to the following examples:

\section{Reference style}

Text: All citations in the text should refer to:

1. Single author: the author's name (without initials, unless there is ambiguity) and the year of publication;

2. Two authors: both authors' names and the year of publication;

3. Three or more authors: first author's name followed by 'et al.' and the year of publication.

Citations may be made directly (or parenthetically). Groups of references should be listed first alphabetically, then chronologically.

Examples: 'as demonstrated (Allan, 2000a, 2000b, 1999; Allan and Jones, 1999). Kramer et al. (2010) have recently shown ....'

List: References should be arranged first alphabetically and then further sorted chronologically if necessary. More than one reference from the same author(s) in the same year must be identified by the letters 'a', 'b', 'c', etc., placed after the year of publication.

\section{Examples:}

Reference to a journal publication:

Van der Geer, J., Hanraads, J.A.J., Lupton, R.A., 2010. The art of writing a scientific article. J. Sci. Commun. 163, 51-59.

Reference to a book:

Strunk Jr., W., White, E.B., 2000. The Elements of Style, fourth ed. Longman, New York.

Reference to a chapter in an edited book:

Mettam, G.R., Adams, L.B., 2009. How to prepare an electronic version of your article, in: Jones, B.S., Smith, R.Z. (Eds.), Introduction to the Electronic Age. E-Publishing Inc., New York, pp. 281-304.

Journal abbreviations source

Journal names should be abbreviated according to the List of Title Word Abbreviations: http://www.issn.org/2-22661-LTWA-online.php. 


\section{Video data}

Elsevier accepts video material and animation sequences to support and enhance your scientific research. Authors who have video or animation files that they wish to submit with their article are strongly encouraged to include links to these within the body of the article. This can be done in the same way as a figure or table by referring to the video or animation content and noting in the body text where it should be placed. All submitted files should be properly labeled so that they directly relate to the video file's content. In order to ensure that your video or animation material is directly usable, please provide the files in one of our recommended file formats with a preferred maximum size of $50 \mathrm{MB}$. Video and animation files supplied will be published online in the electronic version of your article in Elsevier Web products, including ScienceDirect: http://www.sciencedirect.com. Please supply 'stills' with your files: you can choose any frame from the video or animation or make a separate image. These will be used instead of standard icons and will personalize the link to your video data. For more detailed instructions please visit our video instruction pages at http://www.elsevier.com/artworkinstructions. Note: since video and animation cannot be embedded in the print version of the journal, please provide text for both the electronic and the print version for the portions of the article that refer to this content.

\section{Audioslides}

The journal encourages authors to create an AudioSlides presentation with their published article. AudioSlides are brief, webinar-style presentations that are shown next to the online article on ScienceDirect. This gives authors the opportunity to summarize their research in their own words and to help readers understand what the paper is about. More information and examples are available at http://www.elsevier.com/audioslides. Authors of this journal will automatically receive an invitation e-mail to create an AudioSlides presentation after acceptance of their paper.

\section{Supplementary data}

Elsevier accepts electronic supplementary material to support and enhance your scientific research. Supplementary files offer the author additional possibilities to publish supporting applications, highresolution images, background datasets, sound clips and more. Supplementary files supplied will be published online alongside the electronic version of your article in Elsevier Web products, including ScienceDirect: http://www.sciencedirect.com. In order to ensure that your submitted material is directly usable, please provide the data in one of our recommended file formats. Authors should submit the material in electronic format together with the article and supply a concise and descriptive caption for each file. For more detailed instructions please visit our artwork instruction pages at http://www.elsevier.com/artworkinstructions.

\section{D neuroimaging}

You can enrich your online articles by providing 3D neuroimaging data in NIfTI format. This will be visualized for readers using the interactive viewer embedded within your article, and will enable them to: browse through available neuroimaging datasets; zoom, rotate and pan the 3D brain reconstruction; cut through the volume; change opacity and color mapping; switch between 3D and 2D projected views; and download the data. The viewer supports both single (.nii) and dual (.hdr and iimg) NIfTI file formats. Recommended size of a single uncompressed dataset is $100 \mathrm{MB}$ or less. Multiple datasets can be submitted. Each dataset will have to be zipped and uploaded to the online submission system via the '3D neuroimaging data' submission category. Please provide a short informative description for each dataset by filling in the 'Description' field when uploading a dataset. Note: all datasets will be available for downloading from the online article on ScienceDirect. If you have concerns about your data being downloadable, please provide a video instead. For more information see: http://www.elsevier.com/3DNeuroimaging.

\section{Submission checklist}

The following list will be useful during the final checking of an article prior to sending it to the journal for review. Please consult this Guide for Authors for further details of any item.

\section{Ensure that the following items are present:}

One author has been designated as the corresponding author with contact details:

- E-mail address

- Full postal address

- Phone numbers

All necessary files have been uploaded, and contain:

- Keywords

- All figure captions

- All tables (including title, description, footnotes) 
Further considerations

- Manuscript has been 'spell-checked' and 'grammar-checked'

- References are in the correct format for this journal

- All references mentioned in the Reference list are cited in the text, and vice versa

- Permission has been obtained for use of copyrighted material from other sources (including the Web)

- Color figures are clearly marked as being intended for color reproduction on the Web (free of charge)

and in print, or to be reproduced in color on the Web (free of charge) and in black-and-white in print

- If only color on the Web is required, black-and-white versions of the figures are also supplied for printing purposes

For any further information please visit our customer support site at http://support.elsevier.com.

\section{AFTER ACCEPTANCE}

\section{Use of the Digital Object Identifier}

The Digital Object Identifier (DOI) may be used to cite and link to electronic documents. The DOI consists of a unique alpha-numeric character string which is assigned to a document by the publisher upon the initial electronic publication. The assigned DOI never changes. Therefore, it is an ideal medium for citing a document, particularly 'Articles in press' because they have not yet received their full bibliographic information. Example of a correctly given DOI (in URL format; here an article in the journal Physics Letters B):

http://dx.doi.org/10.1016/j.physletb.2010.09.059

When you use a DOI to create links to documents on the web, the DOIs are guaranteed never to change.

\section{Online proof correction}

Corresponding authors will receive an e-mail with a link to our ProofCentral system, allowing annotation and correction of proofs online. The environment is similar to MS Word: in addition to editing text, you can also comment on figures/tables and answer questions from the Copy Editor. Web-based proofing provides a faster and less error-prone process by allowing you to directly type your corrections, eliminating the potential introduction of errors.

If preferred, you can still choose to annotate and upload your edits on the PDF version. All instructions for proofing will be given in the e-mail we send to authors, including alternative methods to the online version and PDF.

We will do everything possible to get your article published quickly and accurately - please upload all of your corrections within 48 hours. It is important to ensure that all corrections are sent back to us in one communication. Please check carefully before replying, as inclusion of any subsequent corrections cannot be guaranteed. Proofreading is solely your responsibility. Note that Elsevier may proceed with the publication of your article if no response is received.

\section{Offprints}

The corresponding author, at no cost, will be provided with a PDF file of the article via email (the PDF file is a watermarked version of the published article and includes a cover sheet with the journal cover image and a disclaimer outlining the terms and conditions of use). For an extra charge, paper offprints can be ordered via the offprint order form which is sent once the article is accepted for publication. Both corresponding and co-authors may order offprints at any time via Elsevier's WebShop (http://webshop.elsevier.com/myarticleservices/offprints). Authors requiring printed copies of multiple articles may use Elsevier WebShop's 'Create Your Own Book' service to collate multiple articles within a single cover (http://webshop.elsevier.com/myarticleservices/offprints/myarticlesservices/booklets).

\section{AUTHOR INQUIRIES}

For inquiries relating to the submission of articles (including electronic submission) please visit this journal's homepage. For detailed instructions on the preparation of electronic artwork, please visit http://www.elsevier.com/artworkinstructions. Contact details for questions arising after acceptance of an article, especially those relating to proofs, will be provided by the publisher. You can track accepted articles at http://www.elsevier.com/trackarticle. You can also check our Author FAQs at http://www.elsevier.com/authorFAQ and/or contact Customer Support via http://support.elsevier.com. 